Portland State University

PDXScholar

$1-1-2010$

\title{
The Moderating Effect of Role Quality on the Relationship between Work-Family Conflict and Well- Being: A Longitudinal Study
}

Jenna Risa LeComte-Hinely

Portland State University

Follow this and additional works at: https://pdxscholar.library.pdx.edu/open_access_etds

Let us know how access to this document benefits you.

\section{Recommended Citation}

LeComte-Hinely, Jenna Risa, "The Moderating Effect of Role Quality on the Relationship between WorkFamily Conflict and Well-Being: A Longitudinal Study" (2010). Dissertations and Theses. Paper 99. https://doi.org/10.15760/etd.99

This Thesis is brought to you for free and open access. It has been accepted for inclusion in Dissertations and Theses by an authorized administrator of PDXScholar. Please contact us if we can make this document more accessible: pdxscholar@pdx.edu. 
The Moderating Effect of Role Quality on the Relationship between Work-Family Conflict and Well-Being: A Longitudinal Study

by

Jenna Risa LeComte-Hinely

A thesis submitted in partial fulfillment of the requirements for the degree of

\author{
Master of Science \\ in \\ Psychology
}

Thesis Committee:

Leslie B. Hammer, Chair

Margaret B. Neal

Charlotte Fritz

Portland State University

(C) 2010 
ABSTRACT

Work-family conflict (WFC) is a stressor that can cause negative consequences, including deleterious effects on an individual's health and well-being. This study examined this relationship through the lens of the Job Demands-Resources (JD-R) Model. This study expanded on two recent applicable studies to examine role quality as a moderator of the WFC-well-being relationship. Well-being was operationalized by three constructs: overall health, depression, and life satisfaction. Hierarchical regression analyses were used to test the hypotheses that a negative relationship existed between WFC and the three well-being outcomes over time, and that this negative relationship between WFC and well-being could be reduced when role quality is high, compared to when role quality is low. These hypotheses were tested using a sample of 234 working, married individuals caring for both children and parents. The use of this sample allowed examination of four types of role quality as potential moderators: job, spousal, child-care and parent-care. Results showed that WFC had a significant and positive relationship with depression over time. Two of the proposed moderators, spousal role quality and child-care role quality, significantly buffered the effects of work-to-family conflict on life satisfaction. Theoretical and practical implications of the findings are discussed. 
Acknowledgements

I would like to thank my thesis committee for their assistance in the completion of this thesis. Without their advice, it would be a far poorer quality document. I would also like to thank my cohort for their support, encouragement, feedback, and assistance. I would also like to thank Dr. Jill Robinson for proofreading an early draft, and for encouraging me when I needed it. I would like to thank Dr. Todd Bodner for his assistance in the statistical aspects of my thesis. His suggestions helped me to avoid errors in my analysis and to feel confident in my results. Most of all, I would like to thank my husband, Braden Hinely, for giving me support and encouragement throughout this process. Without you, there would be no thesis. Thank you. 
Table of Contents

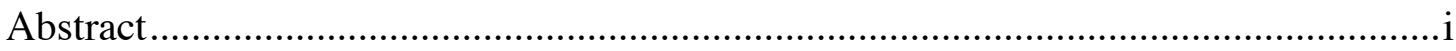

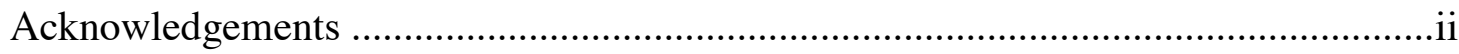

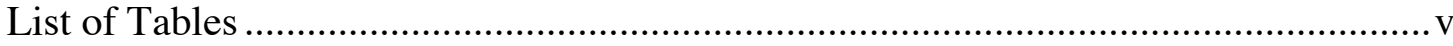

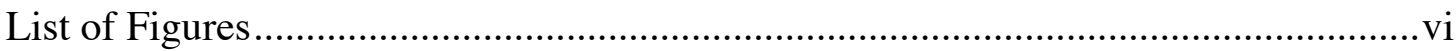

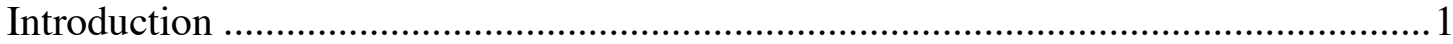

Context of the Study: The Sandwiched Generation .............................................. 3

Work-Family Conflict ............................................................................... 10

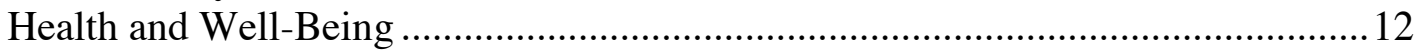

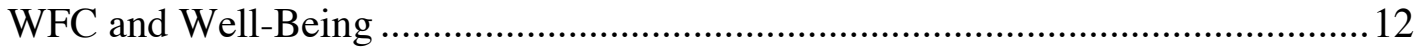

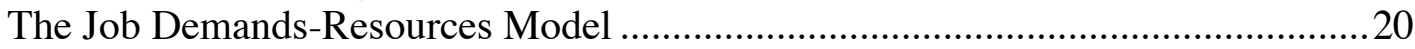

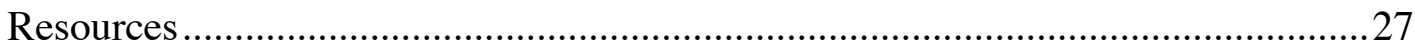

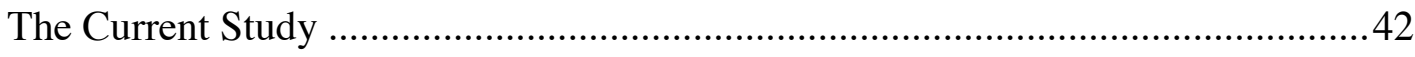

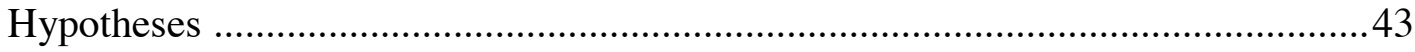

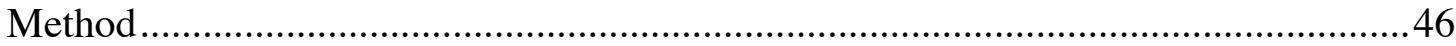

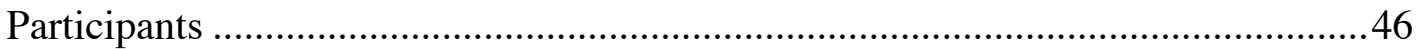

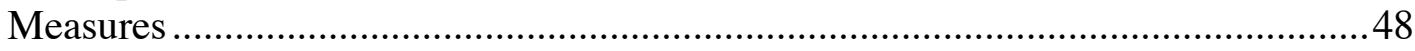

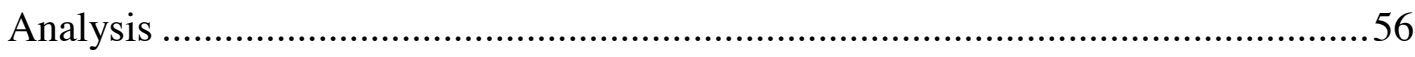

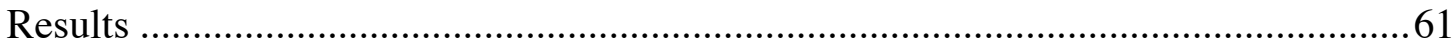

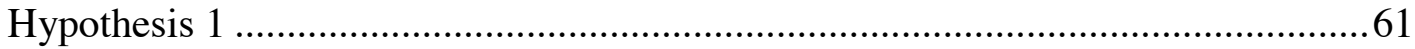

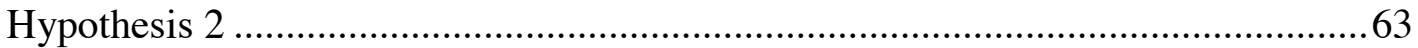

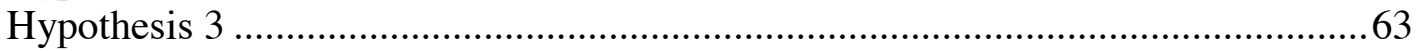

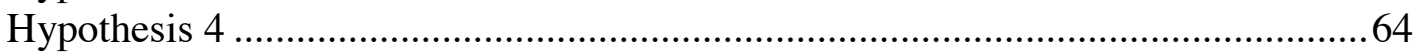

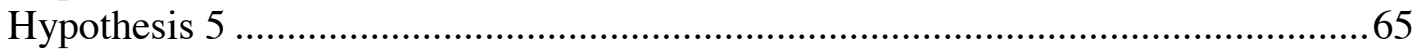

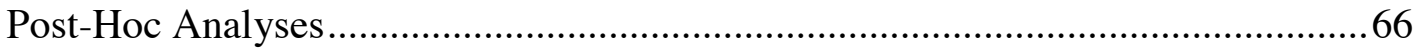

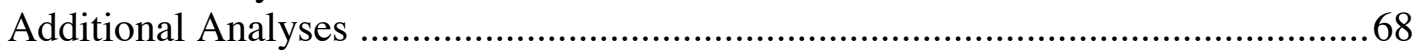

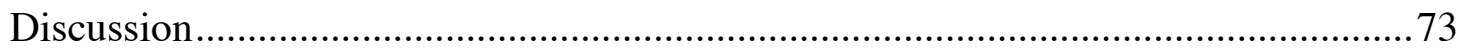

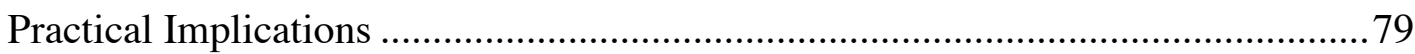

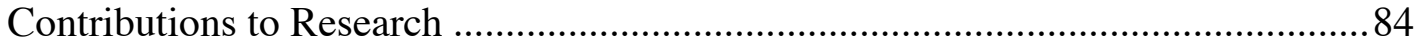

Potential Limitations and Areas for Future Research............................................ 87

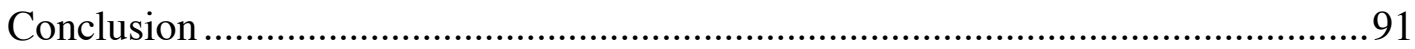

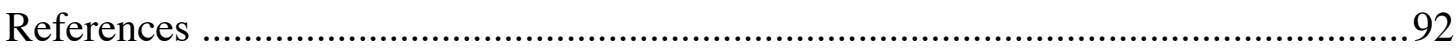

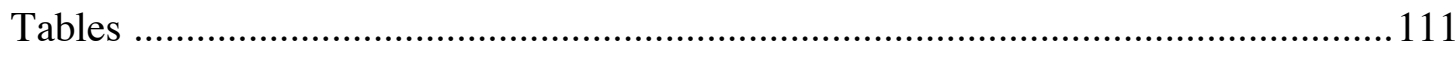

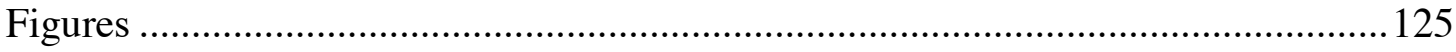

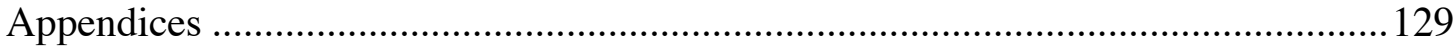




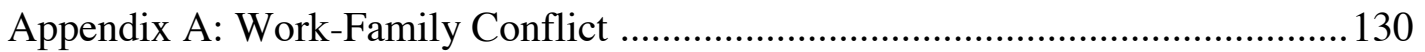

Appendix B: Job Role Quality ........................................................................ 131

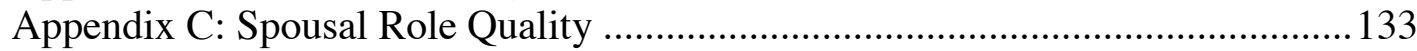

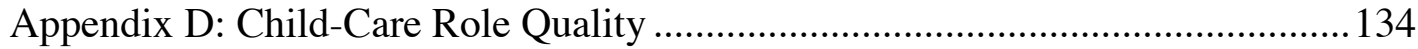

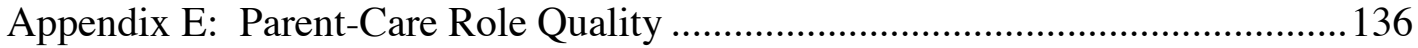

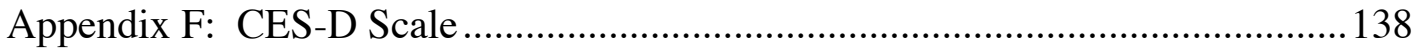

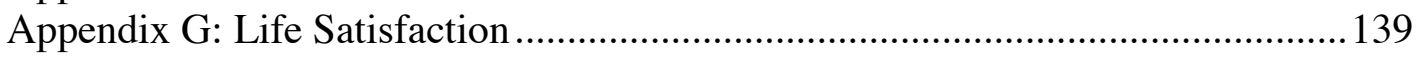

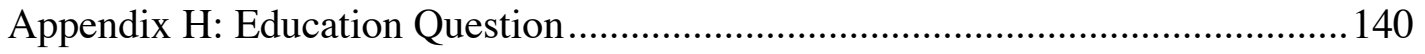


List of Tables

Table 1: Intraclass Correlations for Outcome Variables ......................................... 111

Table 2: Details of Each Regression Analysis with Significane Indicators .............. 112

Table 3: Intercorrelations, Means, and Standard Deviations of Study Variables .... 115

Table 4: Description of Support for Hypotheses in the Three Sets of Analyses ........ 116

Table 5: Summary of Hierarchical Multiple Regression Analysis for WIF and Job

Role Quality on Overall Health, Depression, and Life Satisfaction ......................... 117

Table 6: Summary of Hierarchical Multiple Regression Analysis for FIW and Job

Role Quality on Overall Health, Depression, and Life Satisfaction ..........................118

Table 7: Summary of Hierarchical Multiple Regression Analysis for WIF and Spousal

Role Quality on Overall Health, Depression, and Life Satisfaction ..........................119

Table 8: Summary of Hierarchical Multiple Regression Analysis for FIW and Spousal

Role Quality on Overall Health, Depression, and Life Satisfaction ........................... 120

Table 9: Summary of Hierarchical Multiple Regression Analysis for WIF and Child-

Care Role Quality on Overall Health, Depression, and Life Satisfaction ................. 121

Table 10: Summary of Hierarchical Multiple Regression Analysis for FIW and Child-

Care Role Quality on Overall Health, Depression, and Life Satisfaction ................. 122

Table 11: Summary of Hierarchical Multiple Regression Analysis for WIF and Parent-

Care Role Quality on Overall Health, Depression, and Life Satisfaction ................. 123

Table 12: Summary of Hierarchical Multiple Regression Analysis for FIW and ParentCare Role Quality on Overall Health, Depression, and Life Satisfaction 124 
List of Figures

Figure 1: A Visual Representation of The Hypothesized Relationship Between WFC,

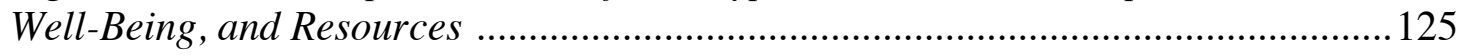

Figure 2: Interaction between SRQ and WIF on Life Satisfaction ........................... 126

Figure 3: Interaction between CCRQ and WIF on Life Satisfaction ......................... 127

Figure 4: Interaction between JRQ and FIW on Life Satisfaction .......................... 128 
The Moderating Effect of Role Quality on the Relationship between Work-Family

$$
\text { Conflict and Well-Being: A Longitudinal Study }
$$

Introduction

Work-family conflict (WFC), the interference of one role (work or family)

with the other, can result in many negative outcomes for both individuals and organizations (Greenhaus \& Beutell, 1985). Previous research has supported the idea that WFC can lead to poorer individual health and well-being, but further examination is needed to properly understand the relationship (Eby, Casper, Lockwood, Bordeaux, \& Brinley, 2005). Workers suffering from stressors such as WFC have higher rates of absenteeism, lower productivity, and higher health care costs. These factors add up quickly; worker stress costs American organizations approximately $\$ 150$ billion each year (Sauter, Murphy, \& Hurrell, 1990). Thus, it is important in times of economic difficulty to better understand how WFC is related to health, and what we as practitioners and researchers can do to alleviate some of the negative effects. It is of particular importance to examine potential moderators of this relationship, as these may present unique, alternative methods for protecting worker well-being in instances where WFC cannot be lowered.

The present study searches for alternative methods to alleviate the negative health consequences of WFC through the lens of the Job Demands-Resources (JD-R) model. To represent the multidimensionality of the construct of well-being, the outcome in this study is measured in tri-fold: general health, depression, and life satisfaction. The sample used for this study is a particularly unique group of married, 
working individuals caring for both children and aging parents (Neal \& Hammer, 2007). The many roles in which these individuals are involved present a unique opportunity to study the moderating effects of the resources of role quality on the relationship between WFC and well-being outcomes. Thus, the resources that are hypothesized here as moderators include job role quality, spousal role quality, childcare role quality, and parent-care role quality. Each of these resources is understudied, but previous research has shown that they all relate to well-being directly (e.g., Barnett \& Baruch, 1985; Plaisier et al., 2008). To my knowledge, no research has been conducted on role quality as a moderator of the WFC-well-being relationship. Thus, the current study seeks to examine the understudied area of moderation effects on the WFC-well-being relationship further, specifically by examining resources as moderators that have never been studied in this area before. The goal of this study is to better understand how WFC impacts health and well-being over time, and what can be done to protect health in both direct and indirect ways.

The organization of this paper is as follows: first, to give the study context, characteristics of the sample used in this study, working couples in the sandwiched generation, are described. Second, WFC is defined, followed by known outcomes of WFC, and the negative health and well-being outcomes specifically. Some of the current findings regarding the relationship between WFC and well-being are discussed. The JD-R model is described, and two particularly pertinent recent studies that examine the JD-R model and the moderating effects of resources on the WFCwell-being relationship are described in depth. Using these previous studies as an 
empirical basis, the current study is outlined and new contributions are described, including the examination of new resources, a longitudinal design, and a unique population. Hypotheses are proposed, and the study methods are described. The population and measures are described in depth, as are the methods of analyses. The full text of the items in each of the scales utilized can be found in the appendices. Results are discussed, followed by my interpretation of these results, as well as practical implications and contributions to knowledge. Lastly, potential limitations to the current study are also noted, with suggestions for future research.

\section{Context of the Study: The Sandwiched Generation}

The sample used for this study is composed of working, married members of the sandwiched generation, who are caring for both children and the elderly (Miller, 1981). Sandwiched generation members are have an increased risk of WFC and the resulting stress and poor health (Neal \& Hammer, 2007). It is easy to see why sandwiched generation members are at a high risk for poor work-family balance, as they are often not only in dual-caregiving roles, but also other roles, such as the individuals included in this study, who are also fulfilling the roles of worker and spouse.

Just how large a group is the sandwiched generation? Prevalence rates vary widely, generally because studies tend to examine a single population rather than a national sample (such as just workers or just caregivers), and also because the definition of what constitutes "sandwiched" tends to vary by study (Neal \& Hammer, 2007). For instance, while it is generally agreed that all sandwiched generation 
members are caring for elders, some studies operationalize the term "elder care" very differently. Some studies define individuals engaged in elder care as only those who participate in the most intense forms of care, such as bathing and dressing elders (e.g., Stone, Cafferata, \& Sangl, 1987), while others have also included individuals who help elders with more instrumental support, such as transportation and emotional support (e.g. Neal \& Hammer, 2007). Some studies define sandwiched generation as only those who care for parents, while others define the caregiving role as extending to grandparents, aunts, uncles, friends, and neighbors (e.g., Neal, Chapman, IngersollDayton, \& Emlen, 1993).

The role of elder care is not the only role where the definition of what constitutes the role is debated; the role of caregiver to children is also operationalized in several different ways, which can lead to varying rates of prevalence. For instance, some studies define the child caregiving role as inclusive of all living children (Ward \& Spitze, 1998), while others are interested only in children for which the sandwiched generation members are providing financial support for (e.g., Nichols \& Junk, 1997). Still others include only those individuals with children under the age of majority living with them at least part of the time (e.g., Neal \& Hammer, 2007).

Bearing in mind that prevalence rates depend on which definition figures are based on, there does seem to be consensus that the sandwiched generation is a relatively sizable portion of Americans today. Nichols and Junk (1997) surveyed randomly sampled individuals in four states and found that $15 \%$ of their sample $(\mathrm{N}=1,466)$ was providing care to both parents and children. Ward and Spitze (1998) 
examined a national sample of 2,129 married individuals and found that approximately $20 \%$ of respondents in their 40 s and 50 s were caring for both children and parents. Neal and Hammer (2007) attempted to ascertain the prevalence of sandwiched generation members with a very strict definition of "sandwiched": they included only individuals who had been living together for at least one year or more, had a child aged 18 or younger living at home at least three or more days per week, were caring for a parent or parent-in-law at least three or more hours a week, and were working at least 20 hours per week. Using this definition, Neal and Hammer then screened more than 33,000 households in the U.S. by phone and found that between $9 \%$ and $13 \%$ of American households with a telephone and one or more individuals between the ages of 30 and 60 qualify as a dual-earner sandwiched couple. This is of particular relevance to this study, as the data used in the present study are those collected by Neal and Hammer (2007). Therefore, the criteria for what constitutes "sandwiched" are identical and relatively strict.

In short, although prevalence rates can vary depending on the definition used to reach those estimates, it is clear that quite a few Americans today are "sandwiched" in some way or form. In addition, the group of sandwiched generation members appears to be growing in size as a result of certain social and demographic trends. One trend is delayed childbearing, which results in couples having young children at the same time that their parents are reaching an age when they need more care (Casper \& Bianchi, 2002). 
Another trend is the aging of the American population, and the workforce along with it, which makes it more likely that older workers have still older parents who need care (Neal \& Wagner, 2002). Approximately $41 \%$ of the American workforce is composed of workers over the age of 55, and in 2007 the growth rate increased by $15 \%$ compared to the previous year's growth rate (Pitt-Catsouphes, Smyer, Matz-Costa, \& Kane, 2007). Middle-aged and older workers are the demographic group of workers most likely to have aging parents in need of care (Neal \& Hammer, 2007).

The number of women in the workforce is also rising. Today, about $59.5 \%$ of women aged 16 and older are active labor force participants in the United States, compared to about $43.3 \%$ in 1970 (U.S. Department of Labor, 2008; U.S. Department of Labor, Bureau of Labor Statistics 2007). Women make up approximately $46.5 \%$ of the total U.S. labor force in the United States (U.S. Department of Labor, 2008). The increasing number of women in the workforce causes changes in the traditional division of household responsibilities by gender, and leaves less time available for fulfilling the traditionally female role of caregiver to children and/or elderly individuals.

Decreases in family size have also led to more workers being sandwiched, as the responsibility for parent care is no longer spread out among many children, but often depends solely on one adult child (Neal \& Wagner, 2002). At the same time, growing health care costs have led to an increase in the amount of care being provided 
by family and friends, leading to more employees caring for others in general (Wagner, 2000).

Aside from one longitudinal study by Neal and Hammer (2007), little previous research has examined the outcomes associated with being a working member of the sandwiched generation. What research there is generally indicates that being a member of the sandwiched generation has a negative impact on work outcomes. For example, research has shown that employees in multiple caregiving roles (e.g., the sandwiched generation) had higher levels of absenteeism than employees who only had a single caregiving responsibility (Neal et al., 1993). Buffardi, Smith, O'Brien, and Erdwins (1999) examined federal employees and found that those in the sandwiched generation tended to have more negative work attitudes and lower job satisfaction than their non-sandwiched counterparts.

The relationship between being a member of the sandwiched generation and well-being is an area of research that presents mixed findings. Neal and colleagues (1993) found that employees who have multiple caregiving roles, such as the sandwiched generation, nearly always experience more stress than employees who only have a single caregiving role. Fernandez (1990) found similar results: sandwiched generation members have higher stress levels and more stress-related health problems than employees with only a single caregiving responsibility or no caregiving roles at all. Neal and Hammer (2007) found that both men and women in the sandwiched generation had higher than average levels of depression, with the women's scores being especially high. 
However, there have also been findings that being a member of the sandwiched generation is not detrimental to one's well-being. One study by Loomis and Booth (1995) examined multigenerational caregivers (e.g., sandwiched generation members) in a national sample. Their results showed that having multigenerational caregiving responsibilities did not significantly affect well-being for either men or women. Penning (1998) examined a Canadian sample of individuals with multiple caregiving roles and the gender differences in the relationship between being sandwiched and well-being outcomes. She found that male caregivers with both child- and parent-care roles had lower stress levels than males who cared only for parents, but that male caregivers who had child-, parent-care, and job roles had worse emotional health than male parent-caregivers who did not have children and work responsibilities. Female working child- and parent-caregivers did not have significantly different emotional health than their counterparts with fewer role responsibilities.

It may be that this lesser amount of stress for some sandwiched generation members is a result of benefits gained from the multiple roles. For instance, IngersollDayton, Neal, and Hammer (2001) found that while sandwiched generation members cared for their aging parents, many also received support from them as well. Their research showed that many aging parents helped their adult sandwiched children by providing emotional support, child care, financial help, and/or assistance with household tasks. Thus, it appears that the role of caregiver is a complex one that can increase an individual's resources as well as decrease them. 
Stephens and Townsend (1997) sought to examine these complex relationships between multiple caregiving roles and well-being by examining role rewards and stressors more closely. Their study examined women who had roles as caregiver to a child, caregiver to a parent, employee, and spouse. Their results showed that stress in the parent, spouse, and employee role exacerbated the effects of stress of the parentcare role on depression and life satisfaction. Alternatively, they found that rewards in the employee role buffered the effects of parent-care stress on depression and life satisfaction.

Along the same lines, Christensen, Stephens, and Townsend (1998) examined the differences in well-being outcomes through the lens of mastery. Mastery is an individual's belief that he or she is in control of life events and competent to handle these events. That study examined 296 women who held the roles of spouse, employee, caregiver to a parent and caregiver to a child. The researchers found that when women experienced mastery in a particular role, it was strongly positively related to psychological well-being. The more roles in which women experienced high mastery levels, the greater their satisfaction with life.

In short, being a member of the sandwiched generation, by definition, means that an individual is involved in several roles. These multiple role responsibilities can affect an individual's performance at work, as well as his or her personal well-being in some situations. In order to gain a clearer understanding of what can help these individuals alleviate their negative outcomes, it is important to examine the intricacies of the relationship between WFC and well-being for these individuals. 


\section{Work-Family Conflict}

Work and family are two of the most important roles in a person's life, and it is not surprising that the combination of these roles can sometimes result in role conflict. Over the past 25 years, much research has been conducted on the interface between work and family, and the effects, both positive and negative, of one role on the other (e.g., Eby et. al, 2005; Hammer, Cullen, Neal, Sinclair, \& Shafiro, 2005). Workfamily conflict (WFC), sometimes also known as work-home interference, has been defined as "a form of interrole conflict in which the role pressures from work and family domains are mutually incompatible in some respect" (Greenhaus \& Beutell, 1985, p. 76).

It has been shown that there are two directions for WFC: conflict that results from the work domain interfering with familial responsibilities, known as work interference with family, or WIF, and conflict that results from the family domain interfering with career responsibilities, called family interference with work, or FIW (Netemeyer, Boles, \& McMurrian, 1996). These two distinct constructs have been shown to have separate antecedents and outcomes, although the two tend to have a positive relationship, such that individuals who experience interference in one domain tend to also experience it in the other (Byron, 2005; Frone, 2003).

Within each of these directions, three types of WFC have been identified: time-based conflict, strain-based conflict, and behavior-based conflict (Greenhaus \& Beutell, 1985). Time-based conflict is defined as conflict where the time demands associated with one role impinge on the time that is ordinarily devoted to the other 
role, such as having to stay late at work and thereby missing a family dinner. Strainbased conflict is defined as conflict that occurs when stress from one role is transferred to the second role, such as where worry over a sick child reduces the efficiency of an employee at work. Behavior-based conflict is defined as a conflict occurring when a behavior that is useful in one role is applied inappropriately to the other role, such as the authoritative behavior necessary for a manager reducing effectiveness in a mother who needs to behave in a nurturing manner (Greenhaus, Allen, \& Spector, 2006).

The construct of WFC is based on the scarcity hypothesis, which posits that individuals have a finite amount of resources, and when resources are put toward one role in life, they are unavailable to use in the other role (Goode, 1960). This has resulted in the study of WFC being oriented strongly toward the stress perspective (Kahn, Wolfe, Quinn, Snoek, \& Rosenthal, 1964).

WFC has many negative outcomes for both the individual and the organization. High levels of WFC have been linked to lower productivity, higher absenteeism, a myriad of health problems, and lower satisfaction in general (Eby et al., 2005). High levels of WFC have been correlated with lowered satisfaction in many arenas, including work satisfaction, marital satisfaction, and overall life satisfaction (Hammer et al., 2005). WFC is also connected to performance at work, such that higher WFC is associated with poorer performance on the job (Kossek \& Ozeki, 1999). High levels of WFC are also associated with high turnover intentions and burnout (Kossek \& Ozeki, 1999; Greenhaus, Parasuraman \& Collins, 2001). The 
current study focuses on the impact of WFC on physical and mental health and wellbeing.

\section{Health and Well-Being}

Health, and, more broadly, overall well-being, are made up of both physical and psychological attributes (Greenhaus et al., 2006). These can include physical health symptoms, overall health problems, emotions, satisfactions, dissatisfactions, mental disorders and more (Greenhaus et al., 2006). The term "health" generally includes both physiological and psychological symptomology in a medical context, while well-being is a broader category that includes health as well as context-free measures of life experiences (Danna \& Griffin, 1999). Positive well-being consists not only of a lack of negative conditions and diseases, but also a presence of positive states and conditions (Nelson \& Simmons, 2003). In other words, the absence of physical and mental complaints does not automatically create positive well-being in an individual. In the present study, multiple indicators of well-being are utilized in order to get a more complete picture of the impacts of WFC on well-being, including general health, depressive symptoms, and overall life satisfaction.

\section{WFC and Well-Being}

The existing WFC literature has shown support for a negative relationship between WFC and an individual's health and well-being. Several meta-analyses of the relationship have found that effect sizes range from small but significant to medium (.13 to .35), depending on the direction of conflict and the indicator of well-being examined (Allen, Herst, Bruck, \& Sutton, 2000; Kossek \& Ozeki, 1999; Mesmer- 
Magnus \& Viswesvaran, 2005). For instance, a meta-analysis by Mesmer-Magnus and Viswesvaran (2005) found that WIF was negatively correlated with job satisfaction $(r=-.12)$, life satisfaction $(r=-.26)$, and health $(r=-.23)$, and that FIW also had negative impacts on the same well-being indicators $(r=-.14,-.20$, and -.23, respectively). In their meta-analysis of 67 articles, Allen and colleagues (2000) also found that WIF was associated with several negative well-being outcomes, including general psychological health $(r=.29)$, somatic/physical symptoms $(r=.29)$, depression $(r=.32)$, alcohol abuse $(r=.13)$, burnout $(r=.18)$, work-related stress $(r=.41)$, and family-related stress $(r=.31)$.

WFC and general health. The findings linking general overall health to WFC are strong. Multiple studies have consistently shown support for the significant negative relationship between WFC and general health (e.g., Frone, Russell, \& Barnes, 1996; Grzywacz, 2000; Netemeyer et al., 1996; Winter, Roos, Rahkonen, Martikainen, \& Lahelma, 2006). Findings have shown that both WIF and FIW are associated with poor self-rated overall health, and many studies have found that this relationship is still significant even after adjusting for demographic, gender, and socioeconomic factors that often account for health differences (e.g., Grzywacz, 2000; Winter et al., 2006). For example, Winter and colleagues (2006) examined more than 4,000 city employees, and found that individuals with high WIF were about $29 \%$ more likely to have poor general health than individuals who had low or no WIF, even when controlling for age, family structure, occupational social class, working conditions, economic resources, social support. Individuals with high FIW were about $33 \%$ more 
likely to have poor general health than individuals who had low or no FIW, when controlling for the same variables (Winter et al., 2006).

WFC and physical health. More specifically, previous research has shown that WFC is positively related to physical symptoms and strain, as well as negatively related to overall physical health (Allen et al., 2000). Correlations for this relationship can be very strong. For example, Guelzow, Bird, and Koball (1991) examined dualcareer men and women and the relationship between their levels of WIF and physical symptomology. Correlations were $r=.48$ and $r=.57$ for women and men respectively (Guelzow et al., 1991). Thomas and Ganster (1995) found similar correlations between WFC and health symptoms $(r=.53)$ in their study of health care workers, as did Googins and Burden (1987; $r=-.44)$ in their study of working parents' levels of WFC and the relationship to physical health and energy.

WFC has been shown to be positively related to several specific health complaints and diseases as well. For example, previous research has indicated that WIF is positively related to instances of hypertension and physical health complaints (Frone, Russell, \& Cooper, 1997). Both WIF and FIW have been shown to have a positive relationship with diastolic blood pressure, one of the leading health problems in the U.S. today (Thomas \& Ganster, 1995). In addition, WIF was positively related to cholesterol levels, another one of the main health complaints in the U.S. (Thomas \& Ganster, 1995). Frone (2000) found that individuals who were experiencing WIF were 1.99 times more likely to have a substance dependence than individuals who were not experiencing WIF. Similarly, individuals who experienced FIW were 11.36 
times more likely to have substance dependence that individuals who did not suffer from FIW (Frone, 2000). Van Hooff et al. (2005) found that WFC is a precursor to health impairment, and that long-term experience of WFC is responsible for an "accumulation of health complaints."

WFC and mental health. Mental health also suffers as a result of WFC. Frone (2000) found that individuals who experienced a high level of either WIF or FIW were more likely to have significant mental health problems. For example, in his comprehensive national study, Frone (2000) found that individuals suffering from WIF were 3.13 times more likely to have a mood disorder than individuals who did not experience WIF. In a similar but even more pronounced finding, individuals with FIW were 29.66 times more likely to have a mood disorder than those who did not experience FIW (Frone, 2000).

Several studies have examined WFC and depression, and have found that individuals with high WFC also have high levels of depression (Frone et al., 1997; Grzywacz \& Bass, 2003; Hammer et al., 2005). Correlations between WFC and depression tend range from moderate to strong, especially for individuals with caregiving roles, such as those in the sandwiched generation. For example, Hammer and colleagues (2005) examined working couples in the sandwiched generation and found evidence that both directions of WFC were correlated with depression for both husbands and wives. Cross-sectional correlations for wives were .32 and .28 for WIF and FIW, respectively, and correlations for husbands were .19 and .18 for WIF and FIW, respectively. Similar findings have also been shown for other populations with 
multiple roles. For instance, Frone and colleagues (1997) examined individuals who had several roles, such as those who were employed, married, and parenting, and found that WFC was positively related to depression with a correlation coefficient of .26. Beatty (1996) found that for female professionals with children, WFC was positively related to depression, $r=.51$. Frone and colleagues (1996) examined employed parents in two studies, and found that correlations between WFC and depression ranged between $r=.20$ and $r=.25$.

WFC has also been shown to be positively related to anxiety, such that employees with high levels of WFC are more likely to suffer high anxiety (e.g., Beatty, 1996; Frone, 2000). In a comprehensive national study, Frone (2000) found that individuals experiencing WIF were 2.46 times more likely to have an anxiety disorder than individuals who were not experiencing WIF. Similarly, individuals experiencing FIW were 9.49 times more likely to have an anxiety disorder than individuals who did not suffer from FIW (Frone, 2000). This seems to be especially true for individuals who hold multiple roles, such as those in the sandwiched generation. For example, Beatty examined the correlations between WFC and anxiety in female professionals, and found that for those without children, the correlation was $r=.30$, and for those with children, the correlation was $r=.43$. Similarly, MacEwen and Barling (1994) examined the correlations between WFC and anxiety in married parents, and found very strong positive correlations between the two ( $r=.57$ for men and $r=.55$ for women). 
There is also strong evidence that high levels of WFC are linked to lowered levels of life satisfaction (Carlson \& Kacmar, 2000; Greenhaus, Collins, \& Shaw, 2003; Netemeyer et al., 1996; Parasuraman, Greenhaus, \& Granrose, 1992; Perrewe, Hochwarter, \& Kiewitz, 1999). For example, the Allen et al. (2000) meta-analysis of 67 studies found a weighted correlation of $r=-.28$ for the relationship between WFC and life satisfaction. Other satisfaction levels were also negatively related to WFC, such as job satisfaction ( $r=-.23)$, marital satisfaction $(r=-.24)$ and family satisfaction (r=-.17; Allen et al., 2000).

Costs of employee health problems. Employee health problems are not only an individual problem, but an organization-wide problem as well. Sick or unhealthy employees can cost an organization in many ways, including higher rates of absenteeism, lowered productivity while at work, higher health insurance costs, workers' compensation, legal costs and more (Goetzel, Guindon, Turshen, \& Ozminkowski, 2001). As mentioned previously, worker stress costs American businesses approximately $\$ 150$ billion each year (Sauter et al., 1990). This is because employees suffering from work-related stress have higher rates of absenteeism, lower productivity when at work, higher health care costs, and file more workers compensation claims (Hillier, Fewell, Cann \& Shepard, 2005; Sauter et al., 1990). In fact, industry in the U.S. loses about 550 million working days each year to absenteeism, and it is estimated that $54 \%$ of those absences are stress-related (Elkin \& Rosch, 1990). 
A series of Consortium Benchmarking Studies was performed in 1998 to attempt to discover how poor worker health can impact organizations (Goetzel et al., 2001). The studies encompassed 43 American companies and nearly one million employees within those companies. These studies estimated that the median losses due to health and well-being issues were $\$ 9,992$ per employee. The majority of this cost came from group health insurance (47\%), followed by costs associated with turnover (37\%), and then by other costs, such as those associated with unscheduled absence, disability, and workers' compensation programs (Goetzel et al., 2001). For companies with many employees, this cost of nearly $\$ 10,000$ per employee can easily escalate to millions of dollars.

Even individual illnesses can have a huge toll on organizations. For instance, depression, one of the well-being outcomes included in the present study, is one of the top ten most common mental health problems for Americans, and also one of the top 10 most costly health problems for organizations (Goetzel et al., 2004). Goetzel and colleagues (2004) used average impairment and prevalence estimates to quantify the economic burden of the 10 most costly illnesses for employers in the U.S., including depression. They compiled data from several large existing surveys, including the Medstat MarketScan Health and Productivity Management database (HPM, $\mathrm{N}=74,799$ ), the McArthur Foundation Midlife Development in the United States Survey (MIDUS; N=2074), and the American Productivity Audit $(\mathrm{N}=25,000)$. Their thorough research found that depressed employees had an average annual productivity loss of $10.7 \%$ due to absenteeism and an additional average annual productivity loss of 
$15.3 \%$ due to lack of presenteeism. Individuals suffering from depression cost their employer an estimated $\$ 4,741$ per depressed employee per year in productivity losses due to absenteeism alone. Results of this study showed that depression costs employers an average of $\$ 348$ per employee per year for the total population of employees - not just the depressed individuals (Goetzel et al., 2004).

It is easy to see why employers might want to decrease stress and improve health to save their bottom line. In times of economic hardship, it is especially crucial to keep stress low and employee health high to avoid these costs. The present study seeks to determine the subtleties of the relationship between stress and health, and to uncover new ways to protect health and well-being, as well as the organization's bottom line.

How can organizations lower stress and encourage employee well-being? What can be done to alleviate the negative relationship between WFC and well-being? Several studies have examined direct effects on this relationship, in an attempt to lower WFC and thereby improve well-being. However, some jobs have inherently high levels of WFC, and lowering WFC in these professions has proved almost impossible. What is to be done for the individuals in these jobs? One answer may be to examine indirect effects on the WFC-well-being relationship. If researchers can determine what variables buffer this relationship, well-being outcomes can be preserved even in situations where lowering WFC is not possible. However, there is a dearth of studies that examine the indirect effects of other variables on the WFC-wellbeing relationship (Mauno, Kinnunen, \& Ruokolainen, 2006). The present study 
seeks to add to the small body of literature concerning indirect effects on the WFCwell-being relationship, and to determine if certain resources can possibly alleviate the negative effects of WFC on well-being. In order to do this, this relationship will be examined through the lens of the Job Demands-Resources Model (Demerouti, Bakker, Nachreiner, \& Schaufeli, 2001).

\section{The Job Demands-Resources Model}

The JD-R model is a heuristic model of employee well-being (Bakker, Hakanen, Demerouti, \& Xanthopoulou, 2007; Demerouti et al., 2001). The model specifies that well-being can be produced by two sets of working conditions: job demands and job resources (Demerouti et al., 2001). Job demands are physical, social, or organizational aspects of the job that require mental or physical effort. Job resources are physical, psychological, social, or organizational aspects of the job that help the individual to achieve goals, reduce demands, and stimulate personal development (Demerouti et al., 2001). An assumption of the JD-R model is that job stress or burnout develops in situations where job demands are high and job resources are low. Previous research has supported this hypothesis and shown that demandresources combinations such as these can evoke two processes: health impairment and employee motivation (Llorens, Bakker, Schaufeli, \& Salanova, 2006). Previous studies have found that conditions of high demands tend to result in exhaustion and health impairment, whereas lack of resources leads to lack of motivation and increased cynicism (Bakker, Demerouti, De Boer, \& Schaufeli, 2003). Tests of robustness of the model have shown support for both the process paths of health impairment and 
employee motivation, and that the model remains strong across cultures, occupations, and data gathering techniques (Llorens et al. 2006). The JD-R model has been shown to predict many outcomes, including burnout (Demerouti et al., 2001), work engagement (Bakker et al., 2007), turnover intent (Schwartz, 2007), workplace bullying (Munoz, Gamarra, Jimenez, \& Herrer, 2006), and job satisfaction (Lewig \& Dollard, 2003).

The JD-R model and resource buffering. Recent research has expanded the JD-R model to include potential buffering effects of resources (Bakker, Demerouti, \& Euwama, 2005; Bakker et al., 2007). This is consistent with the theory provided by Kahn and Byosiere (1992), who claimed that properties of the work situation and characteristics of the individual can buffer the effects of a stressor-strain relationship. The theory is similar to Karasek's demand-control model (1979), which claims that job control or autonomy can buffer the impact of workload on strain. The key difference between Karasek's demand-control model and the JD-R is that the JD-R model of resource buffering expands on Karasek's model to include many different job resources and their buffering effect on many different job demands, rather than the effect of just job control/autonomy. The specific resources and demands involved depend on the characteristics of the specific job (Bakker et al., 2007). This buffering effect could "reduce the tendency of organizational properties to generate specific stressors, alter the perceptions and cognitions evoked by such stressors, moderate responses that follow the appraisal process, or reduce the health-damaging consequences of such responses" (Bakker et al., 2005, p. 171). 
Several recent studies have shown support for the resource buffering component of the JD-R model in multiple outcomes. For instance, Bakker and colleagues (2007) examined Finnish schoolteachers using this model. They found that five out of six job resources examined acted as buffers in the negative relationship between pupil misconduct and work engagement (Bakker et al, 2007). The resources that acted as buffers included supervisor support, innovativeness, information, appreciation, and organizational climate. The only resource that did not significantly moderate the relationship between pupil misconduct and work engagement was job control (Bakker et al., 2007).

Xanthopoulou and colleagues (2007) examined Dutch home care workers and the strong relationship between job demands and burnout. Their findings showed that job resources (autonomy, social support, performance feedback, and opportunities for professional development) buffered the relationship between job demands (emotional demands, patient harassment, workload, and physical demands) and burnout.

Van Vegchel, de Jonge, Soderfeldt, Dormann, and Schaufeli (2004) conducted a longitudinal study to determine if certain resources, specifically, social support and job control, moderated the relationship between job demands and burnout in human service work. The authors proposed that the resources of job control and social support would moderate the relationship, such that individuals with high demands but also high resources would experience less burnout. The study used the well-known Maslach Burnout Inventory (MBI) as an outcome measure, and examined the impact 
of the moderators on each of the three components of burnout: emotional exhaustion, depersonalization, and lack of personal accomplishment (Maslach \& Jackson, 1986).

Results showed that one of the resources measured, job control, moderated the relationship between emotional demands and one component of burnout, emotional exhaustion. There was a lack of significant interaction findings between the other resource, social support, and burnout, which the authors attributed to the relatively small amount of variance in the outcome measure. In addition, the authors emphasized that according to Semmer, Zapf, and Grief (1996), there is an upper limit of about $10 \%$ of the variance that can be explained by a stressor-strain relationship, due to the many contributing factors that can lead to poor well-being. Thus, a lack of significant interaction findings was not surprising, given the small amount of variance that any given stressor can explain in the strain outcome.

There are two studies that are particularly relevant to the present study, in that they both examine the impact of resources as buffers on the relationship between WFC and well-being: one by Bakker and colleagues in 2005, and a second shortly afterward by Mauno and colleagues in 2006. The first of these, conducted by Bakker and colleagues (2005), tested the hypothesis that multiple job resources may buffer the effects of several job demands on burnout (Bakker et al., 2005). The authors hoped to find moderating effects of this nature, as this would imply that the well-being and productivity of employees can be maintained, even in situations where job demands cannot be lowered or changed. 
This study used the JD-R model and examined the impact of four specific resources on the relationship between four specific job demands and burnout. The central hypothesis was that all of the job resources could potentially buffer the relationship between the job demands and burnout. Participants in the study were 1,012 employees of an institute for higher education in the applied science area in the Netherlands. The authors developed a set of job demands and job resources based on interviews with the population as to what demands were prevalent and what resources were needed. Based on these answers, the authors included work overload, emotional demands, physical demands, and work-home interferences as job demands. Resources that were examined included social support, autonomy, performance feedback, and quality of relationship with supervisor. Burnout in this study was measured using the well-known and validated Maslach Burnout Inventory-General Survey, which has three dimensions of burnout: professional efficacy, exhaustion, and cynicism (MBIGS; Schaufeli, Leiter, Maslach, \& Jackson, 1996).

The hypothesis was tested using two-way interaction effects in a series of 16 separate hierarchical regression analyses for each burnout dimension. Results supported previous research findings that demands had greater impact on the exhaustion component of burnout and that lack of resources had greater impact on cynicism and professional efficacy. The authors found that none of the interaction terms explained a significant part of the variance in professional efficacy, which also confirmed previous research that professional efficacy has a different role in burnout than the dimensions of exhaustion and cynicism. Results for the other two 
dimensions of burnout, exhaustion and cynicism, found that 18 out of the 32 possible interactions, or 56\%, explained a significant part of the variance in burnout. The authors found that autonomy was the most frequently significant buffer of job demands, followed by performance feedback, quality of the relationship with the supervisor, and social support from colleagues. Of particular interest to this study, the results showed that autonomy, quality of relationship with supervisor, and feedback all buffered the relationship between work-home interference (also known as WFC) and the exhaustion and cynicism dimensions of burnout. In fact, "When job resources were available in the environment, job demands had a weaker or no relationship with burnout" (Bakker et al., 2005, p. 176).

The authors noted that the study was cross-sectional in design, and called for longitudinal research to be done in this area to definitively determine the direction of the effects. An additional limitation that the authors listed was that their sample was composed of employees from a single organization, and that future research should cover employees of multiple organizations to improve the generalizability of findings (Bakker et al., 2005). The current study addresses these limitations by including a longitudinal design of individuals who are employed at hundreds of organizations across the country, rather than a single organization.

The second study of particular interest to the present study is even more applicable. This study, by Mauno and colleagues (2006) sought to examine the role of three resources as moderators of the negative relationship between WFC and its 
physical well-being, organizational commitment, and job attitudes. This study also utilized the JD-R model to examine the relationship.

The three proposed moderators in the study by Mauno et al. (2006) were job control, supportive work-family climate, and organization-based self-esteem (OBSE). Participants in the study were 1,252 individuals from three organizations: a public health care district, an information, communication and technology company, and a carton board mill. The authors used moderated multiple regression analysis to examine the direct and interaction effects of WFC and the moderator variables on well-being and job attitudes. Interestingly, the authors chose to examine both timeand strain-based WIF in their data, but not FIW.

The results of the moderator analyses were mixed. Of particular interest to this study, results showed that a supportive work-family climate was a significant moderator of the negative effects of strain-based WFC on physical well-being, as well as on organizational commitment. The resource of job control was a moderator for the outcomes of job satisfaction and organizational commitment, but did not seem to buffer the relationship between WFC and physical health. Analyses of the third resource, OBSE, appeared to be approaching significance for some outcomes, but never reached a level of statistical significance for any outcome. Overall, four of the 18 moderator effects examined were significant and in line with both the hypotheses and the JD-R model of resource buffering. The authors proposed that one reason for having a small number of statistically significant moderators is that interaction effects are statistically difficult to find. The authors also reasoned that two of the resources 
studied, OBSE and supportive work-family climate, were relatively new fields of study, and it may be that more empirical and theoretical work needs to be done to clarify these constructs.

As for limitations of the study, the authors noted that, as in the Bakker et al. study (2005), the design was cross-sectional, and that a longitudinal study is needed to examine causal relationships. Another limitation was that only WIF was studied, not FIW. A third and final limitation discussed was that no tests were performed to determine if the chosen constructs were empirically distinct concepts (Mauno et al., 2006). The current study seeks to address these limitations by including a longitudinal design examining both WIF and FIW.

In summary, there is a growing body of research that indicates that many resources can moderate negative relationships to improve or negate outcomes. There are a very small number of studies that support the JD-R theory of resource buffering in the area of WFC and well-being. The present study attempts to provide further support for this theory, to address some of the limitations of previous studies, and to expand on the theory by examining new resources.

\section{Resources}

What could help working sandwiched generation individuals cope with their many demands and reduce negative outcomes? In particular, what resources could help these particular individuals to reduce poor work and well-being outcomes? Since working sandwiched generation individuals by definition hold many roles, it seems prudent to examine these roles and the resources attendant with them. 
Overall role quality. How do the multiple roles that sandwiched generation members hold affect their well-being? Two main hypotheses have examined the relationship between multiple role involvement and well-being: the scarcity hypothesis (Goode, 1960) and the enhancement hypothesis (Marks, 1977). The scarcity hypothesis posits that the amount of energy an individual has is limited, and thus involvement in one role takes energy away from other roles (Goode, 1960). This hypothesis states that well-being is often impaired in individuals who hold multiple roles, as roles are inherently incompatible with each other. In contrast, the enhancement hypothesis posits that individuals gain benefits, such as self-esteem, skills, opportunities to experience success, coping techniques, status, and more, from participation in each role (Marks, 1977). Thus, participation in multiple roles results in multiple benefits that can spill over and enhance other roles and overall well-being. Empirical evidence is mixed, as discussed previously, but tends to support the idea that overall, there is a positive relation between the number of roles a person holds and levels of well-being, thus showing more support for the enhancement hypothesis (McMunn, Bartley, Hardy, \& Kuh, 2006; Janzen \& Muhajarine, 2003)

However, both the scarcity and enhancement hypotheses focus only on the number of roles occupied, and neither of these hypotheses considers the quality of a particular role and how that may effect well-being. The mixed results in this field may be a result of not having the whole picture of role participation, which would include not only the quantitative number of roles occupied but also the perception of stressors and rewards that accompany those particular roles. 
Role quality is the subjectively assessed positive and negative aspects of a particular role (Barnett, Steptoe, \& Gareis, 2005). The quality of experience in a particular role is a relatively understudied topic in the industrial-organizational psychology field. Role quality tends to be more difficult to quantify than its objective counterpart, role quantity, but it is particularly important to examine as it includes the participant's perceptions rather than objective indicators. Several studies have shown that role quality is a much more accurate predictor of well-being than simple quantitative role occupancy numbers (Baruch \& Barnett, 1986; Barnett \& Marshall, 1991; Vandewater, Ostrove, \& Steward, 1997). For example, Baruch and Barnett (1986) examined the impact of both quantitative role occupancy and qualitative role quality of women's roles as worker, mother, and wife and their effect on well-being, as measured by self-esteem, depression, and pleasure. When they examined simple quantitative role occupancy (i.e., the number of roles a woman held), the only significant finding they discovered was that occupancy in the job role predicted selfesteem. In contrast, when qualitative role quality was examined, both the quality of the job role and the quality of the spouse role were strongly related to all three measures of well-being. Their findings suggest that, depending on whether a role gives a "net gain" of benefits over stressors, involvement in that role will positively impact well-being, despite the fact that it increases the number of roles an individual occupies (Baruch \& Barnett, 1986).

Generally speaking, there are two ways that role quality is measured (Neal \& Hammer, 2007). One way is to examine the rewards and satisfaction levels associated 
with a role separately from the stressors or concerns associated with that same role. Several studies listed in this review of the literature examine role quality in this way (Stephens, Franks, \& Atienza, 1997; Martire, Stephens, \& Atienza 1997). A second way to measure role quality is to take the average of the rewards and subtract the average of the concerns from it, thus giving a single score representative of the overall quality of experience of the role. In this manner, a positive number indicates that the individual experiences the role in an overall positive manner, while a negative number indicates that the individual experiences the role in an overall negative manner. In the current study, as well as many others, overall role quality is measured by the difference between the mean of the rewards and the mean of the concerns (Barnett \& Baruch, 1985; Neal \& Hammer, 2007).

Previous research has shown that role quality in one role can exacerbate or buffer the effects of stress from other roles (Stephens \& Townsend, 1997; Voydanoff \& Donnelly, 1999). Role quality can also influence the outcomes, such as well-being, of role participation (Froberg, Gjerdingen, \& Preston, 1986). Thus, it is theorized here that these various types of role quality (job role quality, spousal role quality, child-care role quality, and parent-care role quality) will act as buffers between the stress of WFC and the well-being outcomes. In terms of the JD-R framework, role quality is the resource that may be able to buffer the negative effects of the demand of WFC.

It is worth noting that logically, only one part of role quality, role rewards, should be considered a true "resource," and that the second part of role quality, role concerns, should be conceptualized as a demand instead of aggregated into a global 
measure to use as a resource. However, in the current study, the more comprehensive measure of role quality is conceptualized as a resource that may potentially buffer the negative impact of WFC on well-being. The reasoning behind this is that the scale of role quality has greater variability than the sub-scale of role rewards, and therefore it is the scale most likely to detect true moderation effects. Thus, in the interests of attempting to find true moderation effects, the concept of role quality is utilized in this study. Additionally, previous research has found that individuals tend to experience roles in an overall positive way (Baruch \& Barnett, 1986). Therefore, conceptualizing role quality as a positive resource is reflective of the true state of role perceptions for the majority of individuals. In addition, the majority of research on role quality has been done on the more global scale of role quality, not the specific subscale of role rewards, and thus there is a better theoretical background to support research on role quality. Previous research on several of the specific types of role quality has shown that there are direct effects between role quality and well-being as well, as described below.

Job role quality. Job role quality is the individual's subjective assessment of the stressors and rewards associated with his or her role as a worker (Baruch \& Barnett, 1986). It is much harder to capture than its objective counterpart, job role occupancy, i.e., whether an individual holds a job. Barnett and Brennan (1994) attempted to conceptualize this type of role quality in their research, and were able to identify seven important job conditions that can influence an individual's experience of the role of worker: skill discretion, decision authority, schedule control, job 
demands, pay adequacy, job security, and relations with supervisors. These are conceptually similar to the job dimensions described in the Job Diagnostic Survey (JDS) created by Hackman and Oldham (1975). The JDS includes several core job dimensions, including skill variety, task identity, task significance, autonomy, and feedback, that are hypothesized to provoke critical psychological states which can lead to personal and work outcomes. When these job dimensions are high, outcomes tend to be more positive, such as lower absenteeism and turnover, higher motivation, performance, and satisfaction with work (Hackman \& Oldham, 1975). The literature also indicates that job role quality is significantly and negatively related to several negative health outcomes, including psychological distress and its two separate components, anxiety, and depression (e.g., Baruch \& Barnett, 1986; Barnett \& Brennan, 1994). Findings have also shown that job role quality is significantly and positively related to several positive health outcomes, including mental health and life satisfaction (e.g., Baruch \& Barnett, 1986; Barnett \& Brennan, 1994).

Psychological distress, which includes both anxiety and depression, has been linked to job role quality in several studies (Barnett, Marshall, Raudenbush, \& Brennan, 1993; Barnett, Raudenbush, Brennan, Pleck \& Marshall, 1995; Voydanoff \& Donnelly, 1999). Previous research by Barnett and colleagues (1993) examined 300 dual-earner couples to assess the relationship between job role quality and psychological distress. Their results showed that individuals with high job role quality had significantly less psychological distress than their counterparts with poor job role quality. The authors found no gender differences between men and women in this 
study. A subsequent study examined the changes in job role quality over time and the attendant changes in psychological distress (Barnett et al., 1995). This study found that increases in job role quality were followed by decreases in psychological distress, and that decreases in job role quality were followed by increases in psychological distress. These findings were significant for both men and women, showing no gender differences.

Research by Voydanoff and Donnelly (1999) also supported the idea that job role quality has a strong impact on psychological distress. Their study examined the relationship between psychological distress and both objective and subjective aspects of the roles of worker, spouse, and parent. The results showed that job satisfaction, a job role reward, was negatively related to psychological distress for both men and women. The study also found that WIF, a job role stressor, was positively related to psychological distress for both men and women.

Several studies have shown that job role quality is significantly and negatively associated with depression levels (Gomez, 2006; Neal \& Hammer, 2007; Plaisier et al., 2008; Windle \& Dumenci, 1997). For example, Plaisier and colleagues (2008) conducted a three-year longitudinal study of how several types of role quality affect the mental health of both men and women. In regards to the job role quality, they found that, compared to individuals who did not work or who had medium job role quality, individuals with low work quality had significantly reduced mental health over the three year period, as well as an increased risk of developing clinical anxiety and/or depression disorders. In contrast, their findings also showed that individuals 
with high work-role quality had significantly better mental health than their counterparts who did not work or who only had a medium work-role quality, and they also had a decreased risk of developing clinical depression or anxiety.

Neal and Hammer (2007) examined several types of role quality in working, sandwiched couples. With respect to job role quality, they found that poor job role quality was significantly correlated with high levels of depression for men but not for their female spouses. They also found that job role quality was significantly and positively correlated with life satisfaction for both men and women (Neal \& Hammer, 2007). These results are encouraging, but cross-sectional in nature. The present study examines this same data in a longitudinal manner, which better enables causal inferences, and examines important indirect effects that were not previously examined.

In summation, several studies have shown that work-role quality is related to several aspects of well-being, including psychological distress, mental health, and life satisfaction. This relationship appears to be such that individuals with high work-role quality have better health and well-being than individuals with low work-role quality. In addition, these studies have found that work-role quality is important to mental well-being for both women and men. Although these studies are informative about the main effects, there is virtually no research on the indirect effects of job role quality on well-being outcomes produced by WFC. The current study aims to examine these indirect effects.

Spousal role quality. Similar to research conducted on the role occupancy benefits of the job role, research has generally shown that simply having a spouse or 
partner is beneficial for both mental and physical health (e.g., Khlat, Sermet, \& Le Pape, 2000; Litwak \& Messeri, 1989; Martikainen, 1995). In fact, non-married women have a $50 \%$ greater mortality rate than their married counterparts, and nonmarried men have a $250 \%$ greater mortality rate than their non-married counterparts (Ross, Mirowsky, \& Goldsteen, 1990). But what about the relationship between the quality of the spousal role and well-being? Previous research has shown that high marital role quality is positively related to many positive well-being indicators, including mental health, self-esteem, and life satisfaction (e.g., Cleary \& Mechanic, 1983; Neal \& Hammer, 2007; Barnett et al., 2005).

Previous research has also linked positive spousal role quality to lower levels of several indicators of negative mental health, including psychological distress and its two separate components, depression, anxiety, as well as overall mental health (Barnett, Brennan, \& Marshall, 1994; Cleary \& Mechanic, 1983; Gomez, 2006; Plaisier et al., 2008). Several studies have found that positive spousal role quality is related to lower levels of depression and fewer depressive symptoms (Barnett et al., 1995; Cleary \& Mechanic, 1983; Fincham \& Beach, 1999; Gomez, 2006; Neal \& Hammer, 2007; Plaisier et al., 2008). For example, a study by Cleary and Mechanic (1983) examined one aspect of spousal role quality, marital role satisfaction, in employed men and women, as well as in unemployed women. Their results showed a strong relationship between marital satisfaction and depression for all individuals surveyed, such that individuals with high marital satisfaction were less likely to be depressed than individuals with low marital satisfaction. Their results showed no 
differences between the genders, or between those who were employed outside the home and those who were not. Barnett and colleagues (1995) found that changes in spousal role quality over time were associated with changes in psychological distress: as spousal role quality increased, psychological distress decreased. Also, decreases in spousal role quality led to increases in psychological distress. No gender differences were found.

Additional research by Plaisier and colleagues (2008) also supported the theory that spousal role quality has important impacts on mental health, depression, and anxiety as well. The authors examined spousal role quality over a three-year period in both men and women. They found that having high spousal role quality was associated with significantly better mental health over the three-year period, as well as a reduced incidence of clinical anxiety and depression. Their results showed no significant differences between men and women with respect to the impact of spousal role quality on mental health.

Spousal role quality has been tied to indicators of positive well-being as well. Gomez (2006) found that, for men but not for women, positive spousal role quality was associated with higher levels of self-esteem. Neal and Hammer (2007) examined cross-sectional data on spousal role quality in working sandwiched couples and found that higher spousal role quality was associated with higher levels of life satisfaction in both men and women. Stephens and Townsend (1997) examined spousal role quality in sandwiched generation women who were employed outside the home and its effect 
on their overall well-being. Their results showed that high spousal role quality was associated with higher overall well-being.

Spousal role quality also appears to affect psychobiological indicators of stress. A study by Barnett, Steptoe, and Gareis (2005) examined the relationship between marital role quality and physical health, as assessed by self-reported stress, cortisol levels, and ambulatory blood pressure. This rare examination of psychobiological stress indicators examined 105 men and women. Results showed that individuals with high levels of marital concerns had greater stress throughout the day, increased cortisol levels, and elevated ambulatory diastolic and systolic blood pressure. The other dimension of marital role quality, marital role rewards, had no statistically significant impact on these indicators of well-being. These patterns held true for both genders.

In short, it appears that spousal role quality is an important factor in maintaining positive well-being, and can affect many indicators of well-being, including psychological distress, mental health, anxiety, depression, self-esteem, life satisfaction, blood pressure, and cortisol levels. It is clear that individuals with a more positive perception of their role as a spouse fare better in terms of their well-being than their counterparts with poor spousal role quality. Although this existing research supports the idea that there is a direct effect of spousal role quality on well-being, little research has examined the possibility of spousal role quality as a moderator between a stressor and negative well-being outcomes. The current study seeks to fill this gap. 
Child-care role quality. Findings related to the relationship between role occupancy of the parent role and well-being are more mixed than the research on role occupancy of the other roles examined here. Most of the existing research has been conducted on women, and some has shown that health benefits are associated with being a mother (Fokkema, 2002; Martikainen, 1995), while other studies have shown that being a mother is related to increased strain and psychological distress (Bartley, Popay, \& Plewis, 1992; Lennon \& Rosenfeld, 1992). Research on the quality of the experiences in the parent role, often called parent role quality and here referred to as child-care role quality, seem to show that this role quality is linked to well-being outcomes. Child-care role quality has been negatively linked to negative well-being outcomes such as depression and psychological distress, and positively linked to positive health outcomes such as self-esteem, mental health, life satisfaction, and physical health (e.g., Barnett et al.,1994; Gomez, 2006; Neal \& Hammer, 2007; Plaisier et al., 2008; Windle \& Dumenci, 1997). It appears that, similar to the other roles discussed here, the role quality an individual experiences in the parental role can significantly affect an individual's well-being.

Poor child-care role quality has been linked to high levels of both psychological distress and depressive symptoms (Barnett et al., 1994; Neal \& Hammer, 2007; Windle \& Dumenci, 1997). Windle and Dumenci (1997) examined 200 dual-earner couples and found that child-care role stress predicted depressive symptoms for both men and women. Similarly, Barnett and colleagues (1994) examined child-care role quality in dual-earner couples and its relationship to 
psychological distress. The results showed that the quality of a parent's relationship with his or her children was significantly associated with psychological distress for both men and women, such that individuals with a positive parent-child relationship reported much lower levels of distress than individuals with a negative parent-child relationship. No gender differences were found. Neal and Hammer (2007) found that poor child-care role quality was associated with high levels of depression for working women in the sandwiched generation, but not for their husbands.

Child-care role quality appears to also be related to some positive aspects of mental health. Gomez (2006) found that high child-care role quality was associated with significantly higher self-esteem in both men and women. Neal and Hammer (2007) found that high child-care role quality was positively associated with life satisfaction for working sandwiched women, although not for their male counterparts. Plaisier and colleagues (2008) also examined child-care role quality in their three-year longitudinal study of role quality and mental health. Their findings showed that individuals with medium or high quality child-care roles (called parent-roles in their study) had significantly better mental health over the three-year time period than those with low quality child-care roles or no child-care role at all.

Existing research also shows that child-care role quality may be related to physical well-being. Gomez (2006) examined several types of role quality and the relationship to symptoms of cardiovascular risk and disease in both men and women. Although most of the findings in the area of cardiovascular risk were non-significant, the results did show that child-care role quality for women was negatively related to 
cardiovascular risk indicators. This area needs further research, but this finding indicates that poor child-care role quality may be harmful to an individual's physical health. More research in the area is needed before firm conclusions can be drawn. In short, it appears that having a positive experience of the role of being a parent has an impact on several indicators of well-being. Recent research shows that child-care role quality may have an impact on physical health in addition to mental well-being indicators. The current study seeks to explore the possibility that this role quality can also act as a moderator on the relationship between a particular stressor (WFC) and these same well-being outcomes.

Parent-care role quality. Several studies have examined the effect of parentcare role quality on well-being, and nearly all have shown that poor parent-care role quality (or high parent-care role stress) is associated with indicators of poorer wellbeing, while positive parent-care role quality is associated with positive well-being indicators. Research in this area has linked parent-care role quality to several indicators of well-being, including depression, self-esteem, life satisfaction, and physical health.

Results from several studies have shown that parent-care role quality is negatively related to depression and depressive symptoms of the caregiver (Barnett, Kibria, Baruch, \& Pleck, 1991; Martire et al., 1997; Stephens et al., 1997; Stephens \& Townsend, 1997). For instance, Stephens et al. (1997) examined 105 employed women caring for their parents and the relationship between parent-care role quality and well-being, as measured by depression and positive affect. Researchers found that 
parent-care role stress was significantly and positively related to levels of depression, but not to positive affect. Martire and colleagues (1997) also examined employed women caring for ill or disabled parents, and found that parent-care role stress was significantly associated with higher levels of depression. Stephens and Townsend (1997) also found that the parent-care role stressors were related to high levels of depressive symptoms. Similarly, Barnett, Kibria, and colleagues (1991) found that stressors associated with the role of adult daughters caring for parents were significantly related to psychological distress. The higher the role quality between adult daughters and their aging parents, the less anxiety and depression the caregivers experienced.

The quality of the parent-care role can enhance the positive aspects of mental health as well. Baruch and Barnett (1983) examined adult daughters caring for aging parents and the effects that role quality had on their self-esteem. Results showed that self-esteem of the daughter was positively related to her perception of the motherdaughter role. Neal and Hammer (2007) found that parent-care role quality had a positive association with the life satisfaction of working, sandwiched men, although this did not hold true for their female spouses. Another study showed that the role quality of the adult daughter-parent relationship was significantly and positively associated with self-assessments of overall well-being (Barnett et al., 1991).

Parent-care role quality can also affect physical health. Martire et al. (1997) found that parent-care role rewards were positively associated with individual physical 
health and with positive affect. These authors also found that parent-care role stress was significantly associated with poorer physical health.

In sum, the small amount of existing research points to conclusions that parentcare role quality is positively associated with several indicators of well-being. To my knowledge, no research has yet been conducted on the possibility that parent-care role quality may have a moderating effect on the relationship between stressors such as WFC and well-being. The current study seeks to gain a deeper understanding of the effects of role quality by exploring such a possibility.

\section{The Current Study}

As previous research has shown, the stressor of WFC can be conceptualized as a job demand in the framework of the JD-R model (Bakker et al., 2005; Mauno et al., 2006). Through this lens, WFC is considered a job demand that has been known to cause exhaustion and negatively impact health. Building on the Mauno et al. (2006) study and the Bakker et al. (2005) study, the current study hypothesizes that resources can moderate the negative effects of the demand of WFC on the outcome of wellbeing, such that increased resources will reduce or eliminate the negative effects of the demand of WFC on well-being. Due to previous research that shows that both WIF and FIW are related to multiple markers of well-being, no theories are proposed about possible differential effects of the two directions of WFC on the well-being outcomes.

In order to study a group with particularly high WFC, I chose to use a sample composed of married, working individuals in the sandwiched generation. Based on the unique characteristics of the sample, it appears that role quality is an especially 
salient resource to this particular group. Although previous research has been conducted using these data, the analyses were cross-sectional and did not examine role quality as a moderator (Neal \& Hammer, 2007). The types of resources hypothesized as moderators in the present study include job role quality, spousal role quality, childcare role quality, and parent-care role quality. The limited previous research on role quality has shown that all four of these types of role quality have associations with well-being in their own right, but little has been done to examine these types of role quality as potential buffers.

The current study adds to the previous research by Bakker and colleagues (2005) and Mauno and colleagues (2006) by examining resources that have not been studied in the relationship between WFC and well-being to date. This study is the first to examine multiple types of role quality (work, spouse, child-care, and parent-care) as potential buffers of the WFC-well-being relationship. To address some of the limitations of the existing research, the current study utilizes longitudinal data to determine if WFC at Time 1 has a reduced impact on well-being outcomes at Time 2 when resource levels are high at Time 1. This relationship is visually represented in Figure 1.

\section{Hypotheses}

Based on the previous research summarized above, the hypotheses for this study are as follows:

H1: WFC (both WIF and FIW) at Time 1 will have a detrimental impact on the well-being outcomes measured at Time 2, measured by: 
H1a: overall health

H1b: depression

H1c: life satisfaction.

H2: Job role quality will moderate the WFC-well-being relationship, such that for those with greater job role quality at Time 1 , the negative relationship between WFC (i.e., WIF and FIW) at Time 1 and wellbeing outcomes at Time 2 will be reduced. The well-being outcomes examined include:

H2a: overall health

H2b: depression

H2c: life satisfaction.

H3: Spousal role quality will moderate the WFC-well-being relationship, such that for those with greater spousal role quality at Time 1, the negative relationship between WFC (i.e., WIF and FIW) at Time 1 and well-being outcomes at Time 2 will be reduced. The wellbeing outcomes examined include:

H3a: overall health

H3b: depression

H3c: life satisfaction.

H4: Child-care role quality will moderate the WFC-well-being relationship, such that for those with greater child-care role quality at Time 1, the negative relationship between WFC (i.e., WIF and FIW) at 
Time 1 and well-being outcomes at Time 2 will be reduced. The wellbeing outcomes examined include:

H4a: overall health

H4b: depression

H4c: life satisfaction.

H5: Parent-care role quality will moderate the WFC-well-being relationship, such that for those with greater parent-care role quality at Time 1, the negative relationship between WFC (i.e., WIF and FIW) at Time 1 and well-being outcomes at Time 2 will be reduced. The wellbeing outcomes examined include:

H5a: overall health

H5b: depression

H5c: life satisfaction. 
Method

Participants

As mentioned previously, the sample for this study is based on a national survey of dual-earner couples in the sandwiched generation. These couples were "sandwiched" between their work, child-care, and parent-care responsibilities (Hammer et al., 2005). Initial recruitment was conducted in 1998 by Drs. Margaret Neal and Leslie Hammer and their research associates. Using a targeted list of telephone numbers for households in the continental United States and contained at least one or more adults between the ages of 30 and 60, a total of 33,037 recruitment calls were made to 8,787 telephone numbers. Trained interviewers ascertained if the household qualified as a member of the target population for the study, working couples caring for aging parents and children. In order to be participants in the study, participants had to have the following characteristics: a) be living together for one year or more, although not necessarily married, b) have a child 18 and under living in the home three or more days per week, c) be caring for an aging parent, step-parent, or parent-in-law three or more hours per week, and d) working, one member of the couple at least 20 hours a week and the other at least 35 hours a week.

Interviews were completed with 5,565 (63.3\%) of the total calls made. The other calls resulted in refusal to complete the screening interview $(22.7 \%)$, inability to complete the survey due to language, speech, or hearing issues (1.2\%), unanswered phone calls $(6.9 \%)$, belonging to a business $(1.8 \%)$, or nonworking numbers $(4.1 \%)$. Interview screening showed that 741 households met the criteria for participation, or 
$8.97 \%$ of the working, non-business numbers and $13.3 \%$ of those actually interviewed. These individuals were then asked if they and their spouse would be interested in completing a mailed survey. Participants were informed that couples who returned both surveys would be sent a check for $\$ 40$ as a token of appreciation for their time. Surveys were sent to the 624 couples who agreed to participate. Each couple was mailed a cover letter with instructions, a survey, and a postage-paid, addressed envelope in which to return the completed survey. A total of 309 couples (618 individuals) responded to these surveys in 1998 , for a response rate of $49.52 \%$. One year later, 234 of these couples completed a second, virtually identical survey, for a response rate of $75.7 \%$. Ten years later, in 2009, another follow-up was conducted, that yielded 100 couples and several individuals who were willing to participate without their spouse.

For the purposes of this study, the terms "Time 1" and "Time 2" refer to the time periods in 1998 and 1999. Data from Time 3 were not included in the present analyses, as the sample size was significantly smaller and would have limited the power of the statistical tests. A total of 234 couples (468 individuals) completed a survey at both Time 1 and Time 2 . Only one member of each couple is included in the current study in order to meet statistical assumptions of independence of data points; thus, the total $\mathrm{N}$ for the study is 234 individuals (see Analysis section for details). The new sample of couples was composed of 117 men and 117 women, all of whom were married, but none of which were married to each other. Details on the creation of this dataset appear in the beginning of the analysis section of this paper. 


\section{Measures}

Work-family conflict. All measures were self-report scales used in a larger survey constructed by Neal and Hammer (2007). WFC was measured using the 10item work-family conflict scale by Netemeyer et al. (1996). (See Appendix A for the items comprising the two sub-scales.) This scale consisted of five items on WIF and five items on FIW. WFC levels were assessed on a 5-point scale, where 1 represented “strongly disagree” and 5 represented "strongly agree." Questions included items such as, "The demands of my work interfere with my home and family life," and "I have to put off doing things at work because of demands on my time at home." Neal and Hammer (2007) found that the internal consistency reliability of the WIF scale was .90 for men and .91 for women, and that the internal consistency reliability of the FIW scale was .88 for both men and women.

Job role quality. The job role quality scale used in the larger Neal and Hammer study (2007) and in the current study was adapted from Barnett and Brennan (1995; see Appendix B for the items comprising the scale). The scale is composed of two subscales, job role rewards and job role concerns.

The job role rewards scale included 16 questions that asked the participant how rewarding various situations had been at work in the past month, on a scale from 1 to 4. In this scale, 1 represented "not at all rewarding" and 4 represented "very rewarding." A "not applicable" option was available for some, but not all of the situations. Scale means were computed based on the applicable items only. Situations that were covered included things like, "challenging or stimulating work" and 
"making good money compared to other people in your field." Neal and Hammer (2007) found that the internal consistency reliability for this subscale was .92 for men and .86 for women.

The job role concerns scale included 19 questions that asked the participant how concerned he or she had been with various situations at work in the past month, on a scale from 1 to 4 . In this scale, 1 represented "not at all concerned" and 4 represented "very concerned." A "not applicable" option was available for some, but not all of the situations. Situations that were covered included things such as, "lack of job security on this job" and "lack of good benefits, for example, paid sick leave." Neal and Hammer (2007) found that the internal consistency reliability for this subscale was .91 for men and .87 for women.

To compute a composite job role quality score, first the mean of the responses on the job rewards scale items was calculated, then the mean of the responses on the items comprising the job concerns scale was calculated. The mean of the concerns subscale was then subtracted from the mean of the rewards subscale.

Spousal role quality. The spousal role quality scale from the Neal and Hammer (2007) survey and the current study was adapted from Barnett et al. (1993). (See Appendix C for all items comprising the scale.) This scale is also composed of two subscales, spouse role rewards and spouse role concerns.

The spousal role rewards scale included nine questions that asked participants how rewarding various aspects of their relationship with their spouse had been in the past month, on a scale from 1 to 4 . In this scale, 1 represented "not at all rewarding" 
and 4 represented "very rewarding." No "not applicable" option was offered in this scale. Aspects of the relationship that were covered included things like, "good communication" and "having a spouse or partner who shares in household responsibilities." Neal and Hammer (2007) found an internal consistency reliability of .92 for both men and women on this subscale.

The spousal role concerns scale included eight questions that asked participants how concerning various aspects of the relationship with their spouse had been in the past month, on a scale from 1 to 4 . In this scale, 1 represented "not at all concerned" and 4 represented "very concerned." No "not applicable" option was offered in this scale. Aspects of the relationship that were covered included things like "arguing or fighting" and "your spouse or partner being critical of you." Neal and Hammer (2007) found an internal consistency reliability of .91 for men and .90 for women on this subscale.

To compute a composite spousal role quality score, first the mean of the responses on the spousal rewards scale items was calculated, then the mean of the responses on the items comprising the spousal concerns scale was calculated. The mean of the concerns subscale was then subtracted from the mean of the rewards subscale.

Child-care role quality. The child-care role quality scale used by Neal and Hammer (2007) and in the current study was also adapted from Barnett et al. (1993). (See Appendix D for all items comprising the scale.) There are two subscales of this scale, child-care role rewards and child-care role concerns. 
The child-care role rewards scale contained eight items that asked participants to rate how rewarding various situations had been with their children in the past month, on a scale from 1 to 4 . In this scale, 1 represented "not at all rewarding" and 4 represented "very rewarding." A "not applicable" option was also offered. Situations included things like "feeling needed by your child(ren)" and "seeing your relationship with your child(ren) mature and grow." Neal and Hammer (2007) found that this subscale had a internal consistency reliability of .91 for men and .87 for women.

The child-care role concerns scale contained 13 items that asked the participant to rate how stressful various situations with his or her children had been in the past month, on a scale from 1 to 4 . In this scale, 1 represented "not at all stressful" and 4 represented "very stressful." A "not applicable" option was also offered. Means were computed based on applicable items only. Situations included things like "discipline or correct your child(ren)" and "help with your child(ren)'s personal care (e.g., grooming, dressing).” Neal and Hammer (2007) found that the internal consistency reliability of this subscale was .86 for men and .88 for women.

To compute a composite child-care role quality score, first the mean of the responses on the child-care rewards scale items was calculated, then the mean of the responses on the items comprising the child-care concerns scale was calculated. The mean of the concerns subscale was then subtracted from the mean of the rewards subscale.

Parent-care role quality. The parent-care role quality scale used by Neal and Hammer (2007) and in the current study was adapted from Stephens and Townsend 
(1997). (See Appendix E for all items comprising the scale.) There are two subscales of this scale, parent-care role rewards and parent-care role concerns.

The parent-care role rewards scale included eight questions that asked the participant to consider his or her role as a caregiver for the parent, stepparent, or parent-in-law that they were providing the most assistance to. This scale asked participants how rewarding various situations had been in the past month, on a scale from 1 to 4 . In this scale, 1 represented "not at all rewarding" and 4 represented "very rewarding." A "did not occur" option was also available. Situations that were covered included things like, "this parent showing appreciation for what you do for him/her" and "giving back to this parent some of the care s/he gave to you." According to Neal and Hammer (2007), the internal consistency reliability of this subscale was .91 for men and .87 for women.

The parent-care role concerns scale included 10 questions that asked participants to consider his or her role as a caregiver for the parent, stepparent, or parent-in-law that they were providing the most assistance to. This scale asked participants how stressful various situations had been in the past month on a scale from 1 to 4 . In this scale, 1 represented "not at all stressful" and 4 represented "very stressful." A "did not occur" option was also available. Situations that were covered include things like "this parent's complex medical care needs" and "this parent's criticisms or complaints." According to Neal and Hammer (2007), the internal consistency reliability of this subscale was .91 for men and .92 for women. 
To compute a composite parent-care role quality score, first the mean of the responses on the parent-care rewards scale items was calculated, then the mean of the responses on the items comprising the parent-care concerns scale was calculated. The mean of the concerns subscale was then subtracted from the mean of the rewards subscale.

Well-being. Well-being and health were assessed by three measures: overall health, depression, and life satisfaction. These constructs are frequently used indicators of overall well-being in previous examinations of the topic (Eby et al., 2005; Frone, 2000).

Overall health. Overall health was measured by one item indicating the general level of the participant's health, ranging from 1 (very poor) to 6 (excellent). The question was phrased, "How would you rate your overall health?."

Depression. Depression was measured by the 20 -item Center for Epidemiologic Studies-Depression Scale (CES-D, Radloff, 1977). (See Appendix F for the items comprising the scale.) Each question was framed as how often the participant had felt or behaved in such a way during the past week on a four-point scale, with responses ranging from 1 , representing "Rarely or none of the time (less than 1 day)" to 4, representing "Most of the time (5 to 7 days)." Questions included items such as "I was bothered by things that don't usually bother me" and "I felt that I could not shake off the blues even with help from my family or friends." Neal and Hammer (2007) found that the internal consistency reliability of this measure was .87 for men and .90 for women. 
Life satisfaction. Life satisfaction was measured by an eight-item scale adapted by Neal and Hammer (2007) from Campbell, Converse, and Rodgers (1975) and Quinn and Staines (1979). (See Appendix G for the items comprising the scale.) The measure consisted of eight word pairs, and asked participants to choose the word in the pair that was the best indicator of how their life was in general. Word pairs included things like, "boring-interesting," "discouraging-hopeful," and "lonelyfriendly." Responses were given on a 7-point scale, where 1 was considered low life satisfaction and 7 was considered high life satisfaction. Neal and Hammer (2007) found that the internal consistency reliability of this measure was .95 for both men and women.

Control variables. Previous research has indicated that socioeconomic status has a strong impact on health and well-being outcomes, and that this should be controlled for when attempting to determine other relationships with well-being (e.g., Ross \& Wu, 1996). Physical health has been found to vary with socioeconomic status (SES), such that individuals with higher SES are healthier (e.g., Illsley \& Baker, 1991; Johnson \& Krueger, 2005). The relationship persists across the entire gradient of SES, such that not only do individuals with median level SES have better health than those with poor SES, but the very wealthy have better health than the marginally wealthy (Marmot, Kogevinas, \& Elston, 1987). This relationship holds true even for countries with universal healthcare, across nearly every disease examined, and the trend continues to be significant across the entire lifespan of most individuals (e.g., Illsley \& Baker, 1991; Johnson \& Krueger, 2005; Winkelby, Jatulis, Frank, \& Fortmann, 1992). 
SES is usually measured in three ways: income, education, and occupation (Dutton \& Levine, 1989). Of these three, education level tends to be a better predictor of health outcomes than either household income or occupation (Winkelby et al., 1992). Thus, it seems prudent to control for some measure of SES.

The first control variable included in the analyses is education. Education was measured using a single item that asked participants to indicate the highest level of education they had completed on a 7-point scale. On this scale, 1 indicates an education level of grade school or less, and a 7 indicates a graduate degree. (See Appendix $\mathrm{H}$ for the exact text of the question.) Previous research using these data by Neal and Hammer (2007) found that this measure of education was significantly correlated with all three measures of well-being for men in the Wave 1 sample, and with the well-being outcome of life satisfaction for women in the sample $(\alpha<.05)$. Thus, it appears that this is a control variable worth including in the proposed model. The second control variable included in the analyses was perceived income adequacy, the perceived ability to meet wants and needs with the current amount of income (Voydanoff, 1990). Perceived income adequacy does not measure objective income level, but rather, the perceived financial stress an individual feels. Using this subjective measure enables a better understanding of how an individual actually feels about his or her income level, which triggers the stress that the person feels, and how he or she reacts. Perceived income adequacy was measured by a one-item question developed by Stewart and Archbold (1996). This question asked participants to rate their ability to make ends meet on their income on a 4-point scale. On this scale, 1 
represented "We can't make ends meet," 2 represented "We have just enough, no more," 3 represented "We have enough, with a little extra sometimes," and 4 represented "We always have money left over." Neal and Hammer (2007) found that this measure of perceived income adequacy was significantly correlated with all three well-being outcome measures for both men and women in their Wave 1 sample, indicating that this is likely a good variable to control for $(\alpha<.01)$. The inclusion of both an objective and a subjective measure of SES is intended to better fit the both objective and subjective data included in these analyses.

\section{Analysis}

The first set of analyses that were conducted were several tests of nonindependence of data points to assess if both members of couples could be utilized. Many of the statistical analyses used to test the hypotheses require the assumption of independence of errors. To test whether husband and wife data were independent of each other, an intercepts only model was conducted for each of the three outcome variables at each time point. From these data, an intraclass correlation was calculated for each of the outcome variables to ascertain if this number was zero, which would indicate independence of errors. Previous research has shown that an intraclass correlation of even .01 can inflate a normal Type 1 error rate of .05 to an unacceptable level of .17 (Barcikowski, 1981). Thus, in order to reduce Type 1 error, it is especially important that the assumption of independence of errors be met. Results showed that all of the intraclass correlations were higher than zero, indicating that husband and wife data points could not be considered independent of one another. (See Table 1 for 
the intraclass correlations of each outcome variable.) Therefore, a new dataset was created to include only one member of each couple.

To create a new dataset, dummy codes were used to indicate which member of the couple would be utilized. Half of the dummy codes indicated that the wife's data would be included, while the other half of the dummy codes indicated that the husband's data would be included. These dummy codes were randomly assigned to the couples' identification numbers. After random assignment, data from the member of the couple not indicated in the dummy code were discarded, while data were kept for the member of the couple matching the dummy code. This created a dataset of 117 men and 117 women, none of whom were married to each other.

Missing data were excluded on a casewise basis for each of the variables included. Descriptive statistics were calculated for each of the variables to identify outliers and irregularities in the data. Scatterplots were created to search for univariate outliers. Examination of the descriptive statistics and graphs showed no major irregularities in the data or violations of the assumptions underlying the statistical tests necessary to test the hypotheses (i.e., assumptions of normality and homogeneity of variance).

To prepare the data for hypothesis testing, each of the WFC variables and the role quality variables were centered. The purpose of centering, where each score is converted to a deviation score, is to avoid multicollinearity issues that may arise from examining interactions. This practice follows common conventions regarding any variables involved in an interaction (i.e., Aiken \& West, 1991). Centered variables 
were then used to create interaction terms for each of the proposed interactions. Thus, eight new interaction terms were created: WIF*job role quality, FIW*job role quality, WIF*spousal role quality, FIW*spousal role quality, WIF*child-care role quality, $\mathrm{FIW}^{*}$ child-care role quality, WIF* parent-care role quality and $\mathrm{FIW}^{*}$ parent-care role quality.

To test the hypotheses, hierarchical multiple regression analyses were conducted to test both main and interaction effects of WFC and the types of role quality on well-being outcomes. See Table 2 for a complete description of each regression model, including predictors, outcomes, and the hypotheses that were tested. Hypothesis 1 was tested by default in each of the 24 regression models by examining the direct impact of WIF and FIW on each of the three well-being outcomes, general health, depression, and life satisfaction. Each subsequent hypothesis was tested by six separate regressions. This technique was necessary to examine the individual effects of each direction of WFC (WIF and FIW) on the three well-being indications.

Hypothesis 2 proposed that job role quality moderated the effect of both directions of WFC on all three well-being outcomes. To test this, three regression analyses were conducted to examine the effects of WIF, job role quality, and the interaction on each of the three well-being indicators separately (See Table 2, regression models 1, 3, and 5). Then three more regression analyses were conducted to examine the effect of FIW, job role quality, and the interaction on each of the three well-being indicators (See Table 2, regression models 2, 4, and 6). 
Hypothesis 3 proposed that spousal role quality moderated the effect of both directions of WFC on all three well-being outcomes. To test this, three regression analyses were conducted to examine the effects of WIF, spousal role quality, and the interaction on each of the three well-being indicators separately (See Table 2, regression models 7,9 , and 11). Then three more regression analyses were conducted to examine the effect of FIW, spousal role quality, and the interaction on each of the three well-being indicators (See Table 2, regression models 8, 10, and 12).

Hypothesis 4 proposed that child-care role quality moderated the effect of both directions of WFC on all three well-being outcomes. To test this, three regression analyses were conducted to examine the effects of WIF, child-care role quality, and the interaction on each of the three well-being indicators separately (See Table 2, regression models 13,15 , and 17). Then three more regression analyses were conducted to examine the effect of FIW, child-care role quality, and the interaction on each of the three well-being indicators (See Table 2, regression models 14, 16, and $18)$.

Lastly, Hypothesis 5 proposed that parent-care role quality moderated the effect of both directions of WFC on all three well-being outcomes. To test this, three regression analyses were conducted to examine the effects of WIF, parent-care role quality, and the interaction on each of the three well-being indicators separately (See Table 2, regression models 19, 21, and 23). Then three more regression analyses were conducted to examine the effect of FIW, parent-care role quality, and the interaction on each of the three well-being indicators (See Table 2, regression models 20, 22, and 
24). Thus, since Hypothesis 1 was examined in each regression analysis, and the subsequent four hypotheses required six regression analyses each to fully examine the individual effects, a total of 24 regression analyses were conducted to test all of the hypotheses.

The first step of each regression analysis included the two control variables, education at Time 1 and perceived income adequacy at Time 1 . The second step of each regression then tested the simple main effect of the WFC variables at Time 1 and thesimple main effect of the role quality variable at Time 1 . The third and final step of each regression tested the interaction of the two variables, created from the centered, Time 1 variables, on the well-being outcome (as measured at Time 2). This format was used for each of the 24 regression analyses used to test each combination of the two types of WFC, the four moderator variables, and the three well-being outcomes.

Statistical significance was assessed by the regression coefficients for each of the main effects and the interaction term at the $p<.05$ level. Additionally, the change in $\mathrm{R}^{2}$ in the third and final step was assessed to determine if the interaction term explained a significant amount of variance above and beyond the control variables and the main effects. Significant interaction terms were followed by graphs used to better understand the interaction. See Table 2 for a representation of each regression analysis, the terms included in each step, the dependent variable measured, and which hypothesis was tested by that regression. 
Results

\section{Hypothesis 1}

Intercorrelations of the variables, their means, and standard deviations are shown in Table 3. See Table 2 for a description of each of the regression models that were conducted, along with indicators of which terms were significant. See Table 4 for a description of which hypotheses were supported in each set of analyses. Hypothesis 1 proposed that both directions of WFC would have a significant and detrimental impact on all three well-being outcomes over time. Each of the 24 regression analyses conducted tested this hypothesis in the second step. Thus, this information is included in Tables 5 through 12.

H1a: Overall health. Four regression analyses examined the relationship between the demand of WIF and the outcome of overall health. Results of these analyses showed that, when controlling for education level, perceived income adequacy, and each of the four types of role quality respectively, there was no evidence to support the hypothesis that WIF has a negative impact on overall health, $p$ $>.05$, contrary to prior research. Thus, there was no support for H1a in the WIF direction.

An additional four regression analyses examined the relationship between the demand of FIW and the outcome of overall health. Results showed that when controlling for education level, perceived income adequacy, and each of the four types of role quality separately, there was no evidence to support the hypothesis that FIW 
has a negative impact on overall health, $p>.05$. Thus, there was no support for H1a in the FIW direction.

H1b: Depression. Four regression analyses examined the relationship between the demand of WIF and the outcome of depression. Giving support to H1b, results showed that WIF had a significant and positive relationship with symptoms of depression, even when controlling for job role quality $(\beta=.176, t=2.626, p<.01)$, spousal role quality $(\beta=.242, t=3.693, p<.001)$, child-care role quality $(\beta=.273$, $t=3.565, p<.001)$, and parent-care role quality $(\beta=.244, t=3.408, p<.01)$, as well as the two control variables, education and perceived income adequacy.

FIW also had a significant and positive relationship with symptoms of depression when controlling for job role quality $(\beta=.182, t=2.803, p<.01)$, spousal role quality $(\beta=.178, t=2.607, p<.05)$, child-care role quality $(\beta=.209, t=3.133, p<.01)$ and parent-care role quality $(\beta=.212, t=2.933, p<.01)$, as well as the two control variables, education and perceived income adequacy. Thus, Hypothesis H1b was fully supported.

H1c: Life satisfaction. Four regression analyses examined the relationship between the demand of WIF and well-being outcome of life satisfaction. None of these were statistically significant, showing no support for H1c in the WIF direction.

Four additional regression analyses examined the relationship between the demand of FIW and the outcome of life-satisfaction. Similar to results regarding WIF and life satisfaction, there was no statistical support for $\mathrm{H} 1 \mathrm{C}$ in the FIW direction. Thus, there was no support overall for H1c. 


\section{Hypothesis 2}

Hypothesis 2 proposed that the resource of job role quality could act as a buffer between the demands of WFC, as measured by WIF and FIW, and the outcome of well-being, as measured by overall health, depression, and life satisfaction. The six regression analyses that examined this showed no statistical support for this hypothesis. See Tables 5 and 6 for a summary of results.

\section{Hypothesis 3}

Hypothesis 3 a proposed that the resource of spousal role quality would act as a buffer on the relationship between both directions of WFC and overall health. See Tables 7 and 8 for a summary of results. The results from two regression analyses showed no support for this hypothesis. Hypothesis $3 \mathrm{~b}$ proposed that spousal role quality would act as a buffer on the relationship between both directions of WFC and depression symptoms. This interaction was not statistically significant, giving no support to Hypothesis $3 \mathrm{~b}$. Hypothesis $3 \mathrm{c}$ proposed that spousal role quality would act as a buffer on the relationship between both directions of WFC and life satisfaction. Results showed partial support for this hypothesis. The interaction between WIF and spousal role quality was a significant predictor of life satisfaction, $\beta=.080, t=2.063, p$

$<.05$. The change in $\mathrm{R}^{2}$ for the interaction term was significant, $\Delta \mathrm{R}^{2}=.017, p<.05$, indicating that the interaction between WIF and spousal role quality explained about $2 \%$ of the incremental variance in life satisfaction, more than the main effects alone.

The complete model, including the interaction term, WIF, spousal role quality, and the control variables, explained about $10 \%$ of the variance in life satisfaction, $\mathrm{R}^{2}=.105, p$ 
$<.05$. However, there was no evidence that the interaction between spousal role quality and FIW was a significant predictor of life satisfaction. Thus, Hypothesis 3c was partially supported.

To better understand the subtleties of this relationship, the significant interaction was graphed using regression coefficients from step three of the regression analyses (see Figure 2). From this graph it is apparent that individuals with high spousal role quality tend to have overall better life satisfaction that those with low spousal role quality. For individuals with low WIF, this difference is a small one. However, for individuals with high WIF, having a low spousal role quality leads to drastically lowered levels of life satisfaction, compared to those with high spousal role quality.

\section{Hypothesis 4}

See Tables 9 and 10 for a summary of results. Hypothesis 4 a proposed that child-care role quality could buffer the relationship between both directions of WFC and the outcome of overall health. No statistical support was found to uphold this hypothesis. Hypothesis $4 \mathrm{~b}$ proposed that child-care role quality could potentially buffer the relationship between both directions of WFC and the outcome of depression. Again, there was no evidence that this relationship existed. Hypothesis $4 \mathrm{c}$ proposed that child-care role quality would buffer the relationship between both directions of WFC and the outcome of life satisfaction. Evidence from two regression analyses showed partial support for this hypothesis. When controlling for education, perceived income adequacy, child-care role quality, and WIF, the interaction between 
child-care role quality and WIF was statistically significant, $(\beta=.179, t=2.809, p<.01)$. The change in $\mathrm{R}^{2}$ was statistically significant, $\Delta \mathrm{R}^{2}=.032, p<.01$, indicating that the addition of the interaction between WIF and child-care role quality explained about $3 \%$ of the incremental variance of life satisfaction, above and beyond the variance explained by the controls and the main effects. The full model that included the interaction term along with the control variables and the main effects of WIF and child-care role quality explained about $10 \%$ of the total variance in life satisfaction, $\mathrm{R}^{2}$ $=.104, p<.01$. There was no support that the interaction between FIW and child-care role quality was a significant predictor of life satisfaction. Thus, Hypothesis $4 \mathrm{c}$ was partially supported.

To better comprehend this relationship, the significant interaction was again graphed using regression coefficients from step three of the regression equation (see Figure 3). From this graph, it is apparent that the relationship between WIF and life satisfaction varies greatly as a function of child-care role quality. For individuals with low levels of WIF, life satisfaction is relatively similar, regardless of child-care role quality level. However, at high levels of WIF, individuals with low child-care role quality suffer losses in life satisfaction, while individuals with high child-care role quality actually have rising life satisfaction levels.

\section{Hypothesis 5}

Hypothesis 5 proposed that the resource of parent-care role quality might act as a buffer of the relationship between the demands of WFC, as measured by WIF and FIW, and the outcome of well-being, as measured by overall health, depression, and 
life-satisfaction. No evidence was found to support this hypothesis. See Tables 11 and 12 for a summary of results.

\section{Post-Hoc Analyses}

Simple main effects of role quality on well-being. To better comprehend the intricacies of these relationships, I chose to also examine the main effects of role quality on each of the well-being outcomes, despite the fact that they did not pertain to the hypotheses directly. This information is included in Tables 5 through 12 .

Overall health. Results showed that when controlling for education, perceived income adequacy, and WIF, child care role quality had a significant positive effect on overall health, $\beta=.169, t=2.573, p<.05$. Similarly, child-care role quality was also a significant predictor of overall health when controlling for FIW, perceived income adequacy, and education, $\beta=.182, t=2.787, p<.01$. There were no simple main effects of job role quality, spousal role quality, or parent-care role quality on overall health.

Depression. Analysis of simple main effects in the regression model showed that three of the four types of role quality also had a significant impact on depression symptoms when controlling for education, perceived income adequacy, and WIF. The three types of role quality with significant and negative relationships to depression included job role quality $(\beta=-.288, t=-4.220, p<.001)$, spousal role quality $(\beta=-.222$, $t=-3.396, p<.01)$, and child-care role quality $(\beta=-.181, t=-2.709, p<.01)$.

Similarly, three of the four types of role quality also predicted depression, when controlling for education, perceived income adequacy, and FIW. Again, the three types of role quality that predicted depression included job role quality $(\beta=-.307$, 
$t=-4.645, p<.001)$, spousal role quality $(\beta=-.205, t=-2.994, p<.01)$, and child-care role quality $(\beta=-.206, t=-3.061, p<.001)$. Parent-care role quality did not predict depression when controlling for either WIF or FIW.

Life satisfaction. Results showed that, when controlling for education, perceived income adequacy, and WIF, all four types of role quality were significant predictors of life satisfaction. Job role quality $(\beta=.139, t=1.996, p<.05)$, spousal role quality $(\beta=.234, t=3.634, p<.001)$, child-care role quality $(\beta=.201, t=3.094, p<.01)$, and parent-care role quality $(\beta=.152, t=2.159, p<.05)$ all had a significant and positive impact on life satisfaction.

Similarly, when controlling for education, perceived income adequacy, and FIW, three of the four types of role quality were significant predictors of life satisfaction. These three included spousal role quality $(\beta=.233, t=3.537, p<.001)$, child-care role quality $(\beta=.214, t=3.261, p<.01)$, and parent-care role quality $(\beta=.154$, $t=2.190, \mathrm{p}<.05)$.

Using a Bonferroni correction. Due to the need to examine each predictor individually, 24 regression tests were used. Using multiple comparisons can increase the familywise error rate, thus increasing the probability of finding significant results when none in truth exist (Type I errors; Shaffer, 1995). Because so many regression analyses were conducted, the possibility exists that some of the significant findings are artifacts of familywise error rate. While I could have tested my hypotheses using a more parsimonious model to avoid this risk, it is my belief that due to the fact that this 
is the first study to examine the moderator of role quality on the WFC-well-being relationship, examining the individual effects of the different types of role quality is critical to our understanding of this relationship. Thus, due to the initial nature of the research, I believe sacrificing the familywise error rate is worth the increased depth of understanding of individual predictors. However, the increased risk of Type I errors should not be ignored, even in preliminary research. A frequently used solution to this problem is known as the Bonferroni correction (Holm, 1979). Due to the introductory nature of my research, I chose not to utilize this correction for hypothesis testing, deeming it too conservative for research that was the initial foray into the relationships. However, for the sake of thoroughness, I chose to conduct post-hoc analyses using the Bonferroni correction on my data. This technique divides the desired significance level, in this case .05 , by the number of tests conducted, in this case 24. Thus, the $p$ value needed to achieve significance using the Bonferroni correction for this data is $p<.002$. With this restriction, Hypothesis $1 \mathrm{~b}$ was still partially supported in the WIF direction of WFC when controlling for perceived income adequacy, education, and spousal role quality $(\beta=.242, t=3.693, p<.002)$ and child-care role quality $(\beta=.273, t=3.565, p<.002)$. No other regression models remained significant when utilizing the Bonferroni correction.

\section{Additional Analyses}

Controlling for Time 1 outcomes. Ideally, the hypothesized relationships would remain statistically significant when controlling for the pertinent outcome from Time 1. If effects remained significant, it would indicate that WFC predicted change 
in well-being outcomes over time. While this does not definitively prove that WFC causes changes in well-being, it is an important component to the ability to infer causality. To ascertain if this occurred, the analyses were conducted a second time with the addition of the Time 1 outcome as a control variable. Results of these additional analyses showed that three of the ten significant regression analyses remained significant, and one additional interaction became significant (See Table 4 for a description of hypotheses were supported in each analysis).

Previous analyses that did not control for Time 1 outcomes fully supported H1b, which proposed that both WIF and FIW had a negative impact on depression. This hypothesis was supported in all eight of the eight applicable regression analyses that examined the relationship. When controlling for Time 1 outcomes, this hypothesis was still partially supported, but only two of the eight regression analyses remained significant. WIF had a significant negative impact on depression when controlling for spousal role quality $(\beta=.141, t=2.215, p<.05)$ and parent care role quality ( $\beta=.146, t=2.197, p<.05)$, as well as education, perceived income adequacy, and depression at Time 1. Regressions that examined the WIF-depression relationship while controlling for job role quality and child care role quality were not significant when depression at Time 1 was used as a control variable. There was no evidence supporting the hypothesized relationship between FIW and depression when controlling for depression at Time 1 .

The two significant interactions remained significant when controlling for Time 1 outcomes. Results showed partial support for H3c. The interaction between 
WIF and spousal role quality significantly predicted life satisfaction at Time 2 when controlling for education, perceived income adequacy, life satisfaction at Time 1, and the main effects of WIF and spousal role quality, $\beta=.128, t=2.137, p<.05$. Similarly, the interaction between WIF and child care role quality significantly predicted life satisfaction at Time 2 when controlling for education, perceived income adequacy, life satisfaction at Time 1 , and the main effects of WIF and child care role quality, $\beta=.133$, $t=2.194, p<.05$.

Additionally, there was a significant interaction between FIW and job role quality on life satisfaction at Time 2 when controlling for education, perceived income adequacy, and life satisfaction from Time $1, \beta=-.142, t=-2.33, p<.05$. This interaction in the previous analyses was nearing significance, but did not reach it, $\beta=-.122, t=-$ $1.924, p=.056$. To better comprehend this relationship, the interaction was again graphed using regression coefficients from step three of the regression equation (see Figure 4). Unlike the previous two interactions, this significant moderator appears as a disordinal interaction. For individuals with high job role quality (defined as one standard deviation above the mean of job role quality), life satisfaction is highest when FIW is low, and lowest when FIW is high. This is consistent with previous research and the theoretical background. However, for individuals with low job role quality (defined as one standard deviation below the mean of job role quality), life satisfaction is lowest when FIW is low and highest when FIW is high. It appears that high job role quality does not act as a buffer to the pressures of FIW. Thus, although the interaction 
term for this regression was significant, it was in the opposite direction as predicted, and Hypothesis 2c was not supported.

Thus, WIF did predict some of the change in depression over time, and that it was in the expected direction. Additionally, when controlling for life satisfaction at Time 1, spousal and child-care role quality remained significant buffers of the impact of WIF on life satisfaction at Time 2. The third significant interaction, however, was counter to the hypotheses, showing that individuals with high and low job role quality had nearly opposite patterns of life satisfaction as a result of FIW.

Examining role rewards. As mentioned previously, considering role quality as a resource may be a misnomer for some. Although the majority of individuals tend to experience their roles positively, and thus have positive role quality, there are some individuals who have negative role quality, where their role concerns outweigh the rewards they receive from this role. In these instances, examining one of the subscales of role quality, role rewards, and leaving out the sub-scale of role concerns, may be more appropriate. Thus, to determine if there were any major differences between the effects of role quality and role rewards on health and well-being, the analyses were conducted again using each of the role rewards subscales in place of the role quality. (See Table 4 for a description of hypotheses supported in each of the analyses.)

Results of these analyses were straightforward and followed a similar pattern to the original analyses. WIF significantly and positively predicted depression when controlling for job role rewards $(\beta=.206, t=3.112, p<.01)$, spousal role rewards $(\beta=.245, t=3.670, p<.001)$, child-care role rewards $(\beta=.234, t=3.472, p<.01)$, and 
parent-care role rewards $(\beta=.240, t=3.499, p<.01)$, along with the control variables of perceived income adequacy and education. Similarly, FIW significantly and positively predicted depression when controlling for job role rewards $(\beta=.213$, $t=3.277, p<.01)$, spousal role rewards $(\beta=.191, t=2.771, p<.01)$, child-care role rewards $(\beta=.214, t=3.168, p<.01)$, and parent-care role rewards $(\beta=.214, t=3.067, p$ $<.01)$ in addition to the control variables of perceived income adequacy and education. Thus, H1b was again fully supported. There was no other support for any of the other hypotheses. The similar pattern but smaller scope of significant results is likely due to the fact that the role rewards scale has less variability than the full role quality scale. The similar pattern of results lends credence to the idea that the full concept of role quality can indeed be considered a resource in the framework of the JD-R model. 
Discussion

In an attempt to understand how we can protect and enhance health even in situations where WFC is high, I investigated role quality as a moderator of the WFCwell-being relationship in a sample of working, married, sandwiched individuals. Results showed that both WIF and FIW have a significant and positive relationship with depressive symptoms over time, supporting previous research (e.g., Frone et al., 1997; Grzywacz \& Bass, 2003; Hammer et al., 2005). These results reinforce the idea that both directions of WFC are detrimental to the health and well-being of individuals and gave full support to Hypothesis $1 b$.

Furthermore, results partially supported Hypotheses $3 \mathrm{c}$ and $4 \mathrm{c}$, which proposed that the resources of spousal role quality and child-care role quality have the ability to protect against the negative impact of the demand of WIF on the well-being outcome of life satisfaction. It appears that individuals who have high role resources associated with their home life are somewhat protected against the negative effects of this demand on their well-being. Additional analyses showed that these moderators significantly predicted change in life satisfaction over time. This is an especially interesting finding, given that the majority of research on WFC and well-being has been cross-sectional rather than longitudinal. Knowing that the interaction of spousal and child-care role quality with WIF can influence later levels of life satisfaction is a step toward understanding how we can improve and protect well-being proactively.

Further examination of results showed that each of the four types of role quality examined here plays an important role in maintaining employee well-being. 
Employees with positive role quality in each of these areas are more likely to be healthy, satisfied with their lives, and free from depressive symptoms. These findings are consistent with previous research that has linked the various types of role quality to multiple well-being outcomes (e.g., Baruch \& Barnett, 1986; Barnett \& Brennan, 1994; Barnett, Kibria, Baruch, \& Pleck, 1991; Cleary \& Mechanic, 1983; Gomez, 2006; Martire et al., 1997; Neal \& Hammer, 2007; Plaisier et al., 2008; Stephens et al., 1997; Stephens \& Townsend, 1997; Windle \& Dumenci, 1997).

Additional analyses indicate that WIF does account for a small amount of change in well-being over time. This finding enhances the theory that WIF can impact well-being rather than the reverse, although cyclical trends may still be possible. $\mathrm{T}$ analyses on role rewards showed that role quality and role rewards produced similar changes in well-being over time, affirming the interpretation of role quality as a resource for the majority of the sample.

Contrary to previous research, no support was found for Hypotheses 1a and 1c, which specified that WFC would have a negative impact on general health and life satisfaction over time. Although it is possible that these nonsignificant findings are due to a lack of true relationship between WFC and these aspects of well-being, it is not probable. Previous research and theory in the area have often shown that WFC is a detriment to health and well-being. Thus, it is probable that these relationships do exist, but were not statistically significant due to a number of reasons, as detailed below. 
As was evidenced by the significant interactions, the impact of WFC is not the same across all groups. For example, evidence from this study found that individuals with high spousal role quality did not suffer from the negative impacts of WIF, while individuals with low spousal role quality had a sharp decrease in their life satisfaction when their WIF increased. The overall impact of WIF on life satisfaction was not significant, but would almost certainly be significant for those individuals with low spousal role quality. Thus, it stands to reason that other moderators might be in play in this relationship. This is especially pertinent in a sample as diverse as the current one, where individuals come from many types of occupations, backgrounds, family structures, and ages. It is entirely possible that for some subgroups of the working, married, sandwiched generation, WFC has a significant impact on overall health and life satisfaction. However, this study did not examine many of the potential moderators that could make these relationships clear, and thus, that remains a direction for future research.

Previous research has shown that a particular stressor-strain relationship can explain a maximum of about $10 \%$ of the variance in the outcome, due to the fact that there are many contributing factors to well-being (Semmer et al., 1996). Thus, a lack of significant main effects between WFC and two of the well-being outcomes may be due to the small amount of variance that any given stressor can explain in a strain outcome. This is not to say that WFC is not a predictor of well-being, but rather, to illustrate the difficulty of attaining statistically significant support for this in a given study. 
Additionally, some of the measures are less than ideal. For instance, the measure of health that was used is a simple one-item measure. Having a more thorough measure to examine this important indicator would perhaps uncover subtleties in the relationship that this study cannot assess. Thus, the lack of significant findings on the outcome of general health may be due to the imprecision of the measurement rather than to a lack of true relationships. Further research should be conducted utilizing a more comprehensive, multi-item measure of health to determine if this relationship does exist as hypothesized. It would be especially advantageous to include both subjective and objective measures of health and well-being, including psychobiological indicators, as these are relatively understudied and of great interest to both researchers and practitioners.

The majority of the interactions proposed in this paper were not found to be statistically significant. Similar to the limitations regarding the simple main effects, it may well be that these relationships do exist, but that the results lacked support due to several limitations, as described below. The limitations described previously also can have impact on interaction effects, and thus, should be taken into consideration. Beyond those limitations, one limitation is the size of the sample. It is known that interaction effects often require a large sample in order to be identified, and the sample size in this study is relatively small. The lack of support for many of the interactions may be due to the small sample size. Future research should examine these moderators on a larger sample of married, working, sandwiched individuals to 
ascertain if these types of role quality do in truth act as buffers on the relationship between WFC and well-being.

An alternative explanation for the relatively small number of significant interaction effects may be that mediation is occurring rather than moderation. It is possible that the effects of WFC on health and well-being is mediated by the four types of role quality. In other words, it may be that when WFC is high, role quality becomes more stressful and less rewarding, which leads to poorer health. The variables of WFC, role quality, and well-being are significantly correlated, making this a possibility. While I have made the plausible argument for moderation in this paper, it may also be the case that mediation is occurring. Future research should examine this as a pathway to improved health and well-being.

One of the interactions between WFC and role quality was significant, but not in the hypothesized direction. This was Hypothesis $2 \mathrm{c}$, which proposed that job role quality would buffer the relationship between WFC and life satisfaction. Results showed a disordinal interaction for this relationship, such that individuals who had high job role quality experienced a negative effect of FIW on life satisfaction, while individuals with low job role quality experienced a positive effect of FIW on life satisfaction.

While on the surface this interaction may seem illogical, it may be that this disordinal relationship stems from the concept of role salience. Role salience, also known as role centrality or role commitment, is the degree to which the particular role is an important part of the individual's identity and a way to define the self (Gurin, 
Veroff, \& Feld, 1960; Martire, Stephens, \& Townsend, 2000; Stryker \& Serpe, 1994). Integrating this concept into the current framework may shed some light on this finding. One explanation for this interaction may be that individuals with low job role quality also find the job role less important to their sense of self, when compared to their family roles. Thus, to these individuals, a high level of FIW may mean that there is a great deal of activity going on in their family role. Since their family roles are the roles with which they identify the most strongly, that may translate to a high level of life satisfaction, regardless of what is occurring on the job. In contrast, individuals with a high job role quality most likely incorporate this role strongly into their sense of self. Thus, for these individuals, an increase in FIW is a distraction from their role as a worker, and therefore leads to a reduction in their levels of life satisfaction. Thus, it is possible that while examining role quality is a step beyond examining mere role occupancy, a further step must be taken to also examine role saliency to fully understand how an individual's role affects their well-being. Future research should also include measures of role salience to determine if this is the reason for this relationship, and to determine if this has differential effects on the WFC-well-being relationship.

These results help to clarify several ways in which well-being can be preserved and reinforced. Illuminating the subtleties of the WFC-well-being relationship is an important task, especially for individuals suffering from high WFC. In this day and age, both family and work demands seem to be steadily increasing, as a result of globalized competition in the workplace, delayed childbirth, aging of the Baby 
Boomers, an increasing number of non-traditional family structures, and many other factors. It is important that we understand how to counter these growing demands, and what resources may buffer the effects of such stress and strain on the employees' health. Knowing the details of these relationships is critical if we want to preserve the health of employees and lower the costs associated with worker stress. These pursuits benefit individual employees, work teams, organizations, and society as a whole. The present study adds important knowledge to this slowly growing research program and paves the way for future research to add more knowledge.

\section{Practical Implications}

One main finding of this study was that both directions of WFC were predictive of depression. As mentioned previously, depression is one of the ten most common and most expensive health problems for workers and their organizations today and can cost organizations more than $\$ 4,000$ per employee per year in productivity losses due to absenteeism alone (Goetzel et al., 2004). It is clear from the results of the present study that in order to avoid high costs such as these, WIF and FIW should be reduced for employees. Organizations that can reduce the WFC that their employees experience should see a subsequent decrease in the amount of depression afflicting these employees and enjoy a large cost savings. Practically, how can organizations lower the WFC of their employees? Previous research has shown that WFC is linked to many variables that are within the control of the organization. While not all of these variables are causally linked to WFC, all are correlated with WFC, and thus have a high probability of reducing WFC. One area of research related 
to WFC is that of the nature of work, in other words, the timing, length, or place of work. Previous research has linked many variables of this nature to reduced WFC, including reducing the number of hours worked (e.g., Grzywacz \& Marks, 2000; Keith \& Schafer, 1980; Major, Klein, \& Ehrhart, 2002), reducing the number of hours the employee must commute (Bohen \& Viveros-Long, 1981), and reducing unpredictability in work, such as shift-work demands, weekend work, or rotating shifts (e.g., Fox \& Dwyer, 1999; Pleck, Staines, \& Lang, 1980).

Another way for organizations to reduce the WFC that their workers experience is to create a supportive culture. Previous research has shown that several organizational changes can decrease WFC, including creating a family supportive organizational culture (Allen, 2001; Lapierre et al., 2008), having supervisors that are supportive of family life (Allen, 2001; Hammer, Kossek, Yragui, Bodner, \& Hanson, 2009), allowing employees to set their own goals (Adams \& Jex, 1999), removing a profit-driven focus (Wallace, 1997), having work-family benefits available (Thompson, Beauvais, \& Lyness, 1999), and having a mentor (Nielson, Carlson, \& Lankau, 2001). Thus, it appears that organizations have control over many variables that could reduce the WFC their employees experience, and in this manner, increase the health of employees and decrease the costly effects of depression on the organization.

As hypothesized, some of the types of role quality were able to buffer the effects of the negative impact of WIF on life satisfaction over time. Thus, it appears that it is in the best interests of the organization to increase perceptions of role quality 
among their workers in order to protect their health and benefit the organization. Practically, how can this be done? One excellent example is provided by the research of Pedersen, Minnotte, Kiger, and Mannon (2009) on positive family-to-work spillover and family role quality. Pedersen and colleagues examined dual-earner couples with children, a group with many similarities to the sandwiched generation. Using role theory, the authors hypothesized that participation in multiple roles could be rewarding, rather than stressful, if there were resources available to meet family needs. Thus, the authors sought to predict both positive spillover from family to work, as well as the perceived quality of the family role, from a variety of workplace predictors, such as average number of hours worked, presence of flex time, presence of family leave, on-site childcare, and more. The participants were 104 married couples with children who both worked outside the home. One of the outcome variables of the study, family role quality, conceptually encompasses both of the relevant types of role quality (spousal and child-care) for the present study. Their results showed that family role quality was significantly and positively related to the presence of a socially supportive organizational culture, job pressure, and flexible time use. It was also significantly and negatively related to average number of hours worked (Pedersen et al., 2009). Thus, it appears that organizations can improve family role quality by improving the social support in their organizational culture, offering flex time plans, or offering reduced hours or reduced pressure jobs to workers. Extrapolation of these results to the present study presents the idea that these solutions can improve both spousal and child-care role quality, and thus improve the employees' 
life satisfaction as well, even in the face of high WIF. Although the Pedersen et al. study was relatively small and cross-sectional in nature, it is an important first step to understanding how workplaces can have an impact on role quality perceptions that are outside the work scope. Because an employee's home life and work life are so intertwined, it is important to seek out ways to improve the home life, not just the work life. Research such as the current study and the Pedersen et al. (2009) study indicate that organizations that can alter the work situation to improve employees' perceptions of both their work and home situations will see benefits in the workplace as a result of happier, healthier, less distracted employees. The cyclical nature of this relationship is one that is often neglected, and needs to be taken into account when designing interventions to improve the health of employees and, by doing so, improve the organization.

In sum, organizations will have healthier, happier employees if they can increase role quality and lower WFC. Previous research has shown that there are varying options that employers can take to increase role quality and/or lower WFC, including increasing social support, offering flex time plans, reduced hours, offering reduced pressure jobs, reducing the unpredictability of work times, having workers participate in goal setting, provide mentors, and more (e.g., Adams \& Jex, 1999; Fox \& Dwyer, 1999; Nielson et al., 2001; Pedersen et al., 2009). Although some of these changes are a large or expensive undertaking, such as changing the culture or offering more benefits, others are relatively easy and cheap, such as providing a mentor or being supportive of family concerns. 
A barrier to enacting policies such as these may be the perception that offering alternative schedules such as reduced work hours may result in less work getting done, and thus be detrimental to the organization, although beneficial to the employees' family lives. However, some research has shown that this is an unfounded concern, and that workers who are allowed to work a reduced number of hours when desired have equal or greater productivity when compared to those who work full-time (Olmsted \& Smith, 1994; Warde, 2001). For example, several studies have compared female physicians who choose to work part-time and those who work full-time. Results show that physicians allowed to work part-time have higher productivity and equal or higher quality of performance than their counterparts who work full-time (Fairchild et al., 2001; Parkerton, Wagner, Smith, \& Straley, 2003; Warde, 2001). In reference to these and other similar findings, Barnett, Gareis, and Carr (2005) state:

"With higher productivity, similar patient satisfaction and ambulatory costs, as well as equal to higher quality performance, employers would be wise to encourage programs for reduced hours physicians, improve conditions, and permit flexible work patterns for physicians who desire part- time or reduced hours employment."

Taken together, the present research and these previous findings show that it is crucial for organizations to protect their bottom line and the health of employees by reducing WFC and improving role quality. The previous findings presented here show that these worthwhile goals can be reached in a myriad of ways, and that almost any organization can make some changes to decrease WFC and increase perceptions of role quality. 
Contributions to Research

Research on WFC and its impact on health and well-being is by no means comprehensive at this point. Findings from this study bolster previous results to indicate that both WIF and FIW have significant and positive impacts on depression over time. These findings add to the relatively small body of longitudinal research on WFC and depression. Without experimental methods, it is impossible to say that a causal link exists between these two, but longitudinal research is the first step in establishing directionality of effects and improving our knowledge of these phenomena. It logically follows that this additional support for the relationship between WFC and depression over time is an important step towards a more complete understanding of the concept of WFC and its impact on well-being.

In addition to this, WFC as a topic is relatively lacking in the empirical study of moderation and interaction effects. The majority of research in this area has been focused on direct relationships and main effects of the WFC-outcome relationship (Mauno et al., 2006). By examining role quality as a moderator of the WFC-wellbeing relationship, this study adds to the relatively unexamined area of indirect relationships surrounding WFC. As discussed previously, knowledge of moderators is important to practically determine alternative approaches to maintaining employee health and well-being. While only two of the proposed moderators were statistically significant in the hypothesized direction, these pieces of information add to the overall understanding about the myriad potential moderators of the WFC-well-being relationship. Additionally, the fact that the interaction between these types of role 
quality and WIF is predictive of change over time is an exciting new piece of knowledge that can help clarify causality. The complete picture of what can indirectly affect this relationship will emerge slowly, through many studies similar to the current study. Hence, every piece of knowledge regarding what can influence this relationship is important to making the overall picture more clear and paving the way for effective interventions, as well as future studies.

Considerable research on the JD-R model has been conducted, but the idea of resources buffering the relationship between demands and outcomes is relatively new, with few studies examining this theory. This study adds to the growing body of research that supports the theory that several resources can buffer the impact of demands on outcomes. To my knowledge, only two existing studies examine the moderating effects of resources on the relationship between WFC and well-being (Bakker et al., 2005; Mauno et al., 2006). Their results show support for the idea that resources can moderate the relationship between WFC and well-being, and both call for further examination. The present study answers this call and adds to the body of knowledge by examining the effects of new moderators on the WFC-well-being relationship. Results from the present study show that different levels of spousal role quality and child-care role quality result in drastically differential relationships between WIF and life satisfaction. This is, to my knowledge, an entirely new finding in the area.

Previous research on the JD-R model has primarily involved the workplace. The current study expands the model to examine antecedents, outcomes, and 
moderators that are not strictly limited to the workplace, but also include the individuals' experiences outside the work. This is a unique approach, to my knowledge. The fact that significant results were found in areas outside of the work arena (spousal and child-care role quality) indicates that this new method of utilizing the JD-R model may be worth further examination.

The moderators chosen for this study are all relatively understudied topics in their own right. Examining these variables as potential moderators of the WFC-wellbeing relationship is an entirely new field of study, to my knowledge. The majority of research on role quality has examined them as antecedents to several outcomes, but they are rarely conceptualized as moderators. Thus, the present study not only furthers the understudied body of knowledge of the effects of WFC, but also those of role quality. Results from this study have shown that some types of role quality are indeed moderators of the relationship between one direction of WFC and one well-being outcome.

Both of the previous studies done on resource moderation of the WFC-wellbeing relationship were cross-sectional in design. The present study utilized a longitudinal design, thereby adding even more to the small but growing body of literature by examining the relationship over time. The longitudinal design utilized in the current study enables interpretation of the directionality of relationships, which has not been examined in area of study to date. The possibility of reverse causality remains a valid one (i.e., poor well-being causes increased levels of WFC). However, due to the longitudinal nature of the data, and the fact that results showed that WFC is 
predictive of change in some well-being outcomes over time, it is likely that the direction of the causality is as theorized here, where WFC predicts health and wellbeing. This is not to say that feedback loops and reciprocal relationships do not exist; rather, previous research has shown that this is probable (i.e., van der Heijden, Demerouti, Bakker, \& Hasselhorn, 2008). It is likely that high levels of WFC cause poor health, which in turn then cause more WFC due to a lack of resources. According to Hobfoll's (1989) conservation of resources theory, this vicious cycle is called a 'loss spiral', where a depletion of resources leads to further loss of resources. Future research should continue to include designs where causality can be determined in the WFC-well-being relationship, especially since the moderating effect of role quality found in this study may be a way in which resources can be maintained and the loss spiral may be halted.

\section{Potential Limitations and Areas for Future Research}

As with any research, the current study is by no means perfect. Several of the findings were nonsignificant, or not in the hypothesized direction. Additionally, there are general limitations to the study that should be addressed in future research. Lastly, the findings from this study open up new avenues for research that are worth mentioning and pursuing.

As mentioned previously, there are several potential limitations that could affect the results. For instance, several of the measures were less than ideal, and future research should be conducted using more robust measures from a variety of sources in order to truly understand the relationship between WFC, well-being, and 
potential moderators. Additionally, the relatively small sample size may have hampered the ability to detect true interaction effects in this study. Thus, future research should examine these phenomena in a larger sample.

As discussed previously, a potential limitation of this research may be an increased familywise error rate, which increases the probability of finding significant results when none in truth exist (Shaffer, 1995). However, due to the preliminary nature of research in the area of resources moderating the WFC-well-being relationship, I believe choosing an over-conservative test can make it appear that no interactions exist when, in truth, there are interesting interactions to examine in this relationship. Once it is established that certain resources do moderate the WFC-wellbeing relationship, more conservative tests and corrections should be used. In the mean time, future research on resources that may moderate the WFC-well-being relationship should use theory to narrow hypotheses in order to reduce the number of tests.

A general limitation of the study is that all of the measures used are self-report in nature, and thus could be subject to common method bias. Self-report does appear to be the best measure of the constructs of WFC and role quality, as these constructs involve perceptions that are best described by the individual. However, future research should examine this relationship using other methods of measurement in regards to the health and well-being outcomes. As mentioned previously, measures including psychobiological indicators of health would be of particular interest, due to the relative dearth of such research in this field. 
The choice of the participants poses a potential limit to generalizability. Although married, working, sandwiched individuals are a growing demographic, it is true that the majority of individuals today do not have as many roles as sandwiched individuals do. In addition, it is possible that married, working, sandwiched individuals experience their roles differently than the general population, and thus the relationships found here require further study in different populations before they can be generalized to the population at large. However, the majority of the population holds at least one of the roles studied here, and thus, there will likely be some applicability for nearly everyone. In addition to this, study of this portion of the sandwiched generation is currently limited, and this study seeks to add to the body of knowledge about the sandwiched generation. In this sense, the characteristics of the sample are an asset as well as a limit on generalizability.

As discussed previously, one of the key contributions of the JD-R model of resource buffering is the idea that a plethora of resources can buffer the relationships between a host of demands and outcomes. When examining the relationship between WFC and well-being outcomes, there are many potential resources that may moderate this relationship and indirectly protect well-being. Existing research, including the present study, covers only a small portion of these possibilities. Future research should continue to examine this relationship through the lens of the JD-R model of resource buffering, focusing on new potential moderators of the relationship. It is imperative that we learn more about the moderators of the relationship between WFC 
and well-being in order to best protect the health of employees, especially those in jobs where WFC is high and cannot feasibly be lowered.

The present study took the unique approach of applying the JD-R model to factors outside the scope of work. While not all hypotheses were supported using this model, the presence of some significant results indicates the need for further examination of the possibility that this model has applications to concepts not encompassed in the work role. Future research should continue down this avenue of inquiry, as it is especially relevant to constructs where work and outside roles overlap, such as WFC and its counterpart of positive spillover.

As the disordinal interaction shows, there may be other variables that are impacting the relationships examined here. Future research should attempt to uncover alternate potential moderators of the WFC-well-being relationship in order to gain a clearer picture. In regards to role quality, it would be particularly informative to investigate role salience as an additional variable. It may be possible that both of these constructs have an influence over the relationship between WFC and well-being. Results from the present study, along with evidence from previous research, support the idea that role quality is an important factor in maintaining well-being, via both main effects and interactions. Thus, it is crucial to understand how organizations can promote positive role quality for employees. While some research has been conducted on how to elevate role quality (e.g., Pedersen et al., 2009), more research is needed to understand how best to leverage role quality as an organizational asset. 


\section{Conclusion}

This study adds to the body of work-family literature by examining an intriguing and relevant relationship, that between WFC and individual well-being over time. Results show that both directions of WFC have a detrimental impact on depression. There was also evidence that high levels of spousal role quality and childcare role quality increased life satisfaction, even in the presence of high WIF. Job, spousal, child-care, and parent-care role quality were all important predictors of wellbeing outcomes over time. The findings from this study further knowledge in this area, as well as deepen understanding of what part role quality plays in this relationship. The results of this study are applicable not only to scholars, but also to organizations and employees, who can use this knowledge to enhance well-being, even when WFC is high. 


\section{References}

Adams, G. A., \& Jex, S. M. (1999). Relationships between time management, control, work-family conflict, and strain. Journal of Occupational Health Psychology, 4, 72-77.

Aiken, L. S., \& West, S. G. (1991). Multiple regression: Testing and interpreting interactions. Newbury Park, CA: Sage.

Allen, T.D. (2001). Family-supportive work environments: The role of organization perceptions. Journal of Vocational Behavior, 58, 414-435.

Allen, T. D., Herst, D. E .L., Bruck, C. S., \& Sutton, M. (2000). Consequences associated with work-to-family conflict: A review and agenda for future research. Journal of Occupational Health Psychology, 5, 278-308.

Bakker, A. B., Demerouti, E., De Boer, E., \& Schaufeli, W. B. (2003). Job demands and job resources as predictors of absence duration and frequency. Journal of Vocational Behavior, 62, 341-356.

Bakker, A. B., Demerouti, E., \& Euwama, M. C. (2005). Job resources buffer the impact of job demands on burnout. Journal of Occupational Health Psychology, 10, 170-180.

Bakker, A. B., Hakanen, J. J., Demerouti, E., \& Xanthopoulou, D. (2007). Job resources boost work engagement, particularly when job demands are high. Journal of Educational Psychology, 99, 274-284.

Barcikowski, R. S. (1981). Statistical power with group mean as the unit of analysis. Journal of Educational Statistics, 6, 267-285. 
Barnett, R. C., \& Baruch, G. K. (1985). Women's involvement in multiple roles, role strain, and psychological distress. Journal of Personality and Social Psychology, 49, 135-145.

Barnett, R.C., \& Brennan, R.T. (1994). The relationship between job experiences and psychological distress: A structural equation approach. Journal of Organizational Behavior, 16, 259-276.

Barnett, R.C., Brennan, R.T., \& Marshall, N.L. (1994). Gender and the relationship between parent role quality and psychological distress: A study of men and women in dual-earner couples. Journal of Family Issues, 15, 229-252.

Barnett, R.C., Gareis, K.C., \& Carr, P.L. (2005). Career satisfaction and retention of a sample of women physicians who work reduced hours. Journal of Women's healthy, 14, 146-153.

Barnett, R.C, Kibria, N., Baruch, G.K., \& Pleck, J.H. (1991). Adult daughter-parent relationships and their associations with daughters' subjective well-being and psychological distress. Journal of Marriage and Family, 53, 29-42.

Barnett, R.C., \& Marshall, N.L. (1991). Men, family-role quality, job-role quality, and physical health. Health Psychology, 12, 48-55.

Barnett, R.C., Marshall, N.L., Raudenbush, S.W., \& Brennan, R.T. (1993). Gender and the relationship between job experiences and psychological distress: A study of dual-earner couples. Journal of Personality and Social Psychology, 64, 794-806. 
Barnett, R.C., Raudenbush, S.W., Brennan, R.T., Pleck, J.H., \& Marshall, N.L. (1995). Change in job and marital experiences and change in psychological distress: A longitudinal study of dual-earner couples. Journal of Personality and Social Psychology, 69, 839-850.

Barnett, R.C., Steptoe, A., \& Gareis, K.C. (2005). Marital-role quality and stressrelated psychobiological indicators. Annals of Behavioral Medicine, 30, 36-43.

Bartley, M., Popay, J., \& Plewis, I. (1992). Domestic conditions, paid employment, and women's experience of ill-health. Sociology of Health and Illness, 3, 313343.

Baruch, G.K., \& Barnett, R.C. (1983). Adult daughter's relationships with their mothers. Journal of Marriage and the Family, 45, 601-606.

Baruch, G.K., \& Barnett, R. (1986). Role quality, multiple role involvement, and psychological well-being in midlife women. Journal of Personality and Social Psychology, 51, 578-585.

Beatty, C.A. (1996). The stress of managerial and professional women: Is the price too high? Journal of Organizational Behavior, 17, 233-251.

Bohen, H.H., \& Viveros-Long, A. (1981). Balancing jobs and family life: Do flexible schedules help? Philadelphia: Temple University Press.

Buffardi, L.C., Smith, J.L., O’Brien, A.S., \& Erdwins, C.J. (1999). The impact of dependent-care responsibility and gender on work attitudes. Journal of Occupational Health Psychology, 4, 356-367. 
Byron, K. (2005). A meta-analytic review of work-family conflict and its antecedents. Journal of Vocational Behavior, 67, 169-198.

Campbell, A., Converse, P.E., \& Rodgers, W.L. (1975). The quality of American life. Ann Arbor, MI: Social Science Archive.

Carlson, D.S., \& Kacmar, K.M. (2000). Work-family conflict in the organization: Do life role values make a difference? Journal of Management, 26, 1031-1054.

Casper, L. M., \& Bianchi, S. M. (2002). Continuity and change in the American family. Thousand Oaks, CA: Sage.

Christensen, K.A., Stephens, M.A., \& Townsend, A.L. (1998). Mastery in women's multiple roles and well-being: Adult daughters providing care to impaired parents. Health and Psychology, 17, 163-171.

Cleary, P.D., \& Mechanic, D. (1983). Sex differences in psychological distress among married people. Journal of Health and Social Behavior, 24, 111-121.

Danna, K., \& Griffin, R.W. (1999). Health and well-being in the workplace: A review and synthesis of the literature. Journal of Management, 25, 357-384.

Demerouti, E., Bakker, A.B., Nachreiner, F., \& Schaufeli, W.B. (2001). The job demands-resources model of burnout. Journal of Applied Psychology, 86, 499512.

Dutton, D.B., \& Levine, S. (1989). Overview, methodological critique, and reformulation. In J.P. Bunker, D.S. Gomby, \& B.H. Kehrer (Eds.), Pathways to health (pp. 29-69). Menlo Park, CA: The Henry J. Kaiser Family Foundation. 
Eby, L.T., Casper, W.J., Lockwood, A., Bordeaux, C., \& Brinley, A. (2005). Work and family research in IO/OB: Content analysis and review of the literature (1980-2002). Journal of Vocational Behavior, 66, 124-197.

Elkin, A.J., \& Rosch, P.J. (1990). Promoting mental health at the workplace: The prevention side of stress management. Occupational Medicine: State of the Art Review, 5, 739-754.

Fairchild, D.G., McLoughlin, K.S., Gharib, S., Horsky, J., Portnow, M., Richter, J., Gagliano, N., \& Bates, D.W. (2001). Productivity, quality and patient satisfaction: Comparison of part-time and full-time primary care physicians. Journal of General Internal Medicine, 16, 663-667.

Fernandez, J.P. (1990). The politics and reality of family care in corporate America. Lexington, MA: Heath.

Fincham, F.D., \& Beach, S.R. (1999). Conflict in marriage: Implications for working with couples. Annual Review of Psychology, 50, 47-77.

Fokkema, T. (2002). Combining a job and children: Contrasting the health of married and divorced women in the Netherlands. Social Science and Medicine, 54, 741-752.

Fox, M.L., \& Dwyer, D.J. (1999). An investigation of the effects of time and involvement in the relationship between stressors and work-family conflict. Journal of Occupational Health Psychology, 4, 164-174.

Froberg, D., Gjerdingen, D., \& Preston, M. (1986). Multiple roles and women’s mental health: What have we learned? Women and Health Review, 11, 79-96. 
Frone, M.R. (2003). Work-family balance. In J. C. Quick, \& L. E. Tetrick, (Eds.), Handbook of Occupational Health Psychology. Washington, DC: American Psychological Association.

Frone, M.R. (2000). Work-family conflict and employee psychiatric disorder: The National Comorbidity Survey. Journal of Applied Psychology, 85, 888-895.

Frone, M.R., Russell, M., \& Barnes, G.M. (1996). Work-family conflict, gender, and health-related outcomes: A study of employed parents in two community samples. Journal of Occupational Health Psychology, 1, 57-69.

Frone, M.R., Russell, M., \& Cooper, M.L. (1997). Relation of work-family conflict to health outcomes: A four-year longitudinal study of employed parents. Journal of Occupational and Organizational Psychology, 70, 325-335.

Goetzel, R. Z., Guindon, A. M., Turshen, J.I., \& Ozminkowski, R. J. (2001). Health and productivity management: Establishing key performance measures, benchmarks, and best practices. Journal of Occupational \& Environmental Medicine, 43, 10-17.

Goetzel, R.A., Long, S.R., Ozminkowski, R.J., Hawkins, K., Wang, S., \& Lynch, W. (2004). Health, absence, disability, and presenteeism cost estimates of certain physical and mental health conditions affecting U.S. employers. Journal of Occupational and Environmental Medicine, 46, 398-412.

Gomez, V. (2006). Quality of family and work roles and its relationship with health indicators in men and women. Sex Roles, 55, 787-799. 
Goode, W.J. (1960). A theory of role strain. American Sociological Review, 25, 483496.

Googins, B., \& Burden, D. (1987). Vulnerability of working parents: Balancing work and home roles. Social Work, 32, 295-299.

Greenhaus, J.H., Allen, T.D., \& Spector, P. E. (2006). Health consequences of workfamily conflict: The dark side of the work-family interface. In Perrewe, P.L. \& Ganster, D.C. (Eds.), Research in occupational stress and well-being, Volume 5 (pp. 61-98). Amsterdam: JAI.

Greenhaus, J.H. \& Beutell, N.J. (1985). Sources of conflict between work and family roles. Academy of Management Review, 10, 76-88.

Greenhaus, J.H., Collins, K.M., \& Shaw, J.D. (2003). The relation between workfamily balance and quality of life. Journal of Vocational Behavior, 63, 510531.

Greenhaus, J.H., Parasuraman, S., \& Collins, K.M. (2001). Career involvement and family involvement as moderators of relationship between work-family conflict and withdrawal from a profession. Journal of Occupational Health Psychology, 6, 91-100.

Grzywacz, J.G. (2000). Work-family spillover and health during mid-life: Is managing conflict everything? American Journal of Health Promotion, 14, 236-243. 
Grzywacz, J.G. \& Bass, B.L. (2003). Work, family, and mental health: Testing different models of work-family fit. Journal of Marriage and Family, 65, 248262.

Grzywacz, J.G. \& Marks, N.F. (2000). Family, work, work-family spillover, and problem drinking during midlife. Journal of Marriage and the Family, 62, 336348

Guelzow, M.G., Bird, G.Q., \& Koball, E.H. (1991). An exploratory path analysis of the stress process for dual-career men and women. Journal of Marriage and the Family, 53, 151-164.

Gurin, G., Veroff, J., \& Feld, S. (1960). Americans view their mental health: A nationwide interview survey. New York: Basic Books.

Hackman, J.R., \& Oldham, G.R. (1975). Development of the job diagnostic survey. Journal of Applied Psychology, 60, 159-170.

Hammer, L.B., Cullen, J.C., Neal, M.B., Sinclair, R.R., \& Shafiro, M.V. (2005). The longitudinal effects of work-family conflict and positive spillover on depressive symptoms among dual-earner couples. Journal of Occupational Health Psychology, 10, 128-154.

Hammer, L.B., Kossek, E.E., Yragui, N.L., Bodner, T.E., \& Hanson, G.C. (2009). Development and validation of a multidimensional measure of family supportive supervisor behaviors (FSSB). Journal of Management, 35, 837856. 
Hillier, D., Fewell, F., Cann, W., \& Shephard, V. (2005). Wellness at work: Enhancing the quality of our working lives. International Review of Psychiatry, 17, 419-431.

Hobfoll, S.E. (1989). Conservation of resources: A new approach at conceptualizing stress. American Psychologist, 44, 513-524.

Holm, S. (1979). A simple sequentially rejective multiple test procedure. Scandanavian Journal of Statistics, 6, 65-70.

Illsley, R., \& Baker, D. (1991). Contextual variations in the meaning of health inequality. Social Science and Medicine, 32, 359-365.

Ingersoll-Dayton, B., Neal, M.B., \& Hammer, L.B. (2001). Aging parents helping adult children: The experience of the Sandwiched generation. Family Relations, 50, 262-271.

Johnson, W., \& Krueger, R.F. (2005). Higher perceived life control decreases genetic variance in physical health: Evidence from a national twin study. Journal of Personality and Social Psychology, 88, 165-173.

Karasek, R.A. (1979). Job demands, job decision latitude and mental strain: Implications for job redesign. Administrative Science Quarterly, 24, 285-308.

Kahn, R.L., \& Byosier, P. (1992). Stress in organizations. In M.D. Dunnette \& L.M. Hough (Eds.), Handbook of industrial and organizational psychology (Vol. 3, pp. 571-650). Palo Alto, CA: Consulting Psychologists Press.

Kahn, R.L., Wolfe, D.M., Quinn, R., Snoek, J.D., \& Rosenthal, R.A. (1964). Organizational stress. New York: Wiley. 
Keith, P.M., \& Schafer, R.B.(1980). Role strain and depression in two job families. Family Relations, 29, 483-488.

Khlat, M., Sermet, C., \& Le Pape, A. (2000). Women's health in relation with their family and work roles: France in the early 1990s. Social Science and Medicine, 50, 1807-1825.

Kossek, E.E. \& Ozeki, C. (1999). Bridging the work-family policy and productivity gap: a literature review. Community, Work, \& Family, 2, 7-32.

Lapierre, L.M., Spector, P.E., Allen, T.D., Poelmans, S., Cooper, C.L., O’Driscoll, M.P., Sanchez, J.I., Brough, P., \& Kinnunen, U. (2008). Family-supportive organization perceptions, multiple dimensions of work-family conflict, and employee satisfaction: A test of model across five samples. Journal of Vocational Behavior, 73, 92-106.

Lennon, M.C., \& Rosenfeld, S. (1992). Women and mental health: The interaction of job and family conditions. Journal of Health and Social Behaviour, 4, 316327.

Lewig, K.A., \& Dollard, M.F. (2003). Emotional dissonance, emotional exhaustion, and job satisfaction in call centre workers. European Journal of Work and Organizational Psychology, 12, 366-392.

Litwak, E., \& Messeri, P. (1989). Organizational theory, social supports, and mortality rates: A theoretical convergence. American Sociological Review, $54,49-66$. 
Llorens, S., Bakker, A.B., Schaufeli, W., \& Salanova, M. (2006). Testing the robustness of the job demands-resources model. International Journal of Stress Management, 13, 378-391.

Loomis, L.S., \& Booth, A. (1995). Multigenerational caregiving and well-being: The myth of the beleaguered sandwich generation. Journal of Family Issues, 16, $131-148$.

MacEwen, K.E., \& Barling, J. (1994). Daily consequences of work interference with family and family interference with work. Work and Stress, 8, 244-254.

Major, V.S., Klein, K.J., \& Ehrhart, M. G. (2002). Work time, work interference with family, and psychological distress. Journal of Applied Psychology, 61, 20-52.

Marmot, M.G., Kogevinas, M., \& Elston, M.A. (1987). Social/economic status and disease. Annual Review of Public Health, 8, 111-135.

Marks, S.R. (1977). Multiple roles and role strain: Some notes on human energy, time and commitment. American Sociological Review, 42, 921-966.

Martikainen, P. (1995). Women's employment, marriage, motherhood and mortality: A test of the multiple role and role accumulation hypotheses. Social Science and Medicine, 40, 199-212.

Martire, L.M., Stephens, M.A.P., \& Atienza, A.A. (1997). The interplay of work and caregiving: Relationships between role satisfaction, role involvement, and care-giver's well-being. Journal of Gerontology: Social Sciences, 52B, S279289. 
Martire, L.M., Stephens, M.A.P., \& Townsend, A.L. (2000). Centrality of women's multiple roles: Beneficial and detrimental consequences for psychological well-being. Psychology and Aging, 15, 148-156.

Maslach, C., \& Jackson, S.E. (1986). Manual Maslach Burnout Inventory. Palo Alton, CA: Consulting Psychologists Press.

Mauno, S., Kinnunen, U., \& Ruokolainen, M. (2006). Exploring work- and organization-based resources as moderators between work-family conflict, well-being and job attitudes. Work \& Stress, 20, 210-233.

McMunn, A., Bartley, M., Hardy, R., \& Kuh, D. (2006). Life course social roles and women's health in mid-life: causation or selection? Journal of Epidemiological Community Health, 60, 484-489.

Mesmer-Magnus, J.R. \& Viswesvaran, C. (2005). Convergence between measures of work-to-family and family-to-work conflict: A meta-analytic examination. Journal of Vocational Behavior. 67, 215-232.

Miller, D. A. (1981). The "sandwich" generation: Adult children of the aging. Social Work, 26, 419-423.

Munoz, A.R., Gamarra, M.M., Jimenez, B.M., Herrer, M.G. (2006). Organizational predictors of workplace bullying: Application of job demands-resources model. Revista de Psicologia del Trabajo y las Organizaciones, 22, 333-345.

Neal, M.B., Chapman, N.J., Ingersoll-Dayton, B., Emlen, A.C. (1993). Balancing work and caregiving for children, adults, and elders. Newbury Park, CA: Sage. 
Neal, M.B., \& Hammer, L.B. (2007) Working Couples Caring For Children and Aging Parents: Effects on Work and Well-Being. Mahwah, New Jersey: Lawrence Erlbaum Associates, Publishers.

Neal, M. B., \& Wagner, D. L. (2002). Working caregivers: Issues, challenges and opportunities for the aging network. Retrieved September 5, 2009, from http://www.caregiverslibrary.org/Portals/0/Working\%20Caregivers\%20\%20Issues\%20for\%20the\%20Aging\%20Network\%20Fin-Neal-Wagner.pdf.

Nelson, D.L., \& Simmons, B.L. (2003) Health psychology and work stress: A more positive approach. In J.C. Quick \& L.E. Tetrick (Eds.), Handbook of Occupational Health Psychology, (Chapter 5, pp.97-119). Washington, D.C.: American Psychological Association.

Netemeyer, R.C., Boles, J.S. \& McMurrian, R. (1996). Development and validation of work-family conflict and family-work conflict scales. Journal of Applied Psychology, 81, 400-410.

Nichols, L.S. \& Junk, V.W. (1997). The sandwich generation: Dependency, proximity, and task assistance needs of parents. Journal of Family and Economic Issues, 18, 299-326.

Nielson, T.R., Carlson, D.S., \& Lankau, M.J. (2001). The supportive mentor as a means of reducing work-family conflict. Journal of Vocational Behavior, 59, 364-381.

Olmsted, B., \& Smith, S. (1994). Creating a flexible workplace: How to select and manage alternative work options. New York: AMACOM. 
Parasuraman, S., Greenhaus, J.R., \& Granrose, C.S. (1992). Role stressors, social support, and well-being among two-career couples. Journal of Organizational Behavior, 13, 339-356.

Parkerton, P.H., Wagner, E.H., Smith, D.G., \& Straley, H.L. (2003). Effect of parttime practice on patient outcomes. Journal of General Internal Medicine, 18, 717-724.

Pedersen, D.E., Minnotte, K.L., Kiger, G., \& Mannon, S.E. (2009). Workplace policy and environment, family role quality, and positive family-to-work spillover. Journal of Family and Economic Issues, 30, 80-89.

Penning, M.J. (1998). In the middle: Parental caregiving in the context of other roles. The Journals of Gerontology Series B: Psychological Sciences and Social Sciences, 53B, S188-S197.

Perrewe, P.L., Hochwarter, W.A., \& Kiewitz, C. (1999). Value attainment: An explanation of the negative effects of work family conflict on job and life satisfaction. Journal of Occupational Health Psychology, 4, 318-326.

Pitt-Catsouphes, M., Smyer, M.A., Matz-Costa, C., \& Kane, K. (2007). The National Study Report: Phase II of the National Study of Business Strategy and Workforce Development. Boston College: Center on Aging and Work/Workplace Flexibility.

Plaisier, I., Beekman, A.T.F., de Bruijn, J.G.M., de Graaf, R., ten Have, M., Smit, J.H., van Dyck, R., \& Penninx, B.W.J.H. (2008). The effect of social roles on 
mental health: A matter of quantity or quality? Journal of Affective Disorders, $111,261-270$.

Pleck, J.H., Staines, G.L., \& Lang, L.L. (1980). Conflicts between work and family life. Monthly Labor Review, 79, 702-713.

Quinn, R.P., \& Staines, G.L. (1979). The 1977 Quality of Employment Survey. Ann Arbor: University of Michigan, Institute for Social Research.

Radloff, L.S. (1977). The CES-D scale: A self-report depression scale for research in the general population. Applied Psychological Measurement, 1, 385-501.

Ross, C.E., Mirowsky, J., \& Goldsteen, K. (1990). The impact of the family on health: The decade in review. Journal of Marriage and the Family, 52, 10591078.

Ross, C.E., \& Wu, C.L. (1996). Education, age, and the cumulative advantage in health. Journal of Health and Social Behavior, 37, 104-120.

Sauter, S.L., Murphy, L.R., \& Hurrell, Jr., J.J. (1990). Prevention of work-related psychological disorders. American Psychologist, 45, 1146-1153.

Schaufeli, W.B., Leiter, M.P., Maslach, C., \& Jackson, S.E. (1996). The Maslach Burnout Inventory-General Survey. In C. Maslach, S.E. Jackson, \& M.P. Leiter (Eds.), Maslach Burnout Inventory: Manual (3 ${ }^{\text {rd }}$ ed., pp. 19-26). Palo Alto, CA: Consulting Psychologists Press.

Schwartz, S.L. (2007). Engaging our workforce: How job demands and resources contribute to social worker burnout, engagement, and intent to leave (Doctoral 
dissertation). Available from ProQuest Dissertations and Theses database. (UMI No. 3273613).

Semmer, N., Zapf, D., \& Greif, S. (1996). "Shared job strain": A new approach for assessing the validity of job stress measurements. Journal of Occupational and Organizational Psychology, 69, 293-310.

Shaffer, J. P. (1995). Multiple Hypothesis Testing. Annual Review of Psychology, 46, $561-584$.

Stephens, M.A.P., Franks, M.M., \& Atienza, A.A. (1997). Where two roles intersect: Spillover between parent care and employment. Psychology and Aging, 12, $30-37$.

Stephens, M.A.P., \& Townsend, A.L. (1997). Stress of parent care: Positive and negative effects of women's other roles. Psychology and Aging, 12, 376-386.

Stewart, B., \& Archbold, P. (1996). Oregon family caregiving survey. Unpublished manuscript, Oregon Health Sciences University, School of Nursing.

Stone, R., Cafferata, G.L., \& Sangl, J. (1987). Caregivers of the frail elderly: A national profile. The Gerontologist, 27, 616-626.

Stryker, S., \& Serpe, R.T. (1994). Identity salience and psychological centrality: Equivalent, overlapping, or complementary concepts? Social Psychology Quarterly, 57, 16-35.

Thomas, L.T., \& Ganster, D.C. (1995). Impact of family-supportive work variables on work-family conflict and strain: A control perspective. Journal of Applied Psychology, 80, 6-15. 
Thompson, C.A., Beauvais, L.L., \& Lyness, K.S. (1999). When work-family benefits are not enough: The influence of work-family culture on benefit utilization, organizational attachment, and work-family conflict. Journal of Vocational Behavior, 54, 392-415.

U.S. Department of Labor, Bureau of Labor Statistics. (2008). Employment and Earnings, 2008 Annual Averages and the Monthly Labor Review, retrieved from http://www.dol.gov/wb/stats/main.htm on September 5, 2009.

U.S. Department of Labor, Bureau of Labor Statistics (2007). Women in the Labor Force: A Databook (2007 Edition). Retrieved September $5^{\text {th }}$ from http://www.bls.gov/cps/wlf-databook2007.htm.

Van der heidjen, B.I.J.M, Demerouti, E., Bakker, A.B., \& The Next Study Group Coordinated by Hans-Martin Hasselhorn (2008). Work-home interference among nurses: reciprocal relationships with job demands and health. Journal of Advanced Nursing, 62, 572-584.

Vandewater, E.A., Ostrove, J.M., \& Stewart, A.J. (1997). Predicting women's wellbeing in midlife: The importance of personality development and social role involvements. Journal of Personality and Social Psychology, 72, 1147-1160.

Van Hooff, M.L.M, Geurts, S.A.E., Taris, T.W., Kompier, M.A.J., Dikkers, J.S.E., Houtman, I.L.D., \& van den Heuvel, F.M.M. (2005). Disentangling the causal relationships between work-home interference and employee health. Scandinavian Journal of Work and Environmental Health, 31, 15-29. 
Van Vegchel, N., de Jonge, J., Soderfeldt, M., Dormann, C., \& Schaufeli, W. (2004). Quantitative versus emotional demands among Swedish human service employees: Moderating effects of job control and social support. International Journal of Stress Management, 11, 21-40.

Voydanoff, P. (1990). Economic distress and family relations: A review of the eighties. Journal of Marriage and the Family, 52, 1099-1115.

Voydanoff, P., \& Donnelly, B.W. (1999). Multiple roles and psychological distress: The intersection of the paid worker, spouse and parent roles with the adult child role. Journal of Marriage and the Family, 61, 725-738.

Wagner, D. L. (2000). The development and future of workplace eldercare. In Dimensions of family caregiving: A look into the future. Westport, CT: MetLife Mature Market Institute.

Wallace, J.E.. (1997). It's about time: A study of hours worked and work spillover among law firm lawyers. Journal of Vocational Behavior, 20, 227-248.

Ward, R.A., \& Spitze, G. (1998). Sandwiched marriages: The implications of child and parent relations for marital quality in midlife. Social Forces, 77, 647-666.

Warde, C. Time is of the essence. Journal of General Internal Medicine, 16, 712713.

Windle, M., \& Dumenci, L. (1997). Parental and occupational stress as predictors of depressive symptoms among dual-income couples: A multilevel modeling approach. Journal of Marriage and the Family, 59, 625-634. 
Winkelby, M.A., Jatulis, D.E., Frank, E., \& Fortmann, S.P. (1992). Socioeconomic status and health: How education, income, and occupation contribute to risk factors for cardiovascular disease. American Journal of Public Health, 82, 816-820.

Winter, T., Roos, E., Rahkonen, O., Martikainen, P., \& Lahelma, E. (2006). Workfamily conflicts and self-rated health among middle-aged municipal employees in Finland. International Journal of Behavioral Medicine, 13, 276-285.

Xanthopoulou, D., Bakker, A.B., Dollard, M.F., Demerouti, E., Schaufeli, W.B., Taris, T.W., \& Schreurs, P.J.G. (2007). When do job demands particularly predict burnout? The moderating role of job resources. Journal of Managerial Psychology, 22, 766-786. 
Table 1

Intraclass Correlations for Outcome Variables

Outcome Variable ICC

Health at Year $1 \quad .09$

Depression at Year $1 \quad .10$

Life Satisfaction at Year $1 \quad .36$

Health at Year 2

Depression at Year $2 \quad .34$

Life Satisfaction at Year $2 \quad .25$

Note . ICC = Intraclass Correlation 
Table 2

Details of Each Regression Analysis with Significance Indicators

\begin{tabular}{|c|c|c|}
\hline Regression & $\begin{array}{l}\text { Hypotheses Tested, terms } \\
\text { included in each step }\end{array}$ & $\begin{array}{l}\text { Dependent } \\
\text { Variable }\end{array}$ \\
\hline 1 & $\begin{array}{l}\mathrm{H} 2 \mathrm{a} \\
\text { 1. Education*, PIA } \\
\text { 2. WIF, JRQ } \\
\text { 3. WIF x JRQ }\end{array}$ & Overall Health \\
\hline 2 & $\begin{array}{l}\mathrm{H} 2 \mathrm{a} \\
\text { 1. Education*, PIA } \\
\text { 2. FIW, JRQ } \\
\text { 3. FIW x JRQ }\end{array}$ & Overall Health \\
\hline 3 & $\begin{array}{l}\mathrm{H} 2 \mathrm{~b} \\
\text { 1. Education, PIA } \\
\text { 2. WIF**, JRQ*** } \\
\text { 3. WIF x JRQ }\end{array}$ & Depression \\
\hline 4 & $\begin{array}{l}\mathrm{H} 2 \mathrm{~b} \\
\text { 1. Education, PIA } \\
\text { 2. FIW**, JRQ*** } \\
\text { 3. FIW x JRQ }\end{array}$ & Depression \\
\hline 5 & $\begin{array}{l}\mathrm{H} 2 \mathrm{c} \\
\text { 1. Education, PIA } \\
\text { 2. WIF, JRQ* } \\
\text { 3. WIF x JRQ }\end{array}$ & Life Satisfaction \\
\hline 6 & $\begin{array}{l}\mathrm{H} 2 \mathrm{c} \\
\text { 1. Education, PIA } \\
\text { 2. FIW, JRQ } \\
\text { 3. FIW x JRQ }\end{array}$ & Life Satisfaction \\
\hline 7 & $\begin{array}{l}\text { H3a } \\
\text { 1. Education**, PIA } \\
\text { 2. WIF, SRQ } \\
\text { 3. WIF x SRQ }\end{array}$ & Overall Health \\
\hline 8 & $\begin{array}{l}\text { H3a } \\
\text { 1. Education**, PIA } \\
\text { 2. FIW, SRQ } \\
\text { 3. FIW x SRQ }\end{array}$ & Overall Health \\
\hline 9 & $\begin{array}{l}\mathrm{H} 3 \mathrm{~b} \\
\text { 1. Education, PIA } \\
\text { 2. WIF***, SRQ** }\end{array}$ & Depression \\
\hline
\end{tabular}


3. WIF x SRQ

10

11

12

13

15

14

16

17

18

19
$\mathrm{H} 3 \mathrm{~b}$

1. Education, PIA

2. $\mathrm{FIW}^{*}, \mathrm{SRQ}^{* *}$

3. FIW x SRQ

$\mathrm{H} 3 \mathrm{c}$

1. Education, PIA

2. WIF, SRQ***

3. WIF x SRQ*

$\mathrm{H} 3 \mathrm{c}$

1. Education, PIA

2. FIW, SRQ***

3. FIW x SRQ $\mathrm{H} 4 \mathrm{a}$

1. Education**, PIA

2. WIF, CCRQ*

3. WIF x CCRQ

$\mathrm{H} 4 \mathrm{a}$

1. Education**, PIA

2. FIW, CCRQ**

3. FIW x CCRQ $\mathrm{H} 4 \mathrm{~b}$

1. Education, PIA

2. $\mathrm{WIF}^{* * *}, \mathrm{CCRQ}^{* *}$

3. WIF x CCRQ $\mathrm{H} 4 \mathrm{~b}$

1. Education, PIA

2. $\mathrm{FIW}^{* *}, \mathrm{CCRQ}^{* *}$

3. FIW x CCRQ

$\mathrm{H} 4 \mathrm{c}$

1. Education, PIA

2. WIF, CCRQ**

3. WIF $x \mathrm{CCRQ}^{* *}$ $\mathrm{H} 4 \mathrm{c}$

1. Education, PIA

2. FIW, CCRQ**

3. FIW x CCRQ

H5a

1. Education*, PIA

2. WIF, PCRQ
Depression

Life Satisfaction

Life Satisfaction

Overall Health

Overall Health

Depression

Depression

Life Satisfaction

Life Satisfaction

Overall Health 
3. WIF $x$ PCRQ

20 H5a

Overall Health

1. Education*, PIA

2. FIW, PCRQ

3. FIW x PCRQ

21 $\mathrm{H} 5 \mathrm{~b}$

1. Education, PIA

2. $\mathrm{WIF}^{* *}, \mathrm{PCRQ}$

3. WIF $x$ PCRQ

22 $\mathrm{H} 5 \mathrm{~b}$

1. Education, PIA

Depression

2. $\mathrm{FIW}^{* *}, \mathrm{PCRQ}$

3. FIW x PCRQ $\mathrm{H} 5 \mathrm{c}$

1. Education, PIA

2. WIF, PCRQ*

3. WIF x PCRQ

24

$\mathrm{H} 5 \mathrm{c}$

1. Education*, PIA

2. FIW, PCRQ*

3. FIW x PCRQ

Note. JRQ = Job Role Quality. SRQ = Spousal Role Quality. CCRQ $=$ Child Care Role Quality. PCRQ = Parent Care Role Quality. PIA = Perceived Income Adequacy. All predictor and control variables (Education, PIA, WIF, FIW, JRQ, SRQ, CCRQ, PCRQ) were assessed at Time 1. All interactions were created from centered variables measured at Time 1. All outcome variables (Overall Health, Depression, and Life Satisfaction) were assessed at Time 2.

$* p<.05 . * * p<.01 . * * * p<.001$. 


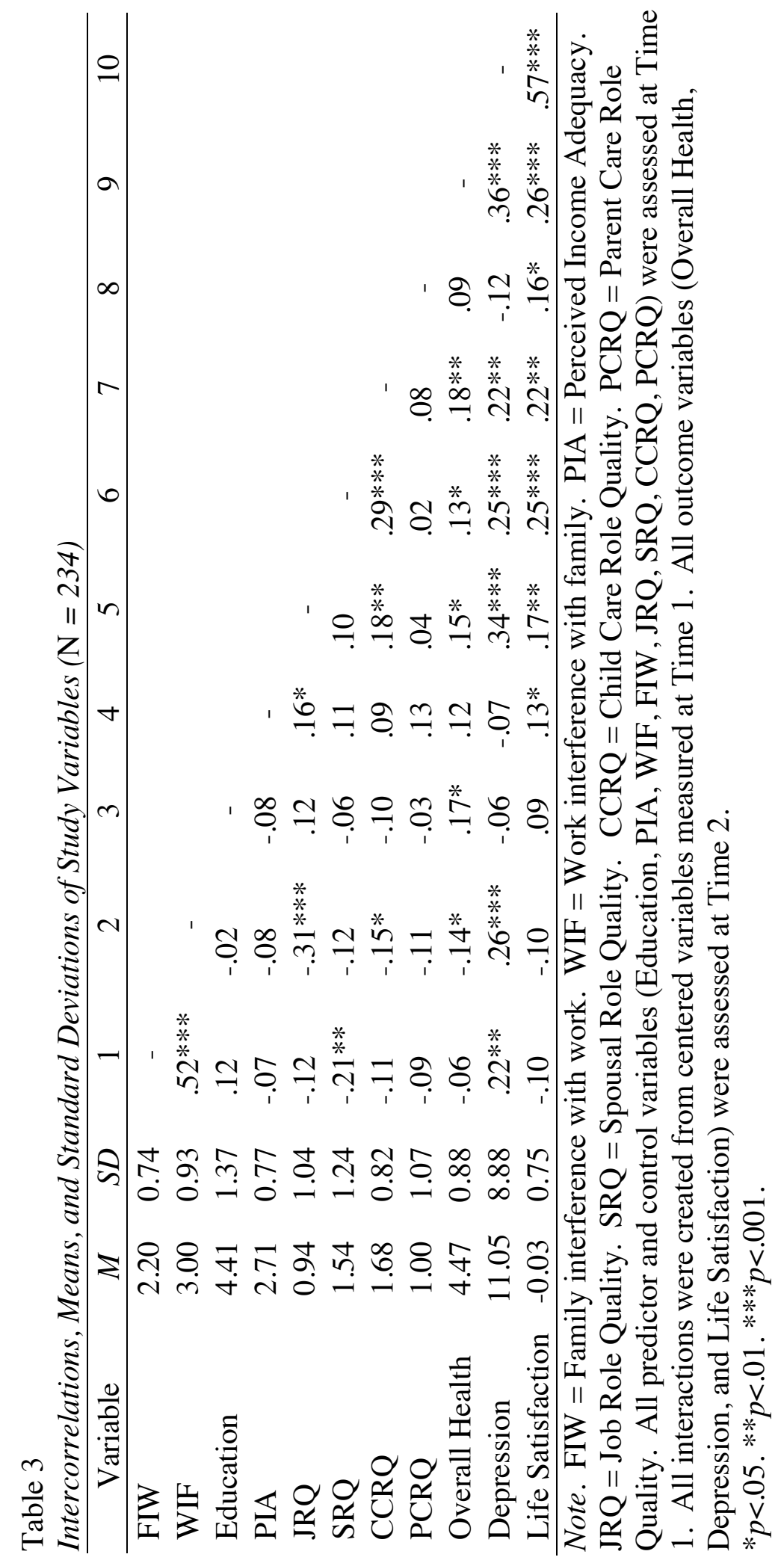

115 
Table 4

Description of Support for Hypotheses in the Three Sets of Analyses

\begin{tabular}{llll}
\hline Hypothesis & \multicolumn{1}{c}{ Results } & $\begin{array}{c}\text { Results Controlling } \\
\text { for T1 Outcomes }\end{array}$ & \multicolumn{1}{c}{$\begin{array}{c}\text { Results Using } \\
\text { Role Rewards }\end{array}$} \\
\hline H1a & Not supported & Not supported & Not supported \\
H1b & Fully supported & Partially supported & Fully supported \\
H1c & Not supported & Not supported & Not supported \\
H2a & Not supported & Not supported & Not supported \\
H2b & Not supported & Not supported & Not supported \\
H2c & Not supported & Not supported & Not supported \\
H3a & Not supported & Not supported & Not supported \\
H3b & Not supported & Not supported & Not supported \\
H3c & Partially supported & Partially supported & Not supported \\
H4a & Not supported & Not supported & Not supported \\
H4b & Not supported & Not supported & Not supported \\
H4c & Partially supported & Partially supported & Not supported \\
H5a & Not supported & Not supported & Not supported \\
H5b & Not supported & Not supported & Not supported \\
H5c & Not supported & Not supported & Not supported \\
\hline
\end{tabular}

Note. Statistical significance assessed at the $p<.05$ level. 


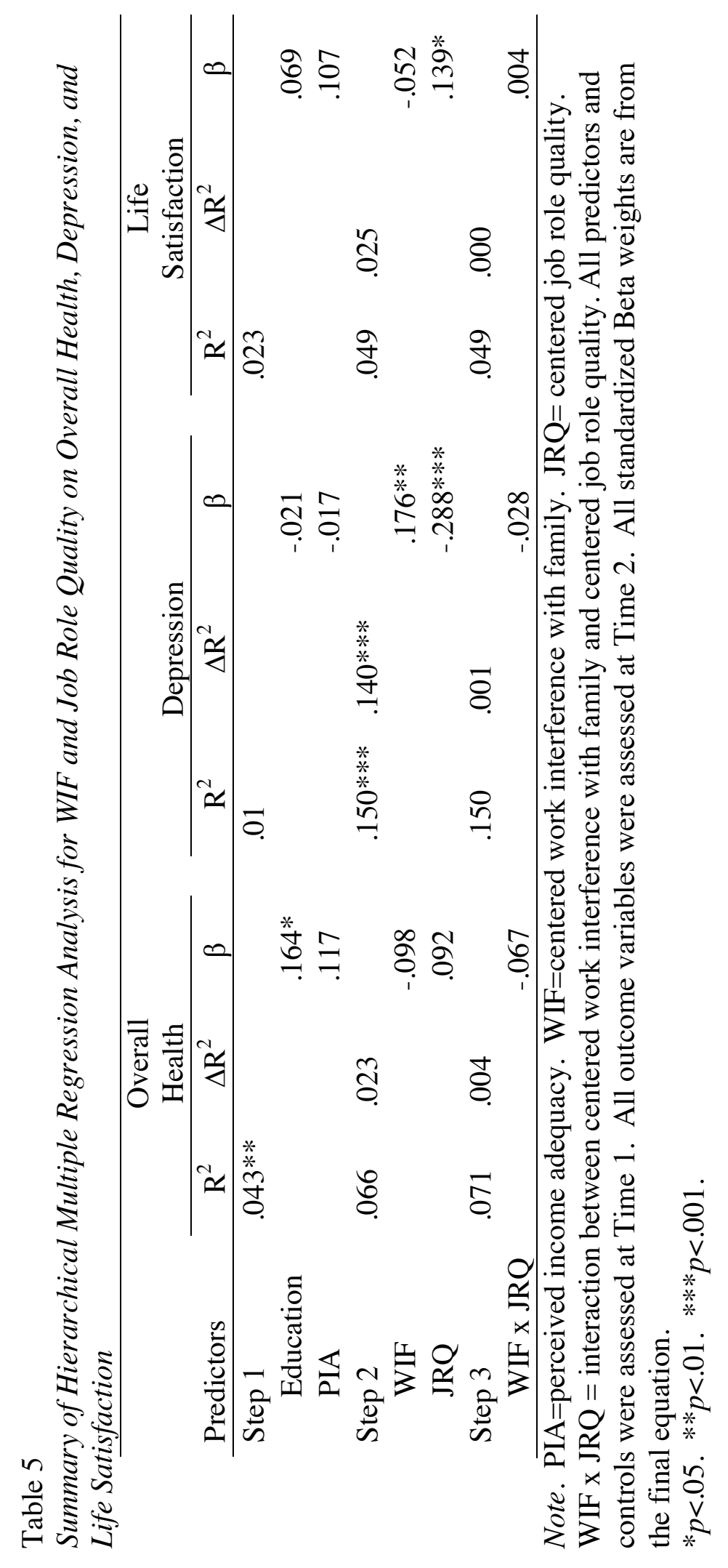




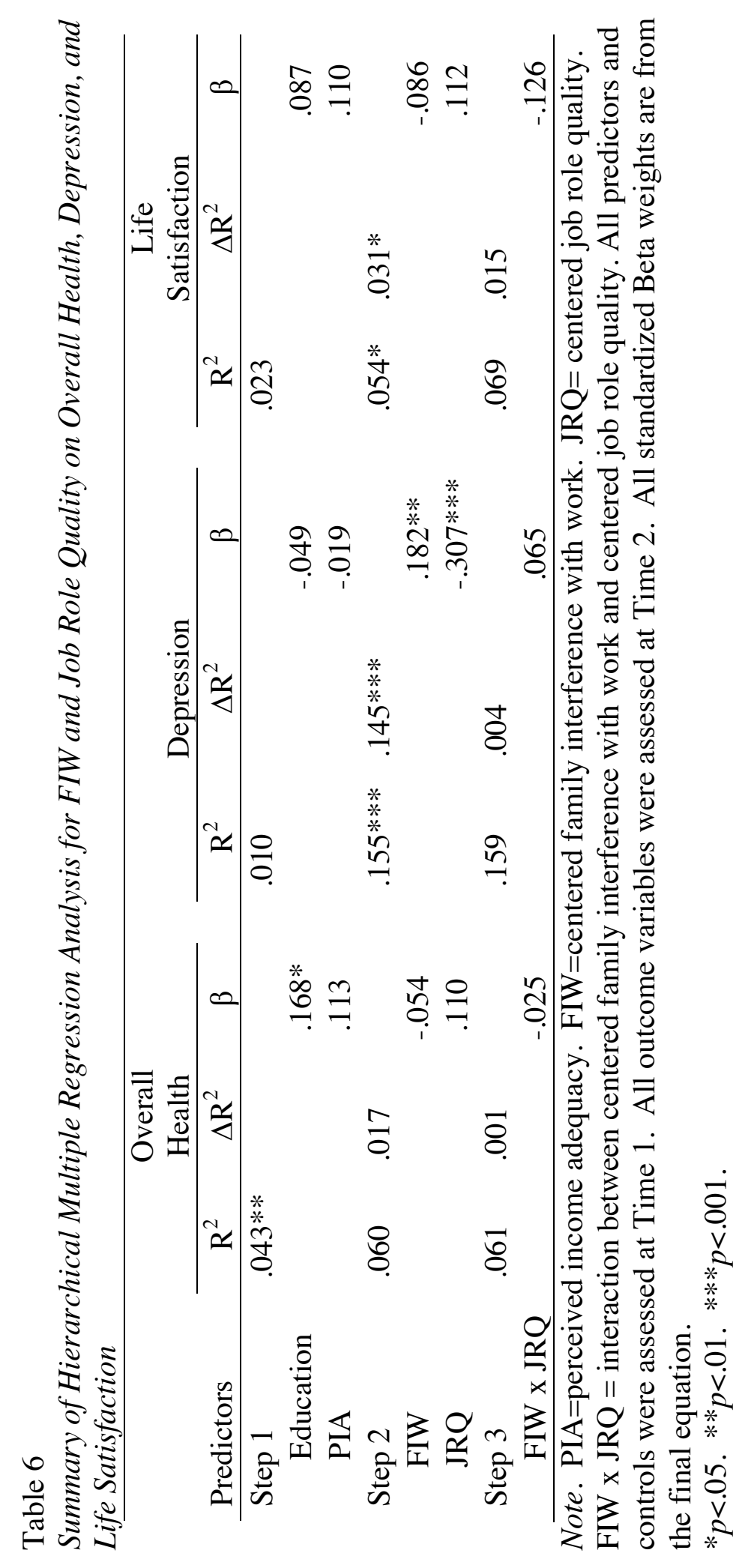




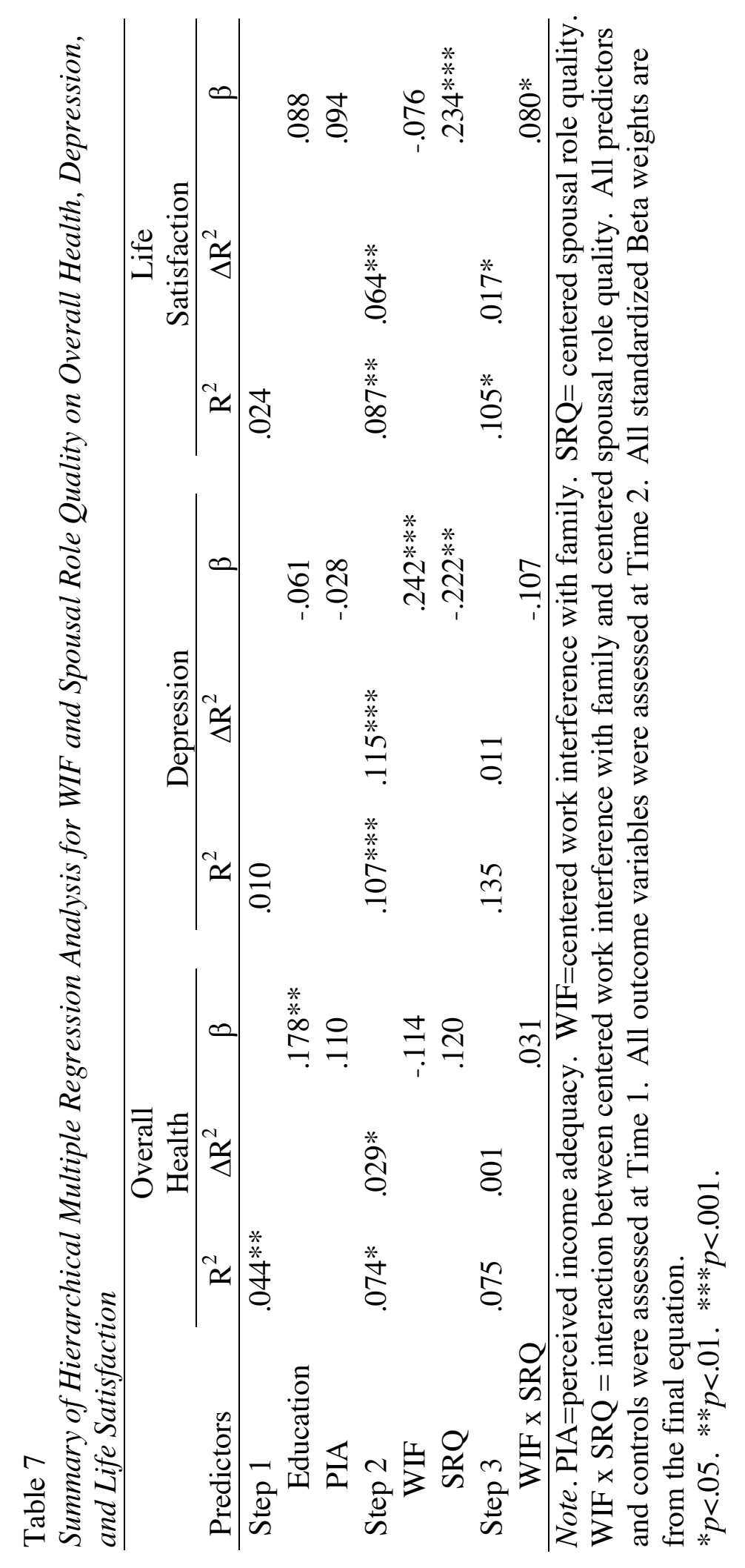




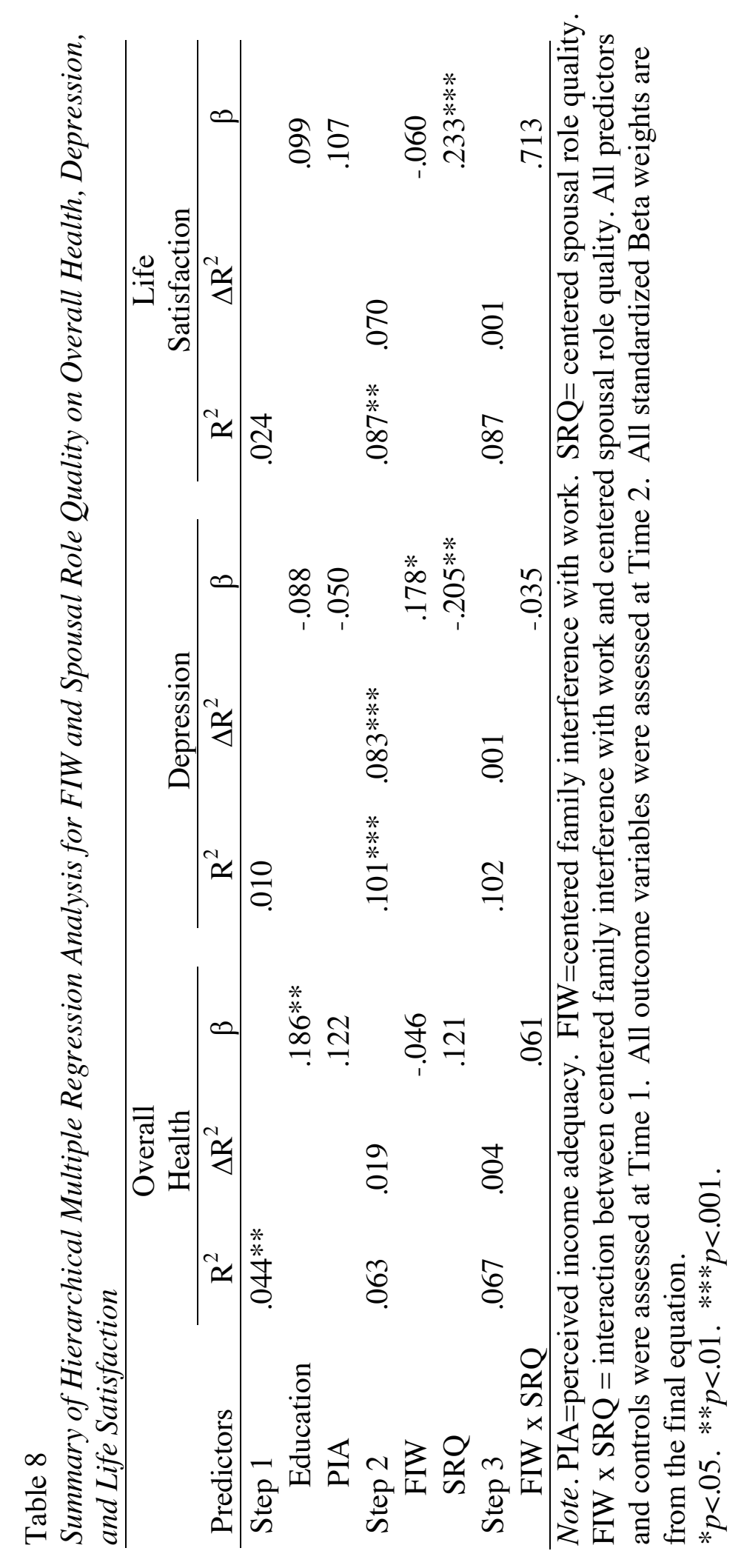




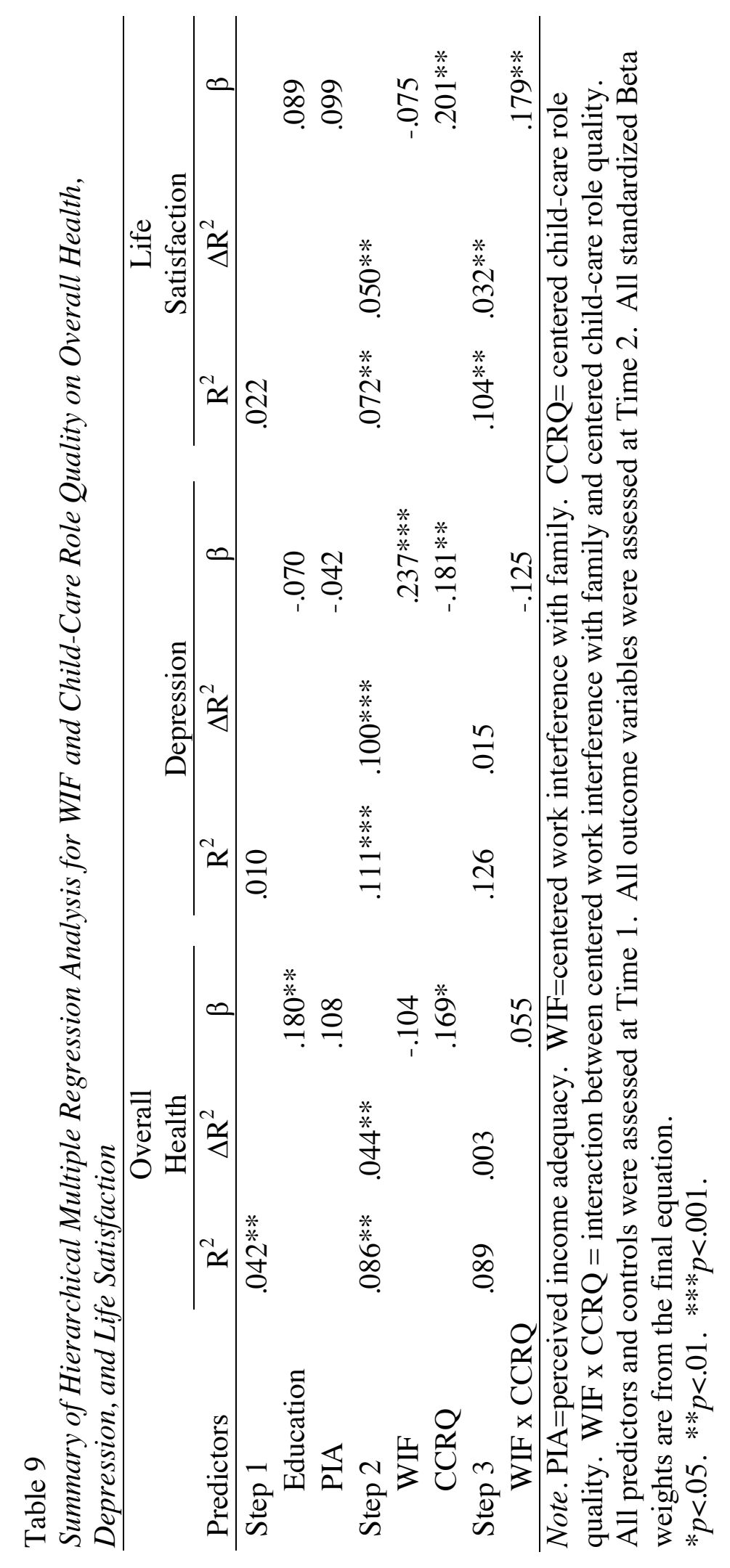




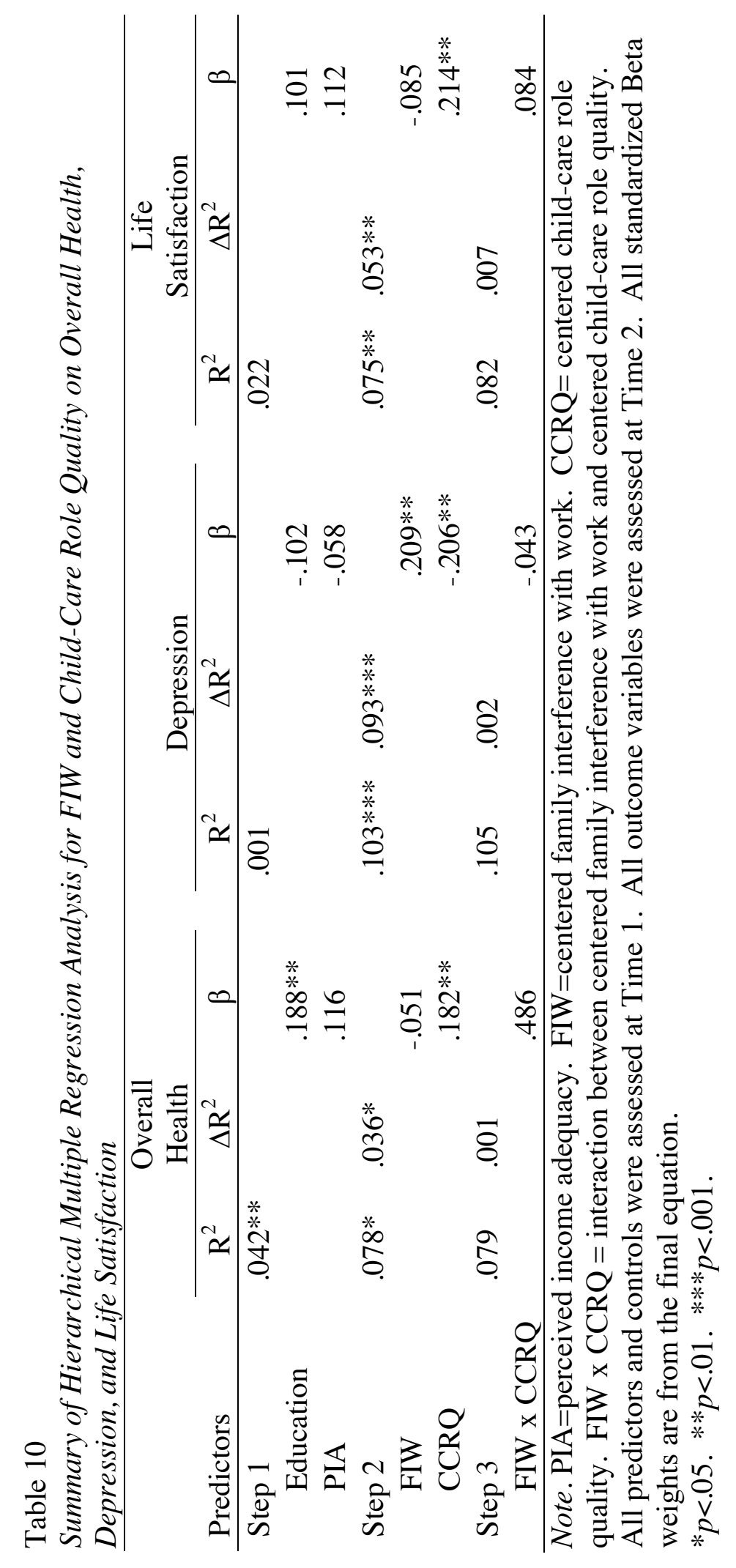




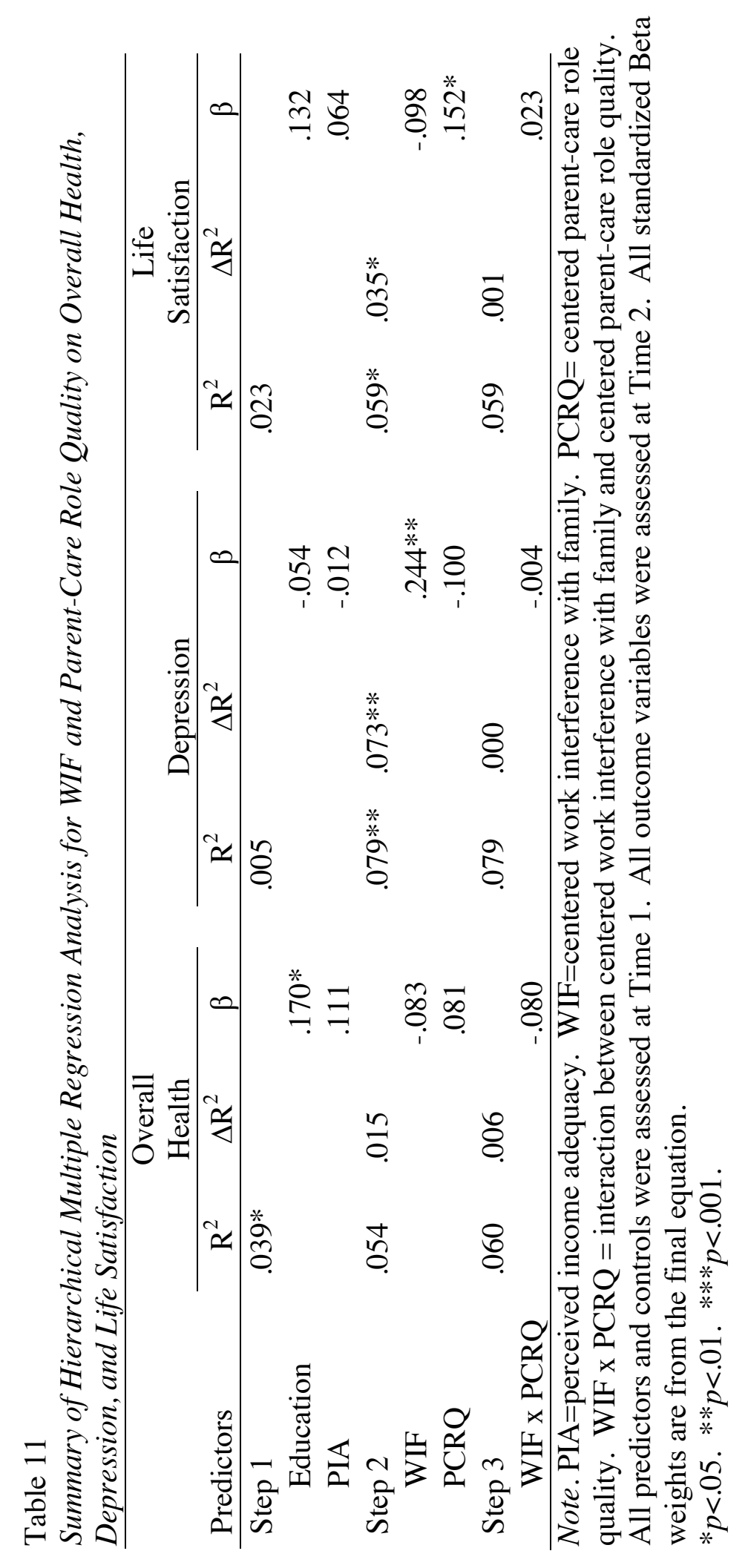




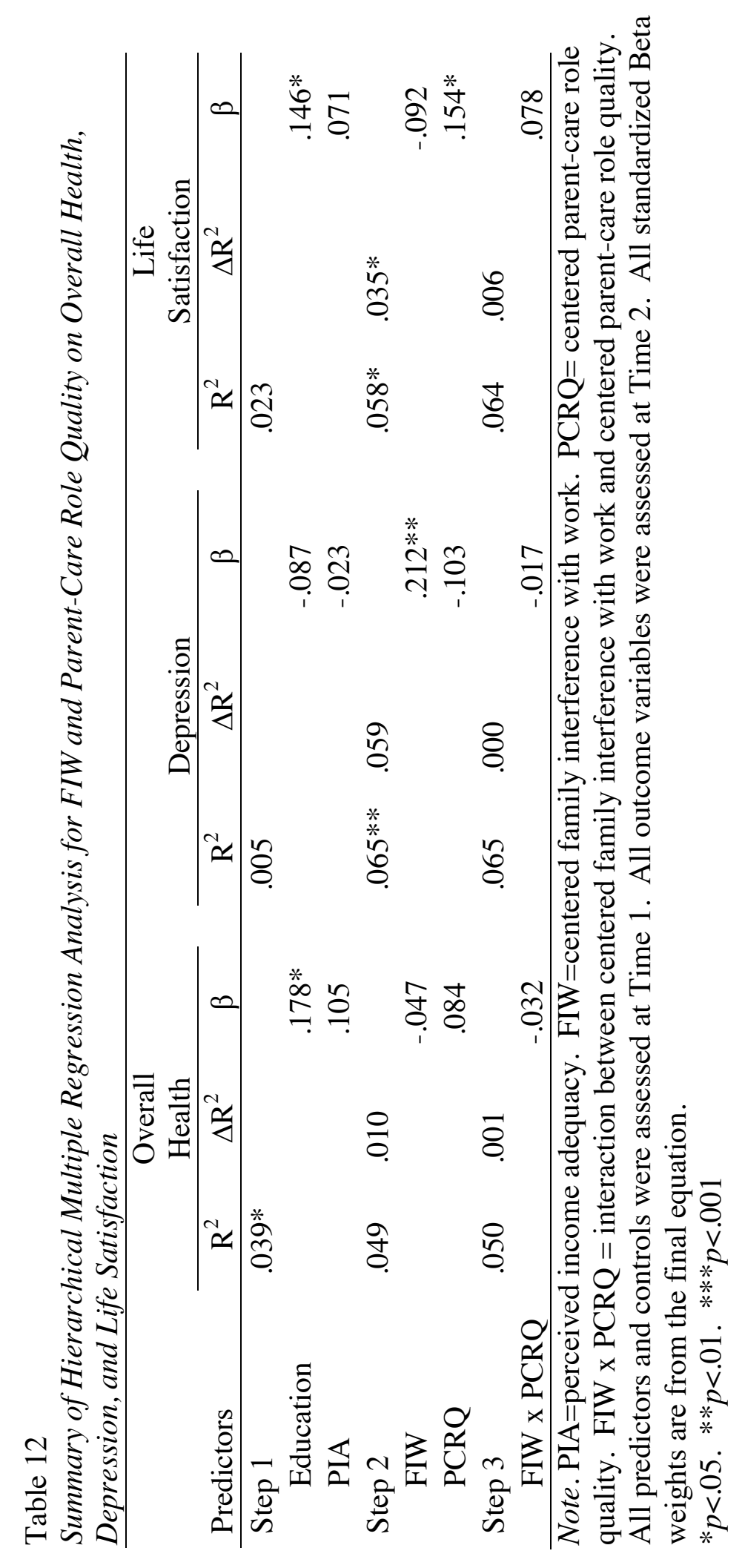


Figure 1. A Visual Representation of The Hypothesized Relationship Between WFC, Well-Being, and Resources

Time 1

Time 2

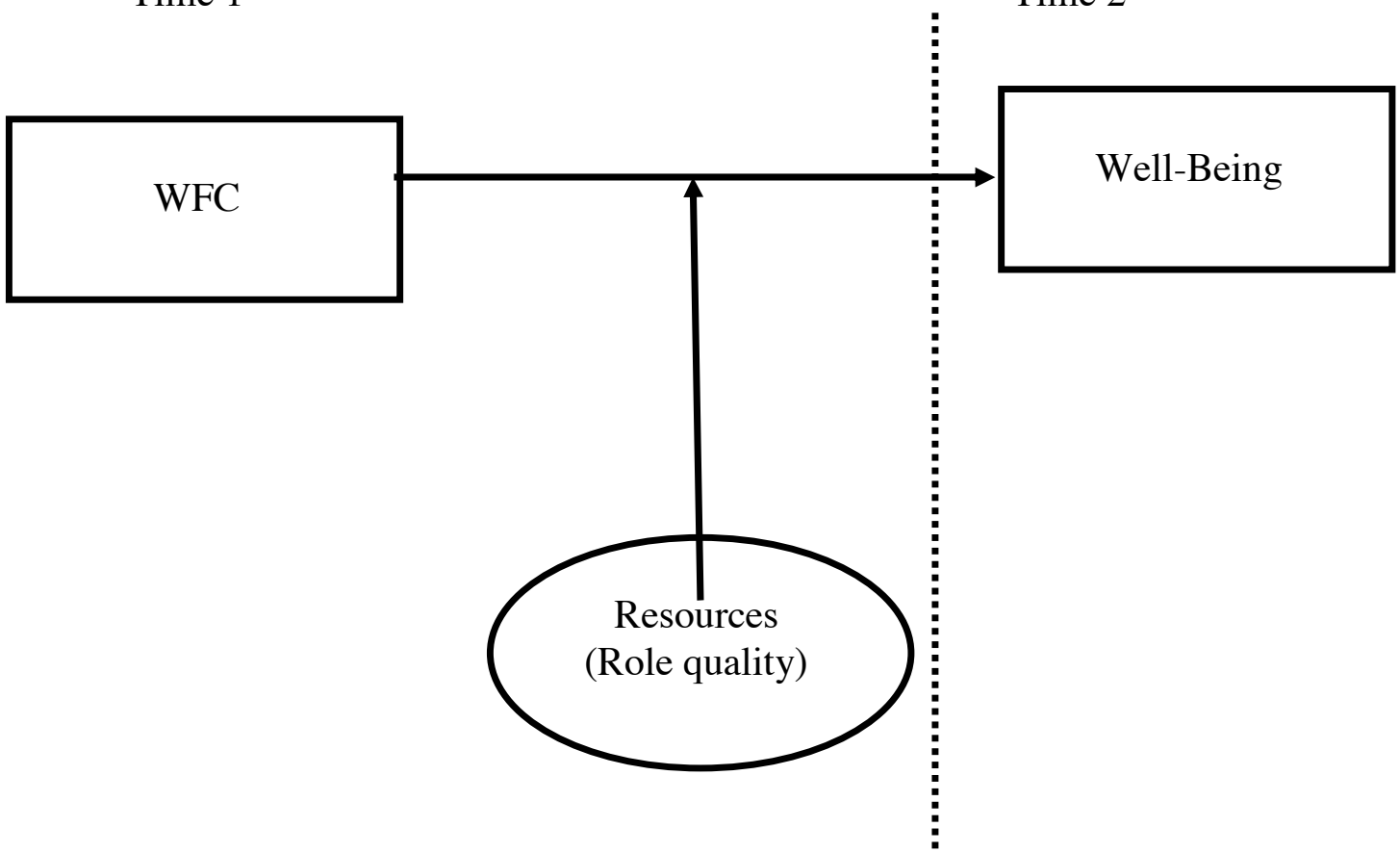

Figure 1. A visual description of the hypothesized model, built upon the Job Demands-Resources Model. Work-family conflict (WFC), measured at Time 1, has a negative impact on well-being outcomes measured at Time 2. High levels of resources, in this case, role quality, can moderate that relationship to protect an individual's well-being. 
Figure 2. Interaction between SRQ and WIF on Life Satisfaction

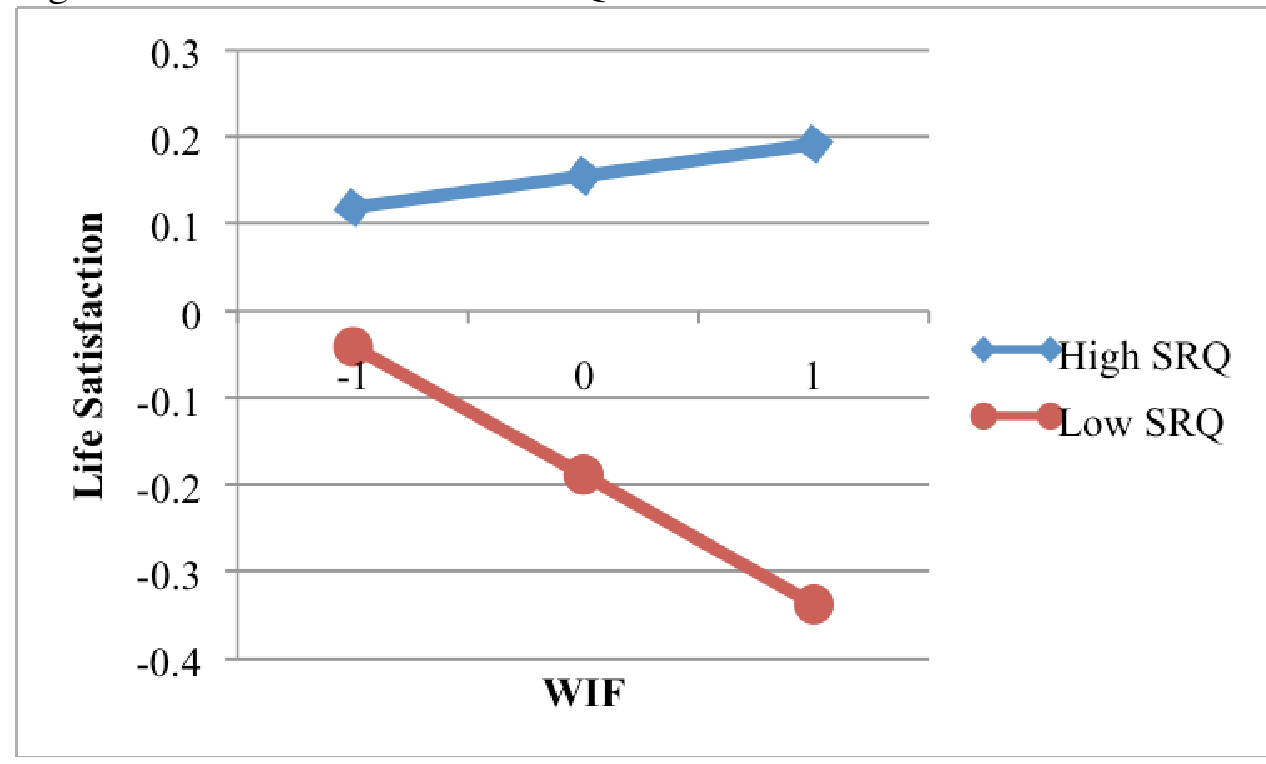

Figure 2. Levels of life satisfaction for individuals with high spousal role quality (SRQ) and individuals with low SRQ as a function of level of work interference with family (WIF). The WIF continuum ranges from one SD below the mean of WIF to one SD above the mean of WIF. High SRQ is a score of one SD above the mean of SRQ, while low SRQ is a score of one SD below the mean of SRQ. 
Figure 3. Interaction between CCRQ and WIF on Life Satisfaction

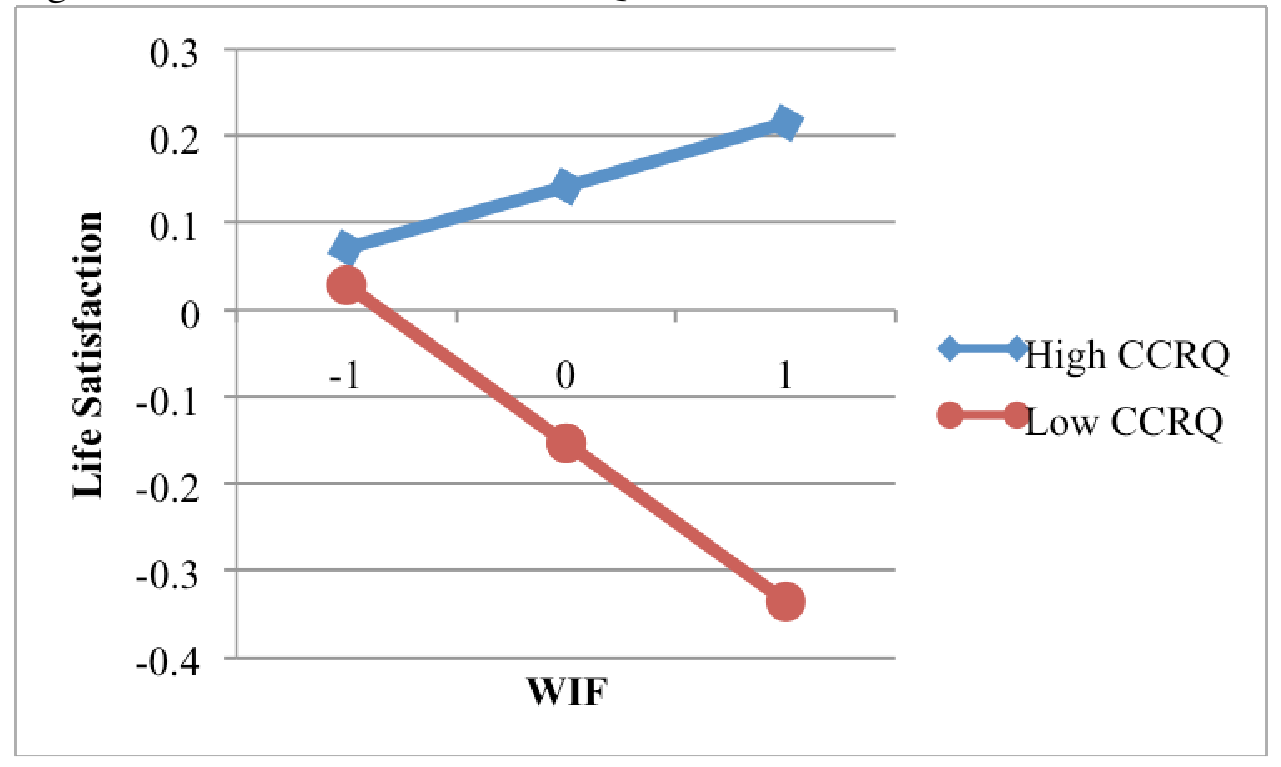

Figure 3. Levels of life satisfaction for individuals with high child-care role quality (CCRQ) and individuals with low CCRQ as a function of level of work interference with family (WIF). The WIF continuum ranges from one SD below the mean of WIF to one SD above the mean of WIF. High CCRQ is a score of one SD above the mean of CCRQ, while low CCRQ is a score of one SD below the mean of CCRQ. 
Figure 4. Interaction between JRQ and FIW on Life Satisfaction

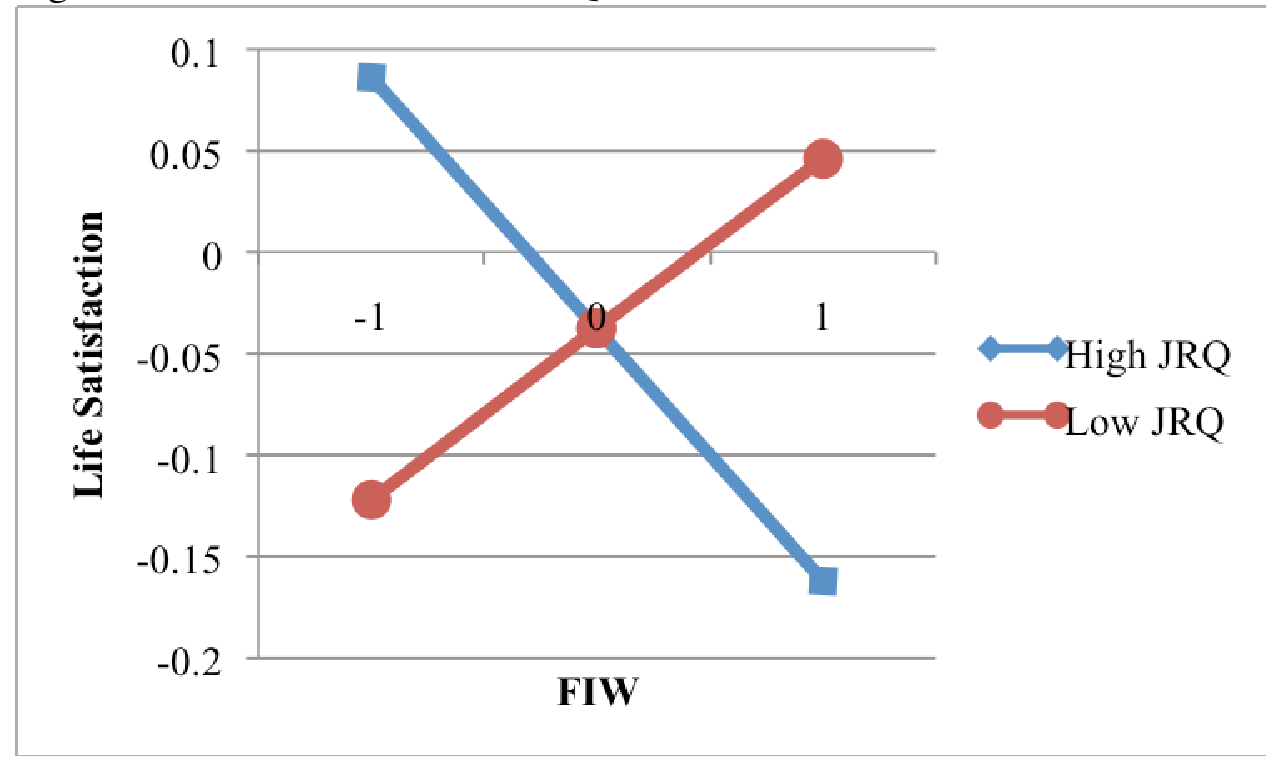

Figure 4. Levels of life satisfaction for individuals with high job role quality (JRQ) and individuals with low JRQ as a function of level of family interference with work (FIW). The FIW continuum ranges from one SD below the mean of FIW to one SD above the mean of FIW. High JRQ is a score of one SD above the mean of JRQ, while low JRQ is a score of one SD below the mean of JRQ. 
Appendices

Appendix A: Work-Family Conflict Scale

Appendix B: Job Role Quality Scale

Appendix C: Spousal Role Quality Scale

Appendix D: Child-Care Role Quality Scale

Appendix E: Parent-Care Role Quality Scale

Appendix F: CES-D (Depression) Scale

Appendix G: Life Satisfaction Scale

Appendix H: Education Question 
Appendix A

\section{Work-Family Conflict}

Now, we'd like you to think about YOUR FAMILY IN GENERAL, including your spouse or partner, children, and parents or parents-in law. For each statement below, please circle the response indicating the extent to which you agree or disagree.

\begin{tabular}{|c|c|c|c|c|c|}
\hline & $\begin{array}{l}\text { Strongly } \\
\text { Disagree }\end{array}$ & Disagree & $\begin{array}{l}\text { Neither } \\
\text { agree } \\
\text { nor } \\
\text { disagree }\end{array}$ & Agree & $\begin{array}{l}\text { Strongly } \\
\text { Agree }\end{array}$ \\
\hline $\begin{array}{l}\text { a. The demands of my work interfere with } \\
\text { my home and family life. }\end{array}$ & 1 & 2 & 3 & 4 & 5 \\
\hline $\begin{array}{l}\text { b. The amount of time my job takes up } \\
\text { makes it difficult to fulfill family } \\
\text { responsibilities. }\end{array}$ & 1 & 2 & 3 & 4 & 5 \\
\hline $\begin{array}{l}\text { c. Things I want to do at home do not get } \\
\text { done because of the demands my job puts } \\
\text { on me. }\end{array}$ & 1 & 2 & 3 & 4 & 5 \\
\hline $\begin{array}{l}\text { d. My job produces strain that makes it } \\
\text { difficult to fulfill family duties. }\end{array}$ & 1 & 2 & 3 & 4 & 5 \\
\hline $\begin{array}{l}\text { e. Due to my work-related duties, I have to } \\
\text { make changes to my plans for family } \\
\text { activities. }\end{array}$ & 1 & 2 & 3 & 4 & 5 \\
\hline $\begin{array}{l}\text { f. The demands of my family interfere } \\
\text { with work-related activities. }\end{array}$ & 1 & 2 & 3 & 4 & 5 \\
\hline $\begin{array}{l}\text { g. I have to put off doing things at work } \\
\text { because of demands on my time at home. }\end{array}$ & 1 & 2 & 3 & 4 & 5 \\
\hline $\begin{array}{l}\mathrm{h} \text {. Things I want to do at work don't get } \\
\text { done because of the demands of my family. }\end{array}$ & 1 & 2 & 3 & 4 & 5 \\
\hline $\begin{array}{l}\text { i. My home life interferes with my } \\
\text { responsibilities at work, such as getting to } \\
\text { work on time, accomplishing daily tasks, } \\
\text { and working overtime. }\end{array}$ & 1 & 2 & 3 & 4 & 5 \\
\hline $\begin{array}{l}\text { j. Family-related strain interferes with my } \\
\text { ability to perform job-related duties. }\end{array}$ & 1 & 2 & 3 & 4 & 5 \\
\hline
\end{tabular}

(Note: items a-e are measures of WIF and items f-j are measures of FIW) 
Appendix B

\section{Job Role Quality}

Job Role Rewards:

In your current JOB, in the past month, how REWARDING to you have the following

been:

$\begin{array}{lcccc} & \begin{array}{c}\text { Not at all } \\ \text { rewarding }\end{array} & \begin{array}{c}\text { Just a } \\ \text { little } \\ \text { rewarding }\end{array} & \begin{array}{c}\text { Somewhat } \\ \text { rewarding }\end{array} & \begin{array}{c}\text { Very } \\ \text { rewarding }\end{array} \\ \begin{array}{l}\text { a.. Challenging or stimulating work } \\ \text { b. The income }\end{array} & 1 & 2 & 3 & 4 \\ \begin{array}{l}\text { c. Being able to set your own work schedule } \\ \text { d. Having a variety of tasks }\end{array} & 1 & 2 & 3 & 4 \\ \begin{array}{l}\text { e. Having hours that fit your needs } \\ \text { f. Your job being flexible enough that you can }\end{array} & 1 & 2 & 3 & 4 \\ \text { respond to non-work situations } & 1 & 2 & 3 & 4 \\ \text { g. Having the authority you need to get your job } & 1 & 2 & 3 & 4 \\ \text { done } & 1 & 2 & 3 & 4 \\ \text { h. The job fitting your skills } & 1 & 2 & 3 & 4 \\ \text { i. The opportunity for learning new things } & 1 & 2 & 3 & 4 \\ \text { j. Making good money compared to other people } & 1 & 2 & 3 & 4\end{array}$

in your field

In the past month, how rewarding have the following been: (Please circle "0" NA if something has not applied to your situation in the past month.)

k. Your supervisor's respect for your abilities

1. Your supervisor's concern about the welfare of those under him/her

$\mathrm{m}$. Your supervisor paying attention to what you have to say

n. Job security

o. The amount of support from coworkers

p. Your job offering good benefits, for example, paid sick leave

$\begin{array}{ccccc}\begin{array}{c}\text { Not at } \\ \text { all } \\ \text { rewardi } \\ \text { ng }\end{array} & \begin{array}{c}\text { Just a } \\ \text { little } \\ \text { rewardi } \\ \text { ng }\end{array} & \begin{array}{c}\text { Somew } \\ \text { hat } \\ \text { rewardi } \\ \text { ng }\end{array} & \begin{array}{c}\text { Very } \\ \text { rewardi } \\ \text { ng }\end{array} & \text { NA } \\ 1 & 2 & 3 & 4 & 0 \\ 1 & 2 & 3 & 4 & 0 \\ 1 & 2 & 3 & 4 & 0 \\ 1 & 2 & 3 & 4 & 0 \\ 1 & 2 & 3 & 4 & 0 \\ 1 & 2 & 3 & 4 & 0\end{array}$




\title{
Job Role Concerns:
}

In your current JOB, in the past month, how CONCERNED have you been about the

\author{
following:
}

a. The job's dullness, monotony, lack of variety

$\begin{array}{cccc}\begin{array}{c}\text { Not at all } \\ \text { concerned }\end{array} & \begin{array}{c}\text { Just a } \\ \text { little } \\ \text { concerned }\end{array} & \begin{array}{c}\text { Somewhat } \\ \text { concerned }\end{array} & \begin{array}{c}\text { Very } \\ \text { concerned }\end{array} \\ 1 & 2 & 3 & 4 \\ 1 & 2 & 3 & 4 \\ 1 & 2 & 3 & 4 \\ 1 & 2 & 3 & 4 \\ 1 & 2 & 3 & 4 \\ 1 & 2 & 3 & 4 \\ 1 & 2 & 3 & 4 \\ 1 & 2 & 3 & 4 \\ 1 & 2 & 3 & 4 \\ 1 & 2 & 3 & 4 \\ 1 & 2 & 3 & 4\end{array}$

In your current JOB, in the past month, how CONCERNED have you been about:

(Please circle " 0 " if something has not applied to your situation in the past month)

1. Lack of job security on this job

m. Your supervisor's lack of appreciation for your work

n. The possibility of unemployment

o. Your supervisor's having unrealistic expectations for your work

p. Not being able to get your own job done because of other people or red tape

q. Lack of support from your supervisor

r. Lack of support from co-workers

s. Lack of good benefits, for example, paid sick leave

$\begin{array}{ccccc}\begin{array}{c}\text { Not at } \\ \text { all } \\ \text { concern } \\ \text { ed } \\ 1\end{array} & \begin{array}{c}\text { Just a } \\ \text { little } \\ \text { concern } \\ \text { ed }\end{array} & \begin{array}{c}\text { Somew } \\ \text { hat } \\ \text { concern } \\ \text { ed }\end{array} & \begin{array}{c}\text { Very } \\ \text { concern } \\ \text { ed }\end{array} & \text { NA } \\ 1 & 2 & 3 & 4 & 0 \\ & 2 & 3 & 4 & 0 \\ 1 & 2 & 3 & 4 & 0 \\ 1 & 2 & 3 & 4 & 0 \\ & & & & \\ 1 & 2 & 3 & 4 & 0 \\ & & & & \\ 1 & 2 & 3 & 4 & 0 \\ 1 & 2 & 3 & 4 & 0 \\ 1 & 2 & 3 & 4 & 0\end{array}$


Appendix C

Spousal Role Quality

Think about your relationship with your SPOUSE OR PARTNER in the past month.

How REWARDING have the following been?

a. Having a spouse or partner who is easy to get

$\begin{array}{cccc}\begin{array}{c}\text { Not at all } \\ \text { rewarding }\end{array} & \begin{array}{c}\text { Just a } \\ \text { little } \\ \text { rewarding }\end{array} & \begin{array}{c}\text { Somewhat } \\ \text { rewarding }\end{array} & \begin{array}{c}\text { Very } \\ \text { rewarding }\end{array} \\ 1 & 2 & 3 & 4 \\ 1 & 2 & 3 & 4 \\ 1 & 2 & 3 & 4 \\ 1 & 2 & 3 & 4 \\ 1 & 2 & 3 & 4 \\ 1 & 2 & 3 & 4 \\ 1 & 2 & 3 & 4 \\ 1 & 2 & 3 & 4 \\ & 2 & 3 & 4\end{array}$

b. Your spouse or partner appreciating you

c. Good communication

d. Your spouse or partner backing you up in what you want to do

e. Having a spouse or partner who is a good friend

f. Your spouse or partner liking you as a person

g. Being able to disagree without threatening the relationship

$\mathrm{h}$. Having a spouse or partner who is a good listener

i. Having a spouse or partner who shares in household responsibilities

Still thinking about your relationship with your SPOUSE OR PARTNER, in the past

month, how CONCERNED have you been about the following?

\begin{tabular}{|c|c|c|c|c|}
\hline & $\begin{array}{l}\text { Not at all } \\
\text { concerned }\end{array}$ & $\begin{array}{c}\text { Just a } \\
\text { little } \\
\text { concerned }\end{array}$ & $\begin{array}{l}\text { Somewhat } \\
\text { concerned }\end{array}$ & $\begin{array}{c}\text { Very } \\
\text { concerned }\end{array}$ \\
\hline $\begin{array}{l}\text { a. Poor communication with your spouse or } \\
\text { partner }\end{array}$ & 1 & 2 & 3 & 4 \\
\hline $\begin{array}{l}\text { b. Your spouse or partner not understanding who } \\
\text { you really are }\end{array}$ & 1 & 2 & 3 & 4 \\
\hline c. Arguing or fighting & 1 & 2 & 3 & 4 \\
\hline $\begin{array}{l}\text { d. Your spouse or partner not backing you up in } \\
\text { what you want to do }\end{array}$ & 1 & 2 & 3 & 4 \\
\hline e. Lack of companionship & 1 & 2 & 3 & 4 \\
\hline f. Your spouse or partner being critical of you & 1 & 2 & 3 & 4 \\
\hline g. Not getting along & 1 & 2 & 3 & 4 \\
\hline h. Your spouse or partner not helping around the & 1 & 2 & 3 & 4 \\
\hline
\end{tabular}




\section{Appendix D}

\section{Child-Care Role Quality}

Now think about being a PARENT to any or all of your children. Please indicate how STRESSFUL each of the following has been in the past month. Circle "0" if a statement does not apply to you.

a. Your child(ren) having problems at

$\begin{array}{ccccc}\begin{array}{c}\text { Not at all } \\ \text { stressful }\end{array} & \begin{array}{c}\text { Just a } \\ \text { little } \\ \text { stressful } \\ 1\end{array} & \begin{array}{c}\text { Somewhat } \\ \text { stressful }\end{array} & \begin{array}{c}\text { Very } \\ \text { stressful }\end{array} & \text { NA } \\ 1 & 2 & 3 & 4 & 0 \\ 1 & 2 & 3 & 4 & 0 \\ 1 & 2 & 3 & 4 & 0 \\ 1 & 2 & 3 & 4 & 0 \\ 1 & 2 & 3 & 4 & 0\end{array}$

\section{How STRESSFUL has it been to:}

g. Discipline or correct your child(ren)

$\begin{array}{ccccc}\begin{array}{c}\text { Not at all } \\ \text { stressful }\end{array} & \begin{array}{c}\text { Just a } \\ \text { little } \\ \text { stressful }\end{array} & \begin{array}{c}\text { Somewhat } \\ \text { stressful }\end{array} & \begin{array}{c}\text { Very } \\ \text { stressful }\end{array} & \text { NA } \\ 1 & 2 & 3 & 4 & 0 \\ 1 & 2 & 3 & 4 & 0 \\ 1 & 2 & 3 & 4 & 0 \\ 1 & 2 & 3 & 4 & 0 \\ 1 & 2 & 3 & 4 & 0 \\ 1 & 2 & 3 & 4 & 0 \\ 1 & 2 & 3 & 4 & 0\end{array}$


Now let's focus on the more positive aspects of being a PARENT to any or all of you children. Please indicate how REWARDING each of the following has been in the past month.

a. Doing things to help your child(ren)

b. Feeling needed by your child(ren)

c. Sharing in your child(ren)'s accomplishments

d. Doing things with your child(ren)

e. Seeing your relationship with your child(ren) mature and grow

f. Watching your child(ren) develop as (an) individual(s)

g. Fulfilling family obligations or expectations

$\begin{array}{cccc}\begin{array}{c}\text { Not at all } \\ \text { rewarding }\end{array} & \begin{array}{c}\text { Jut a little } \\ \text { rewarding }\end{array} & \begin{array}{c}\text { Somewhat } \\ \text { rewarding }\end{array} & \begin{array}{c}\text { Very } \\ \text { rewarding }\end{array} \\ 1 & 2 & 3 & 4 \\ 1 & 2 & 3 & 4 \\ 1 & 2 & 3 & 4 \\ 1 & 2 & 3 & 4 \\ 1 & 2 & 3 & 4 \\ 1 & 2 & 3 & 4 \\ 1 & & & \\ 1 & 2 & 3 & 4\end{array}$

h. Passing on to your child(ren) some of the care that your parents gave you 
Appendix E

\section{Parent-Care Role Quality}

Still thinking about this parent, please indicate how STRESSFUL each of the

following has been for you in the past month. If a particular problem did not occur with this parent in the past month, please circle " $0 . "$

\begin{tabular}{|c|c|c|c|c|c|}
\hline & $\begin{array}{l}\text { Not at all } \\
\text { stressful }\end{array}$ & $\begin{array}{l}\text { Just a } \\
\text { little } \\
\text { stressful }\end{array}$ & $\begin{array}{c}\text { Somewhat } \\
\text { stressful }\end{array}$ & $\begin{array}{l}\text { Very } \\
\text { stressful }\end{array}$ & $\begin{array}{c}\text { Did not } \\
\text { occur }\end{array}$ \\
\hline $\begin{array}{l}\text { a. This parent's emotional problems or } \\
\text { moods (e.g., depression, loss of interest, } \\
\text { sadness) }\end{array}$ & 1 & 2 & 3 & 4 & 0 \\
\hline $\begin{array}{l}\text { b. This parent's memory or cognitive } \\
\text { problems (e.g., living in the past, } \\
\text { forgetfulness, confusion, repetitive } \\
\text { questions) }\end{array}$ & 1 & 2 & 3 & 4 & 0 \\
\hline $\begin{array}{l}\text { c. This parent endangering him/herself } \\
\text { (e.g., wandering off, driving when they } \\
\text { shouldn't) }\end{array}$ & 1 & 2 & 3 & 4 & 0 \\
\hline $\begin{array}{l}\text { d. This parent's aggressive or } \\
\text { inappropriate behaviors (e.g., not } \\
\text { respecting others' privacy, accusing } \\
\text { others) }\end{array}$ & 1 & 2 & 3 & 4 & 0 \\
\hline $\begin{array}{l}\text { e. This parent's communication problems } \\
\text { (e.g., inability to express him/herself) }\end{array}$ & 1 & 2 & 3 & 4 & 0 \\
\hline $\begin{array}{l}\text { f. This parent's agitation (e.g., being } \\
\text { constantly restless, pacing) }\end{array}$ & 1 & 2 & 3 & 4 & 0 \\
\hline $\begin{array}{l}\text { g. This parent's possible alcohol or other } \\
\text { substance use }\end{array}$ & 1 & 2 & 3 & 4 & 0 \\
\hline $\mathrm{h}$. This parent's difficulty sleeping & 1 & 2 & 3 & 4 & 0 \\
\hline $\begin{array}{l}\text { i. This parent's complex medical care } \\
\text { needs }\end{array}$ & 1 & 2 & 3 & 4 & 0 \\
\hline j. This parent's criticisms and complaints & 1 & 2 & 3 & 4 & 0 \\
\hline
\end{tabular}


Next, we focus on the more positive aspects of being a caregiver. Please indicate how REWARDING each of the following has been in the past month. If something did not occur in the past month, please circle " 0. ."

\begin{tabular}{|c|c|c|c|c|c|}
\hline & $\begin{array}{l}\text { Not at all } \\
\text { rewarding }\end{array}$ & $\begin{array}{l}\text { Just a } \\
\text { little } \\
\text { rewarding }\end{array}$ & $\begin{array}{l}\text { Somewhat } \\
\text { rewarding }\end{array}$ & $\begin{array}{l}\text { Very } \\
\text { rewarding }\end{array}$ & $\begin{array}{l}\text { Did not } \\
\text { occur }\end{array}$ \\
\hline a. Doing things to help this parent & 1 & 2 & 3 & 4 & 0 \\
\hline b. Feeling needed by this parent & 1 & 2 & 3 & 4 & 0 \\
\hline $\begin{array}{l}\text { c. Seeing this parent do things for him } \\
\text { or herself }\end{array}$ & 1 & 2 & 3 & 4 & 0 \\
\hline d. Doing things with this parent & 1 & 2 & 3 & 4 & 0 \\
\hline $\begin{array}{l}\text { e. Seeing your relationship with this } \\
\text { parent mature and grow }\end{array}$ & 1 & 2 & 3 & 4 & 0 \\
\hline $\begin{array}{l}\text { f. Fulfilling family obligations or } \\
\text { expectations }\end{array}$ & 1 & 2 & 3 & 4 & 0 \\
\hline $\begin{array}{l}\text { g. This parent showing appreciation } \\
\text { for what you do for him/her }\end{array}$ & 1 & 2 & 3 & 4 & 0 \\
\hline $\begin{array}{l}\text { h. Giving back to this parent some of } \\
\text { the care s/he gave to you }\end{array}$ & 1 & 2 & 3 & 4 & 0 \\
\hline
\end{tabular}




\section{Appendix F}

\section{CES-D Scale}

Below is a list of ways you might have felt or behaved. Please indicate how often you have felt this way during the past week by circling the appropriate number.

During the past week:

a. I was bothered by things that usually don't bother me.

b. I did not feel like eating; my appetite was poor

c. I felt that I could not shake off the blues even with help from my family or friends

d. I felt that I was just as good as other people

e. I had trouble keeping my mind on what I was doing

f. I felt depressed

g. I felt that everything I did was an effort

h. I felt hopeful about the future

i. I thought my life had been a failure

j. I felt fearful

k. My sleep was restless

1. I was happy

m. I talked less than usual

n. I felt lonely

o. People were unfriendly

p. I enjoyed life

q. I had crying spells

r. I felt sad

s. I felt that people disliked me

t. I could not "get going"

$\begin{array}{cccc}\begin{array}{c}\text { Rarely or } \\ \text { none of } \\ \text { the time } \\ \text { (less than } \\ 1 \text { day) }\end{array} & \begin{array}{c}\text { Some or a } \\ \text { little of } \\ \text { the time } \\ (1-2 \text { days })\end{array} & \begin{array}{c}\text { Occasionally } \\ \text { or a } \\ \text { moderate } \\ \text { amount of } \\ \text { time }(3-4 \\ \text { days) }\end{array} & \begin{array}{c}\text { Most of } \\ \text { the time } \\ (5-7 \text { days })\end{array} \\ 1 & 2 & 3 & 4 \\ 1 & 2 & 3 & 4 \\ 1 & 2 & 3 & 4 \\ 1 & & & \\ 1 & 2 & 3 & 4 \\ 1 & 2 & 3 & 4 \\ & & & \\ 1 & 2 & 3 & 4 \\ 1 & 2 & 3 & 4 \\ 1 & 2 & 3 & 4 \\ 1 & 2 & 3 & 4 \\ 1 & 2 & 3 & 4 \\ 1 & 2 & 3 & 4 \\ 1 & 2 & 3 & 4 \\ 1 & 2 & 3 & 4 \\ 1 & 2 & 3 & 4 \\ 1 & 2 & 3 & 4 \\ 1 & 2 & 3 & 4 \\ 1 & 2 & 3 & 4 \\ 1 & 2 & 3 & 4 \\ 1 & 2 & 3 & 4 \\ 1 & 2 & 3 & 4\end{array}$




\section{Appendix G}

\section{Life Satisfaction}

Below are opposite pairs of words that may indicate how people feel overall about their life. Consider each of the word pairs and circle the number that best indicates how YOU feel about your life in general.

$\begin{array}{lllllllll}\text { a. Boring } & 1 & 2 & 3 & 4 & 5 & 6 & 7 & \text { Interesting } \\ \text { b. Enjoyable } & 1 & 2 & 3 & 4 & 5 & 6 & 7 & \text { Miserable } \\ \text { c. Worthwhile } & 1 & 2 & 3 & 4 & 5 & 6 & 7 & \text { Useless } \\ \text { d. Lonely } & 1 & 2 & 3 & 4 & 5 & 6 & 7 & \text { Friendly } \\ \text { e. Empty } & 1 & 2 & 3 & 4 & 5 & 6 & 7 & \text { Full } \\ \text { f. Hopeful } & 1 & 2 & 3 & 4 & 5 & 6 & 7 & \text { Discouraging } \\ \text { g. Rewarding } & 1 & 2 & 3 & 4 & 5 & 6 & 7 & \text { Disappointing } \\ \begin{array}{l}\text { h. Doesn't give me } \\ \text { much of a chance }\end{array} & 1 & 2 & 3 & 4 & 5 & 6 & 7 & \begin{array}{l}\text { Brings out the best } \\ \text { in me }\end{array}\end{array}$




\section{Appendix $\mathrm{H}$}

\section{Education Question}

What is the highest grade/degree in school that you completed?

1. Grade school or less

2. Some high school

3. Graduated high school

4. Some college

5. Graduated college

6. Some graduate study

7. Graduate degree 